Octávio Ambrósio Pereira Júnior

\title{
Análise da influência de processos hidrodinâmicos na distribuição de fito e zooplâncton no sistema estuarino de Santos - São Vicente através de modelagem numérica
}

Dissertação apresentada ao Instituto Oceanográfico da Universidade de São Paulo, como parte dos requisitos para obtenção do título de Mestre em Ciências, área de concentração Oceanografia Física.

Orientador: Prof. Dr. Joseph Harari 
Universidade de São Paulo

Instituto Oceanográfico

Octávio Ambrósio Pereira Júnior

Análise da influência de processos hidrodinâmicos na distribuição de fito e zooplâncton no sistema estuarino de Santos - São Vicente através de modelagem numérica 


\section{Universidade de São Paulo \\ Instituto Oceanográfico}

Análise da influência de processos hidrodinâmicos na distribuição de fito

e zooplâncton no sistema estuarino de Santos - São Vicente através de modelagem numérica

Octávio Ambrósio Pereira Júnior

Dissertação apresentada ao Instituto Oceanográfico da Universidade de São Paulo, como parte dos requisitos para obtenção do título de Mestre em Ciências, área de concentração Oceanografia Física.

Julgada em $-1-1$

$\operatorname{Prof}(a) . \operatorname{Dr}(a)$.

Conceito

$\operatorname{Prof}(\mathrm{a}) . \operatorname{Dr}(\mathrm{a})$.

Conceito

$\operatorname{Prof}(a) . \operatorname{Dr}(a)$.

Conceito 


\section{Agradecimentos}

Gostaria de agradecer ao Prof. Joseph Harari pela orientação, confiança e ensinamentos durante a minha graduação e mestrado no Instituto Oceanográfico.

Aos meu amigos do Colégio: Cheng Yao pelo apoio; Mari Miura e Georges Akira, sinto muito a falta de vocês; Tamy Oishi por ter me ajudado quando eu estava perdendo as esperanças; Lucas Akira por sempre me receber com animação; Caio Chama pela ajuda; Felipe Monobe pelos momentos geek; Rafael Issamu por seus desafios e jogos de tabuleiro; Vinicius Nakama pela amizade. Passamos bons tempos juntos nesses últimos 14 anos.

À turma 9, em especial ao Leonardo Bertini por sempre me incentivar; Paula Birocchi por não esquecer de mim; Marina Tenório pela ajuda; Luíza Stein e Isabela Goulart por sempre me receberem com um sorriso.

Aos meus médicos Dra. Greta Tanaka e Dra. Helenita por cuidar da minha saúde.

Ao Nestor, Lúcia Mitsuhashi e à família Souza que sempre me receberam bem. À Gabriela C. Mitsuhashi por sempre estar ao meu lado mesmo quando distante.

Ao pessoal do LabSip, em especial ao Samuel Hora e Celina Honório pela ajuda e companhia; Pela equipe de natação Facanamantega que me recebeu muito bem; And to $\mathrm{HN}$ for all our achievements together.

À minha mãe, que nasceu em família humilde e do interior, trabalhou e estudou contra a vontade de seus pais e mesmo aposentada continua trabalhando. Mesmo com as nossas discussões e brigas, sou grato e tenho muito orgulho de ser seu filho.

Ao meu pai que me ensinou tantas coisas e sempre se preocupou em criar um homem direito. Sinto falta dos momentos que nos divertíamos quanto contava suas histórias. Cada dia que lembro de ti, penso que deveria ter aproveitado melhor o tempo que passamos juntos.

Eu peço desculpas aos meus amigos e à minha família pela ausência nesses últimos anos.

Sou muito grato, pois sempre que alguma coisa ruim aparece na minha vida eu consigo seguir em frente por causa de vocês. 


\section{Resumo}

O conhecimento de regiões costeiras é relevante para o manejo de recursos e segurança, portanto, é de interesse social, uma vez que grande parte da população mundial vive próximo às áreas costeiras. Uma forma de se estudar o ambiente marinho é através da modelagem numérica. Modelos ecológicos proporcionam a possibilidade de avaliar o estado de eutrofização do ambiente, prever consequências ambientais, estimar respostas à variações nas concentrações de nutrientes, quantificar os fluxos nos sistemas costeiros, dentre outros. A hipótese de trabalho é que condições meteorológicas determinam a hidrodinâmica, que por sua vez influencia as propriedades da água. Além disso, o crescimento populacional de zooplâncton depende da disponibilidade de fitoplâncton como alimento, e o crescimento populacional de fitoplâncton é influenciado por nutrientes, luz e temperatura da água. Com isso, o objetivo foi analisar a influência da hidrodinâmica, disponibilidade de luz e temperatura da água na distribuição de fito e zooplâncton, através da implementação de um modelo numérico hidrodinâmico tridimensional, acoplado a um modelo ecológico, no sistema estuarino de Santos - São Vicente. Ecossistemas estuarinos são dinâmicos, complexos, biodiversos e regidos principalmente por fenômenos físicos como maré, vento e chuva. A região de estudo está localizada na região Metropolitana da Baixada Santista, abrangendo os municípios de Praia Grande, São Vicente, Cubatão, Santos e Guarujá. Para desenvolver este trabalho, foi utilizado o modelo Mohid, desenvolvido pela MARETEC no Instituto Superior Técnico (IST), que pertence à Universidade Técnica de Lisboa. Condições iniciais e de contorno foram especificadas para os processamentos do modelo; dados da literatura e trabalhos anteriores foram usados para sua implementação. Com os resultados da modelagem, distribuições de fitoplâncton foram analisadas em função das respectivas condições hidrodinâmicas, de modo a estabelecer suas interações. Os resultados do modelo para variação do nível do mar, corrente, temperatura da água, concentração de fitoplâncton e zooplâncton foram satisfatórios. Apesar disto, alguns resultados podem ser melhorados uma vez que nutrientes foram subestimados e a temperatura da água foi superestimada.

Palavras-chave: Modelagem numérica, MOHID, Modelo ecológico, fitoplâncton, Estuário de Santos-São Vicente. 


\begin{abstract}
Knowledge on coastal regions are relevant for the management of resources and safety, therefore of social interest, because most of the world's population live near coastal regions. One way to study the marine environment is by the numerical modelling. Ecological models enable the possibility to measure the state of eutrophication of a given environment, foresee ambiental consequences, evaluate response from variation on nutrient concentration, quantify fluxes on coastal environments and more. The hypothesis of this work is that meteorological conditions define hydrodynamics, that in it's turn define water properties. Moreover, zooplankton populational growth is dependent on phytoplankton availability as a food source, and phytoplankton populational growth is affected by nutrients, light and water temperature. Thereby, the objective was to analyze the influence of hydrodynamics, light availability and water temperature on the phyto and zooplankton, using a tridimentional hydrodynamic model, coupled with a ecological model, at Santos-São Vicente estuarine complex system. Estuarine ecosystems are dynamic, complex, biodiverse and governed mostly by physical phenomena like tides, wind and rain. The study area is located at Baixada Santista metropolitan region, encompassing Praia Grande, São vicente, Cubatão, Santos and Guarujá. To develop this work, the model MOHID was used, which is developed by MARETEC on IST, which belongs to the Technical University of Lisbon. Initial and boundary conditions were defined for the processing of the model; literature and previous work data were used to implement the model. With the results from the modelling, phytoplankton were analyzed in function to the respective hydrodynamical conditions, in a way to establish it's interactions. The modeling results for the water level, current, water temperature, zooplankton and phytoplankton concentration were satisfactory. Despite that, some results can be improved since nutrients were underestimated and water temperature was overestimated.
\end{abstract}

Keywords: Numerical Modeling, MOHID, Ecological Model, Phytoplankton, Santos-São vicente Estuary. 


\section{Lista de Figuras}

$1 \quad$ Localização da área de estudo. . . . . . . . . . . . . . . . . . . . 2

2 Esquema do fluxo interno do fitoplâncton (A - assimilação, F - fotossíntese, \begin{tabular}{|l|l|l|}
\hline $\mathrm{R}$ - respiração, M - mortalidade, E - excreção, G - forrageio, S - deposição) & 10
\end{tabular}

3 Grade numérica, com resolução horizontal de $0.0022^{\circ}(x=223.5 m, y=$

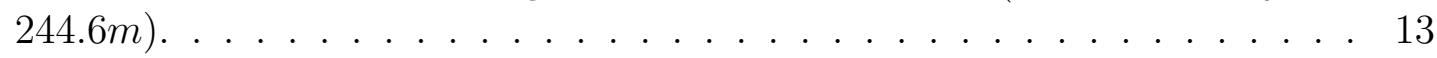

4 Coordenada vertical sigma com 10 camadas. . . . . . . . . . . . . . . . . 14

$5 \quad$ Grade batimétrica $(\mathrm{m}) . \ldots \ldots \ldots \ldots$. . . . . . . . . . . 14

$6 \quad$ Posição dos pontos onde foram feitas séries temporais. . . . . . . . . . . . . 15

7 Representação das regiões, esquematizadas por caixas, onde foram feitas os cálculos de integração de propriedades físicas, biogeoquímicas, produção bruta e limitação do crescimento do fitoplâncton por radiação solar, nutrientes e temperatura. . . . . . . . . . . . . . 16

8 Evolução temporal da cobertura de nuvens para o mês de Fevereiro (vermelho) e Agosto (azul) de 2015, na posição $24^{\circ} 1^{\prime} 13.44^{\prime \prime} S$ e $46^{\circ} 13^{\prime} 37.2^{\prime \prime}$. O eixo inferior é referente ao mês de Fevereiro e superior ao mês de Agosto. 19

$9 \quad$ Evolução temporal da umidade relativa do ar para o mês de Fevereiro (vermelho) e Agosto (azul) de 2015, na posição $24^{\circ} 0^{\prime} 0.0^{\prime \prime} S$ e $46^{\circ} 0^{\prime} 0.0^{\prime \prime}$. O eixo inferior é referente ao mês de Fevereiro e superior ao mês de Agosto. 20

10 Evolução temporal da temperatura do ar $\left({ }^{\circ} \mathrm{C}\right)$ para o mês de Fevereiro (vermelho) e Agosto (azul) de 2015, na posição $24^{\circ} 1^{\prime} 13.44^{\prime \prime} S$ e $46^{\circ} 13^{\prime} 37.2^{\prime \prime}$. O eixo inferior é referente ao mês de Fevereiro e superior ao mês de Agosto. 20

11 Evolução temporal da temperatura do $\operatorname{ar}\left({ }^{\circ} \mathrm{C}\right)$ para o período de 2011 a 2016 (colorido) e a média mensal (preto), na posição $24^{\circ} 1^{\prime} 13.44^{\prime \prime} S$ e $46^{\circ} 13^{\prime} 37.2^{\prime \prime}$. 21

12 Evolução temporal da radiação solar para o mês de Fevereiro (vermelho) e Agosto (azul) de 2015, na posição $24^{\circ} 1^{\prime} 13.44^{\prime \prime} S$ e $46^{\circ} 13^{\prime} 37.2^{\prime \prime}$. O eixo inferior é referente ao mês de Fevereiro e superior ao mês de Agosto. . . . . 21

13 Evolução temporal da radiação solar média máxima $\left(\mathrm{W} / \mathrm{m}^{2}\right)$ para o período de 2011 a 2016 (colorido) e a média mensal (preto), na posição $24^{\circ} 1^{\prime} 13.44^{\prime \prime} S$ e $46^{\circ} 13^{\prime} 37.2^{\prime \prime}$. . . . . . . . . . . . . . . . . 22

14 Evolução temporal da velocidade do vento $\left(m s^{-1}\right)$ para o mês de Fevereiro de 2015 , na posição $24^{\circ} 1^{\prime} 13.44^{\prime \prime} S$ e $46^{\circ} 13^{\prime} 37.2^{\prime \prime}$. . . . . . . . . . . . . . . . 22

15 Evolução temporal da velocidade do vento $\left(m s^{-1}\right)$ para o mês de Agosto de 2015 , na posição $24^{\circ} 1^{\prime} 13.44^{\prime \prime} S$ e $46^{\circ} 13^{\prime} 37.2^{\prime \prime}$. . . . . . . . . . . . . . . . 23

16 Rosa dos ventos para o período de 2011 a 2016 . . . . . . . . . . . . . . . 23

17 Rosa dos ventos para o mês de Fevereiro de 2015 . . . . . . . . . . . . . . . 24

18 Rosa dos ventos para o mês de Agosto de 2015 . . . . . . . . . . . . . . . . 24

19 Evolução temporal do módulo da velocidade do vento $\left(\mathrm{ms}^{-1}\right)$ para o mês

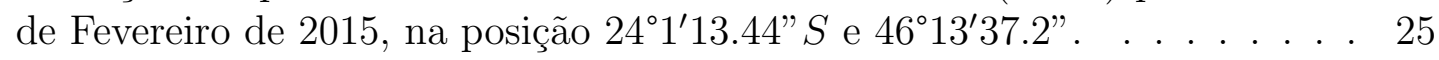


20 Localização dos rios utilizados no modelo. . . . . . . . . . . . . . . 25

21 Localização dos pontos onde rios, esgoto e o emissário foram simulados. . . 26

22 Variação da vazão dos rios utilizada no modelo. . . . . . . . . . . . . . . . 27

23 Variação da temperatura utilizada nas descargas de rios, esgotos e do

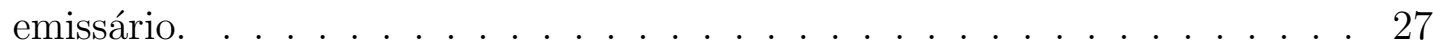

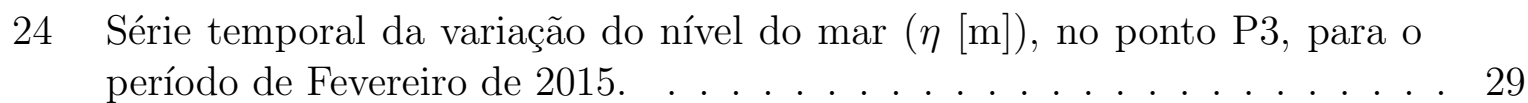

25 Série temporal da variação do nível do mar $(\eta[\mathrm{m}])$, no ponto P3, para o período de Agosto de 2015. . . . . . . . . . . . . . . . . . . . . . 29

26 Campo de velocidade $(\mathrm{m} / \mathrm{s})$ referente à camada superficial para o dia 15 de Fevereiro de 2015. . . . . . . . . . . . . . . . . . 30

27 Campo de velocidade $(\mathrm{m} / \mathrm{s})$ referente à camada de fundo para o dia $15 \mathrm{de}$ Fevereiro de 2015. . . . . . . . . . . . . . . . . . . . . 30

28 Campo de velocidade $(\mathrm{m} / \mathrm{s})$ referente à camada superficial para o dia 15 de Agosto de 2015. . . . . . . . . . . . . . . . . . . . 31

29 Campo de velocidade $(\mathrm{m} / \mathrm{s})$ referente à camada de fundo para o dia 15 de Agosto de 2015. . . . . . . . . . . . . . . . . . . . 31

30 Série temporal da temperatura da água $\left({ }^{\circ} \mathrm{C}\right)$, para o período de Fevereiro

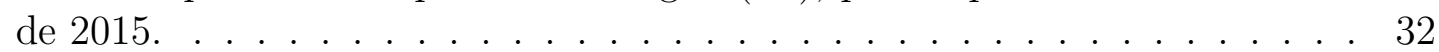

31 Série temporal da temperatura da água $\left({ }^{\circ} \mathrm{C}\right)$, para o período de Agosto de

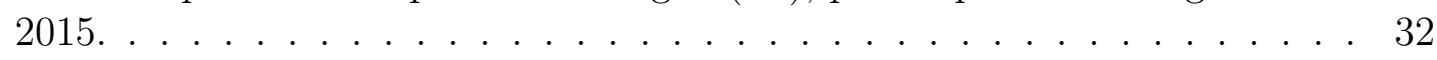

32 Temperatura da água $\left({ }^{\circ} \mathrm{C}\right)$ referente à camada superficial para o dia 12 de Fevereiro e Agosto de 2015. . . . . . . . . . . . . . . . . . 33

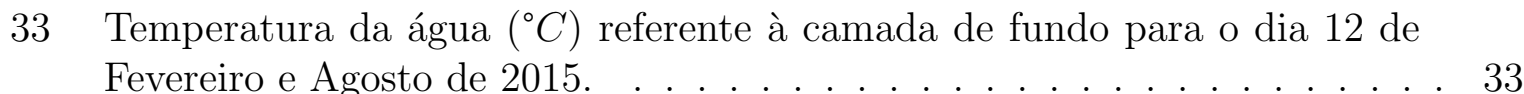

34 Série temporal da salinidade da água ( $p s u)$, para o período de Fevereiro de

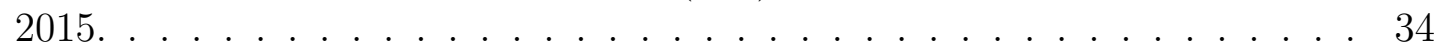

35 Série temporal da salinidade da água (psu), para o período de Agosto de

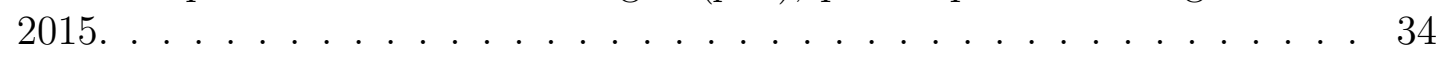

$36 \quad$ Salinidade da água ( $p s u$ ) referente à camada superficial para o dia 12 de Fevereiro e Agosto de 2015. . . . . . . . . . . . . . . . . . . . 34

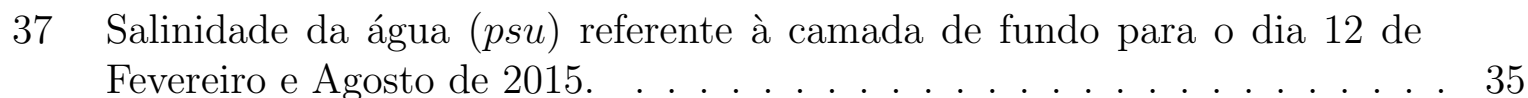

38 Série temporal da concentração de oxigênio $(m g / l)$, para o período de Fevereiro de 2015. . . . . . . . . . . . . . . . . . . . . . . . . 35

39 Série temporal da concentração de oxigênio $(m g / l)$, para o período de Agosto de 2015. . . . . . . . . . . . . . . . . 36

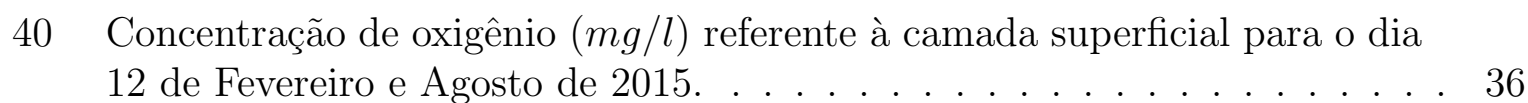


41 Concentração de oxigênio $(m g / l)$ referente à camada de fundo para o dia 12 de Fevereiro e Agosto de 2015. . . . . . . . . . . . . . . . . . . 36

42 Série temporal da concentração de amônia $(m g / l)$, para o período de Fevereiro de 2015. . . . . . . . . . . . . . . . . . . 37

43 Série temporal da concentração de amônia $(m g / l)$, para o período de Agosto

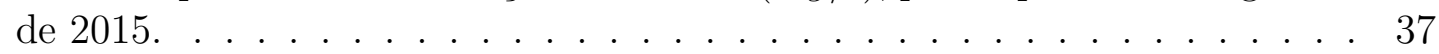

44 Concentração de amônia $(m g / l)$ referente à camada superficial para o dia 12 de Fevereiro e Agosto de 2015. . . . . . . . . . . . . . . . . . . . 38

45 Concentração de amônia $(\mathrm{mg} / \mathrm{l})$ referente à camada de fundo para o dia 12 de Fevereiro e Agosto de 2015. . . . . . . . . . . . . . . . . . . . . 38

46 Série temporal da concentração de nitrato $(m g / l)$, para o período de Fevereiro de 2015. . . . . . . . . . . . . . . . . . . . . . 39

47 Série temporal da concentração de nitrato $(\mathrm{mg} / \mathrm{l})$, para o período de Agosto

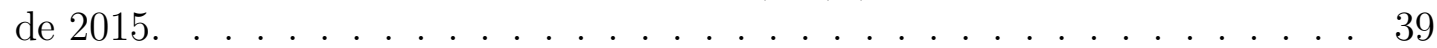

48 Concentração de nitrato $(\mathrm{mg} / \mathrm{l})$ referente à camada superficial para o dia 12 de Fevereiro e Agosto de 2015. . . . . . . . . . . . . . . . . . . . . . 39

49 Concentração de nitrato $(\mathrm{mg} / \mathrm{l})$ referente à camada de fundo para o dia 12 de Fevereiro e Agosto de 2015. . . . . . . . . . . . . . . . . . . . . . . 40

50 Série temporal da concentração de nitrito $(m g / l)$, para o período de

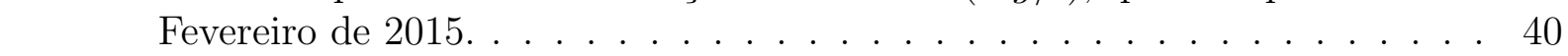

51 Série temporal da concentração de nitrito $(m g / l)$, para o período de

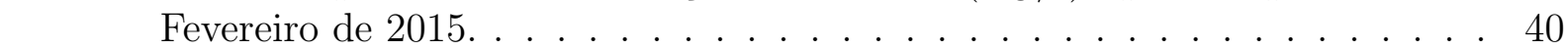

52 Concentração de nitrito $(\mathrm{mg} / \mathrm{l})$ referente à camada superficial para o dia 12 de Fevereiro e Agosto de 2015. . . . . . . . . . . . . . . . . . . . . . 41

53 Concentração de nitrito $(\mathrm{mg} / \mathrm{l})$ referente à camada de fundo para o dia 12 de Fevereiro e Agosto de 2015. . . . . . . . . . . . . . . . . . . . . . . 41

54 Série temporal da concentração de fósforo inorgânico $(m g / l)$, para o período de Fevereiro de 2015. . . . . . . . . . . . . . . . . . . . . . . 41

55 Série temporal da concentração de fósforo inorgânico $(m g / l)$, para o período de Agosto de 2015. . . . . . . . . . . . . . . . . . . . . . . . 42

56 Concentração de fósforo inorgânico $(m g / l)$ referente à camada superficial para o dia 12 de Fevereiro e Agosto de 2015. . . . . . . . . . . . . . . . . . 42

57 Concentração de fósforo inorgânico $(\mathrm{mg} / \mathrm{l})$ referente à camada de fundo para o dia 12 de Fevereiro e Agosto de 2015. . . . . . . . . . . . . . . . . . 42

58 Série temporal da concentração de fitoplâncton $(m g C / l)$, para o período de Fevereiro de 2015. . . . . . . . . . . . . . . . . . . 43

59 Série temporal da concentração de fitoplâncton $(m g C / l)$, para o período de Agosto de 2015. . . . . . . . . . . . . . . . . . . . . . 43

60 Concentração de fitoplâncton $(m g C / l)$ referente à camada superficial para o dia 12 de Fevereiro e Agosto de 2015. . . . . . . . . . . . . . . . . . . . . 43 
61 Concentração de fitoplâncton $(m g C / l)$ referente à camada de fundo para o dia 12 de Fevereiro e Agosto de 2015. . . . . . . . . . . . . . . . . . . . 44

62 Série temporal da concentração de zooplâncton $(m g C / l)$, para o período de Fevereiro de 2015. . . . . . . . . . . . . . . . . . . . . . . . . . 44

63 Série temporal da concentração de zooplâncton $(m g C / l)$, para o período de Agosto de 2015. . . . . . . . . . . . . . . . . . . . . . . . 45

64 Concentração de zooplâncton $(m g C / l)$ referente à camada superficial para o dia 12 de Fevereiro e Agosto de 2015. . . . . . . . . . . . . . . . . 45

65 Concentração de zooplâncton $(m g C / l)$ referente à camada de fundo para o dia 12 de Fevereiro e Agosto de 2015. . . . . . . . . . . . . . . . . . 45

66 Temperatura média da água $\left({ }^{\circ} \mathrm{C}\right)$ referente à camada superficial para o \begin{tabular}{|c|c|}
\hline mês de Fevereiro sobre influência da temperatura do ar de $26^{\circ} \mathrm{C}$ e $21^{\circ} \mathrm{C}$ \\
\hline
\end{tabular} constantes durante a simulação . . . . . . . . . . . . . . . . . . . 47

67 Concentração média de fitoplâncton $(m g C / l)$ referente à camada superficial para o mês de Fevereiro sobre influência da temperatura do ar de $26^{\circ} \mathrm{C}$ e $21^{\circ} \mathrm{C}$ constantes durante a simulação. . . . . . . . . . . . . . . . . . 48

68 Concentração média de zooplâncton $(m g C / l)$ referente à camada superficial para o mês de Fevereiro sobre influência da temperatura do ar de $26^{\circ} \mathrm{C}$ e $21^{\circ} \mathrm{C}$ constantes durante a simulação. . . . . . . . . . . . . . . . . . 48

69 Temperatura média da água $\left({ }^{\circ} \mathrm{C}\right)$ referente à camada superficial para o mês de Fevereiro sobre influência da radiação solar limitadas à $838 \mathrm{Wm}^{-2}$ e à $475 \mathrm{Wm}^{-2}$. . . . . . . . . . . . . . . . . 51

70 Concentração média de fitoplâncton $(m g C / l)$ referente à camada superficial para o mês de Fevereiro sobre influência da radiação solar limitadas à $838 \mathrm{Wm}^{-2}$ e à $475 \mathrm{Wm}^{-2}$. . . . . . . . . . . . . . . . . . . . 51

71 Concentração média de zooplâncton $(m g C / l)$ referente à camada superficial para o mês de Fevereiro sobre influência da radiação solar limitadas à $838 \mathrm{Wm}^{-2}$ e à $475 \mathrm{Wm}^{-2}$. . . . . . . . . . . . . . . . . . . 51

72 Campo de corrente média $(\mathrm{m} / \mathrm{s})$ referente à camada superficial para o mês de Fevereiro sobre influência de ventos de norte. . . . . . . . . . . . . . . . 54

73 Concentração média de fitoplâncton $(m g C / l)$ referente à camada superficial para o mês de Fevereiro sobre influência de ventos de norte. . . . . . . . . 54

74 Concentração média de zooplâncton $(m g C / l)$ referente à camada superficial para o mês de Fevereiro sobre influência de ventos de norte. . . . . . . . . 55

75 Campo de corrente média $(\mathrm{m} / \mathrm{s})$ referentes à camada superficial para o mês de Fevereiro sobre influencia de ventos de leste. . . . . . . . . . . . . . 55

76 Concentração média de fitoplâncton $(m g C / l)$ referente à camada superficial para o mês de Fevereiro sobre influência de ventos de leste. . . . . . . . . . 56

77 Concentração média de zooplâncton $(m g C / l)$ referente à camada superficial para o mês de Fevereiro sobre influência de ventos de norte. . . . . . . . . 56 
78 Campo de corrente média $(\mathrm{m} / \mathrm{s})$ referentes à camada superficial para o mês de Fevereiro sobre influência de ventos de sul. . . . . . . . . . . . . . . . . 57

79 Concentração média de fitoplâncton $(m g C / l)$ referente à camada superficial para o mês de Fevereiro sobre influência de ventos de sul. . . . . . . . . . . 57

80 Concentração média de zooplâncton $(m g C / l)$ referente à camada superficial para o mês de Fevereiro sobre influência de ventos de norte. . . . . . . . . 58

81 Campo de corrente média $(\mathrm{m} / \mathrm{s})$ referente à camada superficial para o mês de Fevereiro sobre influência de ventos de sudoeste. . . . . . . . . . . . . . 58

82 Concentração média de fitoplâncton $(m g C / l)$ referente à camada superficial para o mês de Fevereiro sobre influência de ventos de sudoeste. . . . . . . . 59

83 Concentração média de zooplâncton $(m g C / l)$ referente à camada superficial para o mês de Fevereiro sobre influência de ventos de norte. . . . . . . . . 59 


\section{Lista de Tabelas}

$1 \quad$ Principais módulos do Mohid. . . . . . . . . . . . . . . . . . . . . 6

2 Coordenadas geográficas dos pontos onde foram geradas séries temporais com os resultados do modelo. O ponto P1 próximo do Estuário de Santos, P2 próximo da Baía de São Vicente, P3 na Baía de Santos, P4 e P5 pontos distantes da costa. . . . . . . . . . . . . . . . . . . 16

3 Constantes harmônicas das componentes de maré obtidas através do TPXO para o ponto na borda de coordenadas $24^{\circ} 6^{\prime} 0^{\prime \prime} S$ e $46^{\circ} 17^{\prime} 60^{\prime \prime} W \ldots$. . . . . . 17

4 Principais parâmetros utilizados no módulo qualidade da água. . . . . . . . . 18

5 Condições iniciais e de fronteira aberta. . . . . . . . . . . . . . . . . . 18

$6 \quad$ Parâmetros utilizados nas descargas de rio, emissário e esgoto. . . . . . . . 26

7 Resultados da simulação para o mês de Fevereiro sob forçante de temperatura do ar de $26^{\circ} \mathrm{C}$. "all" são resultados para todo o domínio, "int" refere à região interna e "C1" à Baía de Santos . . . . . . . . . . . . . 49

8 Resultados da simulação para o mês de Fevereiro sob forçante de temperatura do ar de $21^{\circ} \mathrm{C}$. "all" são resultados para todo o domínio, "int" refere à região interna e "C1" à Baía de Santos . . . . . . . . . . . . . 50

9 Resultados da simulação para o mês de Fevereiro sob forçante de radiação solar limitada à $838 \mathrm{Wm}^{-2}$. "all"são resultados para todo o domínio, "int" refere à região interna e "C1" à Baía de Santos . . . . . . . . . . . . . 52

10 Resultados da simulação para o mês de Fevereiro sob forçante de radiação solar limitada à $475 \mathrm{Wm}^{-2}$. "all"são resultados para todo o domínio, "int"refere à região interna e "C1" à Baía de Santos . . . . . . . . . . . . . 53

11 Resultados da simulação para o mês de Fevereiro sob forçante de ventos de norte. "all" são resultados para todo o domínio, "int" refere à região interna e "C1"à Baía de Santos . . . . . . . . . . . . . . . . . . . . . . . . . . 60

12 Resultados da simulação para o mês de Fevereiro sob forçante de ventos de leste. "all"são resultados para todo o domínio, "int" refere à região interna e "C1"à Baía de Santos . . . . . . . . . . . . . . . . . . . . . . . . . 61

13 Resultados da simulação para o mês de Fevereiro sob forçante de ventos de sul. "all" são resultados para todo o domínio, "int" refere à região interna e "C1"à Baía de Santos . . . . . . . . . . . . . . . . . . . . . . . . . 62

14 Resultados da simulação para o mês de Fevereiro sob forçante de ventos de sudoeste. "all"são resultados para todo o domínio, "int"refere à região interna e "C1"à Baía de Santos . . . . . . . . . . . . . . . . . . 63

15 Resultados de velocidade de corrente $\left(m s^{-1}\right)$ para a simulação do mês de Fevereiro sob diferentes regimes de ventos. "all"são resultados para todo o domínio, "int" refere à região interna e "C1" à Baía de Santos. O sentido do vento segue a convenção meteorológica. . . . . . . . . . . . . . . . . . . 64 


\section{Glossário}

ACTION Modulers Empresa Portuguesa de consultoria, focada na modelagem numérica, desenvolvimento de soluções tecnológicas e serviços de planejamento e segurança.

ADCP Instrumento hidroacústico capaz de medir correntes na coluna d'água através do efeito Doppler.

DELTARES Instituto pesquisa voltado para assuntos relacionados a água, solo e subsuperfície sediado na holanda.

ECOMANAGE Sistema Integrado de Gerenciamento Ecológico de Zonas Costeiras.

EPA Agência de Proteção Ambiental dos Estados Unidos.

ERS Satélite de sensoriamento remoto europeu equipado de um radar de abertura sintética, altímetro e instrumentos para medir temperatura do oceano e campos de vento.

GFO Missão sucessora do GEOSAT, que foi um satélite artificial projetado para medir a altura da superfície do mar.

MARETEC Centro de Pesquisa Tecnológica Marinha e Ambiental.

OTPS2 Software de predição maregráfica da Universidade do Estado de Oregon.

TOPEX Poseidon Sonda espacial voltada para pesquisas oceanográficas, capaz de medir a superfície dos oceanos com uma precisão de $4.2 \mathrm{~cm}$.

TPXO Modelo global de maré desenvolvido pela Universidade do Estado de Oregon. 


\section{Lista de Siglas}

ASA Applied Science Associates.

CFSR Climate Forecast System Reanalysis.

CHM Centro de Hidrografia da Marinha.

CPU Unidade de Processamento Central.

DHI Danish Hydraulic Institute.

DHN Diretoria de Hidrografia da Marinha.

FOD Fósforo Orgânico Dissolvido.

FOP Fósforo orgânico particulado.

GOTM General Ocean Turbulence Model.

GPU Unidade de Processamento Gráfico.

HDF Formato Hierárquico de Dados.

IOUSP Instituto Oceanográfico da Universidade de São Paulo.

IST Instituto Superior Técnico.

LABSIP Laboratório de Simulação e Previsão Numérica Hidrodinâmica.

MPI Message Passing Interface.

NCEP National Center for Environmental Prediction.

NOD Nitrogênio Orgânico Dissolvido.

NODnr Fósforo Orgânico Dissolvido não refratário.

NODnr Nitrogênio Orgânico Dissolvido não refratário.

NODr Fósforo Orgânico Dissolvido refratário.

NODr Nitrogênio Orgânico Dissolvido refratário.

NOP Nitrogênio Orgânico Particulado. 


\section{Sumário}

Lista de Figuras vi

Lista de Tabelas $\quad$ xi

1 Introdução 1

1.1 Área de Estudo . . . . . . . . . . . . . . . . . . . . . . 2

2 Hipótese científica 4

\begin{tabular}{lll}
\hline 3 & Objetivos & 4 \\
\hline
\end{tabular}

4 Descrição do Mohid

4.1 Módulo Hidrodinâmico $\ldots \ldots$. . . . . . . . . . . . . . . . . . . . . . . . . . . 6

4.2 Módulo Propriedades da Água . . . . . . . . . . . . . . . . . . . . . . 7

4.3 Módulo Qualidade da Água . . . . . . . . . . . . . . . . . . . . 7

4.3 .1 Fitoplâncton . . . . . . . . . . . . . . . . . . . . . . 8

4.3 .2 Zooplâncton . . . . . . . . . . . . . . . . . . . . . . . 11

$\begin{array}{lll}5 & \text { Métodos } & 13\end{array}$

5.1 Grade Numérica . . . . . . . . . . . . . . . . . . . . . . . . . . . . . 13

5.2 Grade Batimétrica $\ldots \ldots \ldots \ldots \ldots$. . . . . . . . . . . . 14

5.3 Pontos de Série Temporal . . . . . . . . . . . . . . . . . . . . 15

5.4 Condições iniciais e de fronteira . . . . . . . . . . . . . . . . . . . . . . . . 17

5.5 Forçantes meteorológicas $\ldots \ldots \ldots$. . . . . . . . . . . . . 19

5.5 .1 Temperatura do Ar . . . . . . . . . . . . . 20

5.5 .2 Radiação Solar . . . . . . . . . . . . . . . . . . . 21

5.5 .3 Velocidade do Vento . . . . . . . . . . . . . . . . . 22

5.6 Descargas de rios . . . . . . . . . . . . . . . . . 25

5.7 Período de simulação e considerações . . . . . . . . . . . . . . . . . 27

$\begin{array}{llr}6 & \text { Resultados: Parte I } & 29\end{array}$

6.1 Hidrodinâmico . . . . . . . . . . . . . . . . . . . . . . . . . . . . . . . . . . . . 29

6.2 Qualidade da Água . . . . . . . . . . . . . . . . . . . . . . . 32

6.2 .1 Temperatura . . . . . . . . . . . . . . . . . . 32

6.2 .2 Salinidade . . . . . . . . . . . . . . . . . . 33 
6.2 .3 Oxigênio . . . . . . . . . . . . . . . . . . . 35

6.2 .4 Nutrientes . . . . . . . . . . . . . . . . . . . . 37

6.2 .5 Fitoplâncton e Zooplâncton . . . . . . . . . . . . . . . . . . . 43

\begin{tabular}{lll}
\hline 7 & Resultados: Parte II & 47
\end{tabular}

7.1 Temperatura do $\mathrm{Ar} \ldots \ldots \ldots \ldots \ldots$. . . . . . . . . . . . . . 47

7.2 Radiação Solar . . . . . . . . . . . . . . . . . . . . . . 50

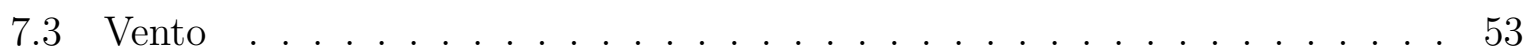

\begin{tabular}{lll}
\hline 8 & Discussão & 65
\end{tabular}

$\begin{array}{lll}9 & \text { Conclusão } & 66\end{array}$

\begin{tabular}{ll}
\hline 10 Referências & 67
\end{tabular} 


\section{Introdução}

A modelagem oceanográfica está intimamente relacionada com a modelagem atmosférica. Esta foi desenvolvida para prever condições meteorológicas. Inicialmente não existiam máquinas de computação automáticas, portanto, os cálculos eram realizados a mão utilizando régua de cálculo e tabela de log. Atualmente, avanços em informática e o aprimoramentos das técnicas de computação permitem que modelos detalhados da atmosfera e do oceano sejam implementados (Miller, 2007).

A modelagem numérica tem sido um componente essencial na maioria das pesquisas da Oceanografia Física. Nos últimos anos, o interesse da comunidade científica mundial pelas regiões costeiras aumentou, principalmente pelas necessidades de manejo de recursos e segurança, envolvendo grande interesse social, uma vez que grande parte da população mundial vive perto da linha da costa (Miller, 2007).

Atualmente, esforços para a modelagem ecológica têm sido realizados em países onde há preocupação com a qualidade da água. Uma forma apropriada de estudar o ambiente marinho é através do estabelecimento de cenários e simulação de suas consequências com modelos numéricos (MOHID, 2009).

Ecossistemas complexos podem ser estudados através da formulação de modelos que simulem os principais processos que ali se desenvolvem, sejam eles físicos, químicos ou biológicos (Ribeiro, 2012). Apesar de serem simplificações de sistemas reais, modelos numéricos permitem estudar respostas para previsões referentes à questões importantes que afetam o ambiente marinho (WALTERS, 1988). Além de serem utilizados para lidar com acidentes ambientais ou desastres naturais, modelos possibilitam compreender o meio ambiente e visualizá-lo de forma integrada, uma vez que associam as informações físicas, químicas e biológicas (Chapra, 1997).

A modelagem ambiental é particularmente importante às regiões vulneráveis a atividades humanas, em que o tempo de residência é limitado. Ambientes assim são suscetíveis ao enriquecimento por nutrientes associados à degradação da qualidade da água. Tais ambientes podem sofrer eutrofização, podendo proliferar blooms de algas, prejudicando recursos pesqueiros, causando intoxicação alimentar e mortalidade de peixes. Alguns sintomas de eutrofização são: a alta concentração de fitoplâncton, hipóxia na superfície da água e anoxia nas camadas profundas. Assim, instituições governamentais vem se organizando para formar diretrizes para garantir o manejo sustentável dos recursos hídricos (Malhadas et al., 2014).

A utilização desse tipo de modelo permite avaliar o estado de eutrofização do ambiente, prever consequências resultantes da redução ou aumento da quantidade de nutrientes, estimar a resposta do ambiente a variações nas concentrações de nutrientes, quantificar os fluxos de nutrientes nos sistemas costeiros, entre outros (Bernardes, 2007).

Atualmente existem diversos modelos capazes de simular os processos físicos, químicos e biológicos em corpos de água. Dentre eles são: QUAL2K modelo unidimensional de qualidade da água utilizado em rios e córregos, desenvolvido pela EPA; WASP7 também desenvolvido pela EPA, é um modelo 3D capaz de simular a qualidade da água a partir de forçantes naturais ou antropogênicas; ECOLab módulo de qualidade da água do modelo numérico MIKE3D, desenvolvido pela Danish Hydraulic Institute (DHI); WQMAP é um sistema de modelagem integrada projetado para o estudo de qualidade da água 
e desenvolvido pela Applied Science Associates (ASA); DELFT3D desenvolvido pela DELTARES, é um sistema de modelos, capaz de simular hidrodinâmica, transporte de sedimentos, morfologia, qualidade da água para estuários e ambientes costeiros.

O modelo a ser utilizado neste trabalho é o MOHID. Este sistema de modelagem, criado em 1985 para o estudo de estuários e áreas costeiras (Neves, 1985), atualmente é desenvolvido pela MARETEC no IST, que pertence à Universidade Técnica de Lisboa. Seu código é escrito em ANSI FORTRAN 95, insigne na área da computação de alta performance. Este sistema é integrado por diversas ferramentas, permitindo a simular processos físicos e biogeoquímicos, tanto na coluna d'água como no sedimento (MOHID, 2009).

O sistema de modelagem MOHID vem mostrando bons resultados em simulações para estudos de casos ao redor do mundo (Brandimarte et al., 2015). Simulações em áreas costeiras e estuários conseguiram mostrar características complexas do escoamento (Martins et al., 2001). É capaz de simular a evolução no tempo de processos da qualidade da água que ocorrem em rios, estuários, lagos e ambientes oceânicos (Brandimarte et al., 2015).

O sistema de modelos MOHID foi aplicado em diversos estudos no sistema estuarino de Santos - São Vicente pela equipe do projeto ECOMANAGE, sendo grande parte destes relacionados à hidrodinâmica e ao transporte de sedimentos (Neves et al., 2008). Nos últimos anos (Mateus et al. 2008; Sampaio et al., 2008aa, 2008bb; Sampaio 2010; Ribeiro 2012) o MOHID passou a ser utilizado para simular processos de qualidade de água e produção primária no sistema estuarino de Santos-São Vicente.

\section{1 Área de Estudo}

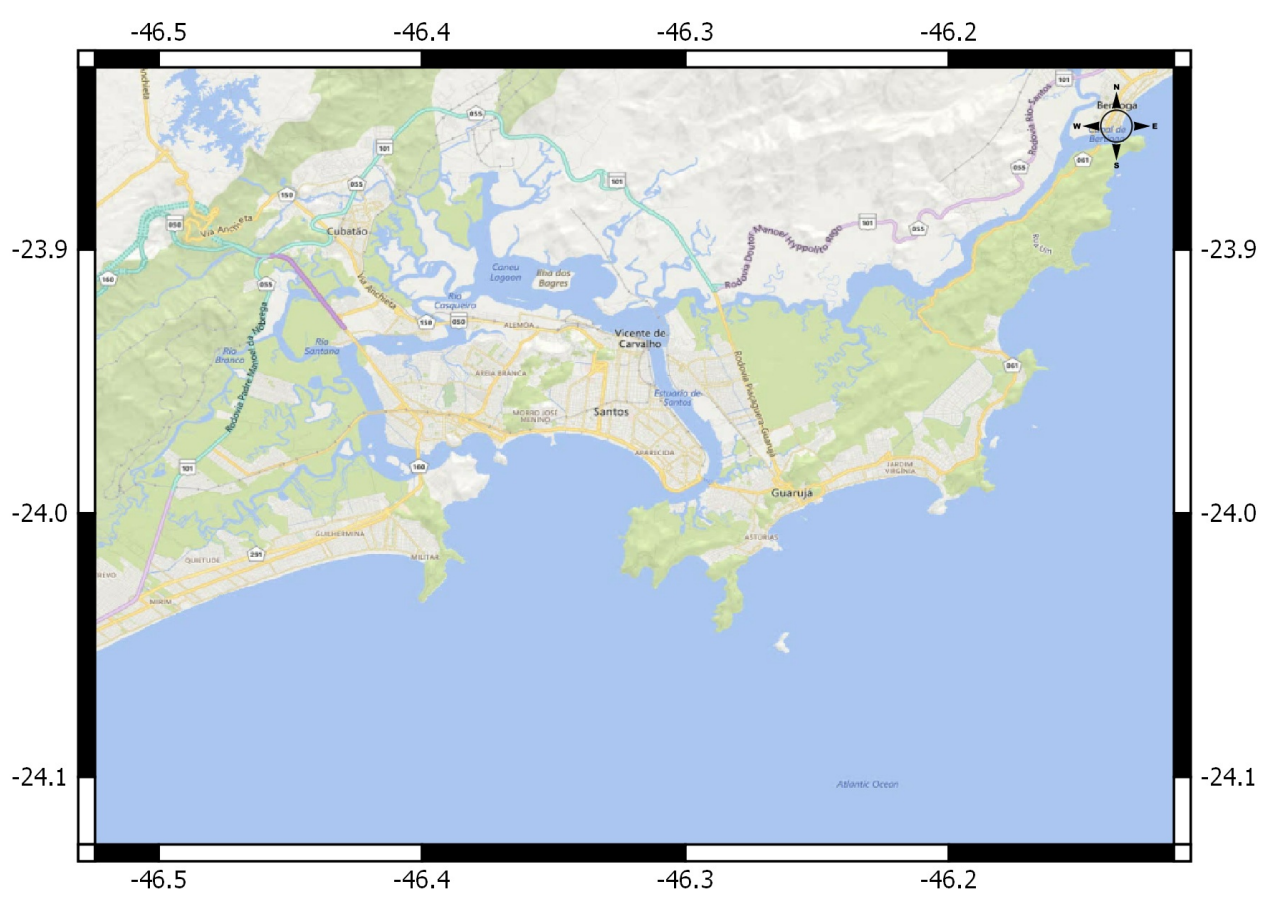

Figura 1: Localização da área de estudo.

Os ecossistemas estuarinos são ambientes dinâmicos, complexos, biodiversos e 
regidos principalmente por fenômenos físicos como maré, vento e chuva. Sua elevada produtividade se deve ao aporte de nutrientes de bacias hidrográficas, correntes geradas pela maré, rápida regeneração e fixação de nutrientes através da atividade microbiana e de organismos filtradores, além da presença de outros grupos de produtores primários como fitoplâncton, marismas, manguezais, pradarias de macrófitas submersas e macroalgas (Day, 1989).

A área de estudo do presente trabalho compreende o sistema estuarino de Santos - São Vicente que está localizado na região Metropolitana da Baixada Santista, abrangendo os municípios de Praia Grande, São Vicente, Cubatão, Santos e Guarujá - delimitado por $23.86^{\circ} \mathrm{S}$ a $24.1^{\circ} \mathrm{S}$ e $46.5^{\circ} \mathrm{W}$ a $46.14^{\circ} \mathrm{W}$ (Figura 1 ).

Os rios desta região são acidentados em seu curso superior e no curso inferior podem apresentar meandramentos (CETESB, 2006). São rios pouco extensos e de alta competência devido à proximidade da Serra do Mar. Os mais importantes são os rios Itapanhaú, Cubatão, Moji, Quilombo e Jurubatuba. A área de estudo apresenta um sistema de canais, destacando-se os de Santos, São Vicente (Barreiros), Bertioga e Piaçaguera e canais que apresentam pontos de alargamento, como o Largo do Canéu, Largo de São Vicente, Largo do Candinho e Largo da Pompeba.

O clima da região é tropical com temperaturas amenas, no mês mais frio a temperatura não fica abaixo de $18^{\circ} \mathrm{C}$, não apresenta estação invernosa e possui precipitação em todos os meses do ano (Lamparelli et al., 1999).

A pluviosidade anual média é em torno de 2000 - $3000 \mathrm{~mm}$, sendo o verão o período mais chuvoso e o outono o menos chuvoso (Monteiro, 1973).

No período entre os anos de 2003 a 2008, a média das temperaturas máximas foi de $26,3^{\circ} \mathrm{C}$ e a média das mínimas de $19.3^{\circ} \mathrm{C}$, com média (anual) igual a $23,5^{\circ} \mathrm{C}$. A pressão atmosférica média foi de 1.015,6 mb e a umidade relativa média foi de 75,9\% (Sampaio et al., 2009).

A maré dos canais estuarinos apresenta amplitude média de 1,23m na sizígia e $0,24 \mathrm{~m}$ na quadratura. As frentes frias, que são mais frequentes no inverno, produzem alterações no nível do mar, que podem ultrapassar 0,5 m (Harari et al., 1999).

A vegetação da Baixada Santista é constituída de 40,3\% por mata atlântica, 10,6\% por vegetação de restinga e 8,8\% por manguezais (Afonso, 2006).

A região da Baixada Santista sofre com descargas diretas de esgoto doméstico nos rios e estuários, uma vez que os municípios possuem habitações irregulares, localizadas em margens de rios ou sobre áreas de manguezais (PRIMAD, 2005). 


\section{$2 \quad$ Hipótese científica}

A hipótese de trabalho é que condições meteorológicas determinam a circulação costeira que, em conjunto com os processos de dispersão, influencia a concentração de elementos químicos, matéria orgânica, fitoplâncton e zooplâncton. Além disso, o crescimento populacional de zooplâncton depende da disponibilidade de fitoplâncton como alimento, e o crescimento populacional de fitoplâncton depende de nutrientes, luz e temperatura da água.

\section{Objetivos}

Analisar da influência da hidrodinâmica, disponibilidade de luz e temperatura da água na distribuição de fito e zooplâncton, através da implementação de um modelo numérico hidrodinâmico tridimensional, acoplado a um modelo ecológico, no sistema estuarino de Santos - São Vicente. 


\section{Descrição do Mohid}

O desenvolvimento do MOHID começou em 1985 e vem sendo atualizado e melhorado frequentemente devido a sua importância em pesquisas científicas e projetos de Oceanografia e Engenharia (MOHID, 2009). É uma ferramenta de modelagem que simula processos físicos e biogeoquímicos tanto na coluna d'água como no sedimento. Integra diversos módulos, cada um responsável por controlar certo tipo de informação.

Este modelo utiliza filosofia de programação orientada por objetos, o que permite a modelagem integrada de processos físicos e biogeoquímicos, através de modelos aninhados e sistemas com escalas desde as bacias oceânicas até os estuários. Vem sendo aplicado em diferentes estudos de caso, em áreas costeiras e estuarinas, como também processos oceânicos e de reservatórios, simulando com sucesso diferentes escalas temporais e espaciais. (MOHID, 2009)

Dentre as suas características é possível destacar a possibilidade de rodar diferentes aplicações simultaneamente; fácil adaptação a diferentes áreas; pode usar diferentes passos de tempo em diferentes módulos; pode ser usado em qualquer dimensão (1D, 2D, 3D); utiliza a técnica de abordagem de volumes finitos para a discretização espacial; permite a utilização de modelos aninhados; permite o processamento em paralelo através de Message Passing Interface (MPI), que resulta em uma redução significativa do tempo de processamento. (MOHID, 2009)

A página oficial do MOHID é http://www.mohid.com. Seu código é livre e pode ser acessado em https://github.com/Mohid-Water-Modelling-System/Mohid. Além do software para rodar o modelo, também estão disponíveis softwares gratuitos para organizar e preparar os dados, analisar os resultados, como também uma versão comercial chamada MOHID Studio desenvolvida pela ACTION Modulers. 
Tabela 1: Principais módulos do Mohid.

\begin{tabular}{l|l}
\hline Nome & Descrição \\
\hline Model & $\begin{array}{l}\text { Controla o fluxo de informação entre o módulo } \\
\text { hidrodinâmico e os módulos de transporte, assim como } \\
\text { a comunicação entre os modelos aninhados }\end{array}$ \\
\hline Hydrodynamic & Calcula o nível, as velocidades e os fluxos d'água \\
\hline Water Properties & $\begin{array}{l}\text { Controla a evolução das propriedades da água } \\
\text { (temperatura, salinidade, oxigênio, etc) }\end{array}$ \\
\hline Water Quality & $\begin{array}{l}\text { Modelo adimensional da qualidade da água. Simula o } \\
\text { ciclo do oxigênio, nitrogênio e fósforo }\end{array}$ \\
\hline Sediment Properties & $\begin{array}{l}\text { Controla a evolução das propriedades do sedimento } \\
\text { particulado e dissolvido }\end{array}$ \\
\hline Turbulence & $\begin{array}{l}\text { Modelo de turbulência 1D, que utiliza diversas } \\
\text { formulações incluindo a do GOTM }\end{array}$ \\
\hline Geometry & Guarda e atualiza informações sobre os volumes finitos \\
\hline Surface & Condições de contorno no topo da coluna d'água \\
\hline Bottom & Condições de contorno no fundo da coluna d'água \\
\hline Open Boundary & Condição de contorno na fronteira com o oceano aberto \\
\hline Discharges & Descargas de rios ou de origem antrópica \\
\hline
\end{tabular}

\subsection{Módulo Hidrodinâmico}

O módulo hidrodinâmico é capaz de simular escoamentos em massas de água, sob a condição da velocidade ser menor que a celeridade da onda de pressão. Seu objetivo é de auxiliar no entendimento de processos biogeoquímicos e esclarecer problemas ecológicos associados às atividades humanas. (MOHID, 2009)

Este módulo resolve as equações primitivas em três dimensões (Equações 1, 2 e 3) assumindo incompressibilidade, equilíbrio hidrostático, aproximação de Reynolds e aproximação de Boussinesq. A discretização espacial é feita utilizando a técnica de volumes finitos e a discretização temporal é baseada na utilização de um esquema semiimplícito.

$$
\begin{aligned}
& \frac{D u}{D t}-f v=-\frac{1}{\rho_{r}} \frac{\partial p}{\partial x}+\frac{\partial}{\partial x}\left(A_{H} \frac{\partial u}{\partial x}\right)+\frac{\partial}{\partial y}\left(A_{H} \frac{\partial u}{\partial y}\right)+\frac{\partial}{\partial z}\left(A_{V} \frac{\partial u}{\partial z}\right) \\
& \frac{D v}{D t}+f u=-\frac{1}{\rho_{r}} \frac{\partial p}{\partial y}+\frac{\partial}{\partial x}\left(A_{H} \frac{\partial v}{\partial x}\right)+\frac{\partial}{\partial y}\left(A_{H} \frac{\partial v}{\partial y}\right)+\frac{\partial}{\partial z}\left(A_{V} \frac{\partial v}{\partial z}\right) \\
& \frac{D w}{D t}=\rho_{r} \vec{g}-\frac{1}{\rho_{r}} \frac{\partial p}{\partial z}+\frac{\partial}{\partial x}\left(A_{H} \frac{\partial w}{\partial x}\right)+\frac{\partial}{\partial y}\left(A_{H} \frac{\partial w}{\partial y}\right)+\frac{\partial}{\partial z}\left(A_{V} \frac{\partial w}{\partial z}\right)
\end{aligned}
$$


onde $u, v$ e $w$ são componentes do vetor velocidade nas direções $x, y$ e $z$ respectivamente, $t$ o tempo, $f$ o parâmetro de Coriolis, $A_{H}$ e $A_{V}$ as viscosidades cinemáticas turbulentas na direção horizontal e vertical, $\rho_{r}$ a densidade da água, $\vec{g}$ a aceleração da gravidade e $p$ a pressão. A evolução temporal da velocidade é o balanço do transporte advectivo, força de Coriolis, gradiente de pressão e diffusão turbulenta (MOHID, 2009).

A aproximação hidrostática é assumida:

$$
\frac{\partial p}{\partial z}+g \rho=0
$$

onde $g$ é a gravidade, $\rho$ a densidade e $p$ a pressão.

A discretização temporal é feita por meio do algoritmo semi-implícito de direção alternada (Alternate Direction Implicit - ADI). Este algoritmo computa alternativamente uma componente da velocidade horizontal implicitamente enquanto a outra é calculada explicitamente. O sistema de equações resultante é tridiagonal e pode ser resolvido pelo algoritmo de Thomas de forma eficiente e rápida. Isto permite preservar as vantagens da estabilidade do método implícito sem a desvantagem do custo computacional associado ao erro de fase, permitindo um passo de tempo maior (MOHID, 2009).

\subsection{Módulo Propriedades da Água}

Este módulo coordena a evolução das propriedades na coluna d'água, usando a abordagem euleriana. Esta coordenação inclui o transporte devido à advecção e difusão, descarga de águas dos rios e de fontes antrópicas, troca de informações com o fundo e superfície, sedimentação de material particulado (MOHID, 2009).

O sistema de modelos MOHID pode simular diversas propriedades diferentes da água. Algumas das propriedades utilizadas neste trabalho são: temperatura, salinidade, oxigênio, amônia, nitrato, nitrito, nitrogênio orgânico dissolvido refratário e não refratário, nitrogênio ogânico particulado, fósforo inorgânico, fósforo orgânico dissolvido refratário e não refratário, fósforo orgânico particulado, fitoplâncton, zooplâncton.

\subsection{Módulo Qualidade da Água}

O módulo ecológico incluído no Mohid é adaptado do EPA, e pertence à categoria de modelos de simulações de ecossistemas, ou seja, conjunto de equações conservativas que descrevem da melhor forma possível o funcionamento e as inter-relações das componentes de um ecossistema real.

Algumas variáveis deste módulo são: fitoplâncton, zooplâncton, nutrientes dissolvidos, matéria orgânica na fase pelágica e bentônica, bactéria pelágica e bactéria bentônica. E o processo de produção primária move todas as transferências de massa entre os compartimentos biológicos.

O módulo de qualidade da água foi desenvolvido em termos de fontes e sumidouros. Muitas das equações dependem de um fator regulador, que representa a resposta dos organismos a parâmetros ambientais como luz, nutrientes ou temperatura. Cada recurso pode ser considerado fator limitante, reduzindo a taxa de crescimento em baixas 
concentrações.

A densidade é calculada em função da temperatura e salinidade pela equação de estado da água do mar (UNESCO and SCOR, 1981).

\subsubsection{Fitoplâncton}

Fitoplâncton são organismos unicelulares que medem 0,2 $\mu \mathrm{m}$ a $200 \mu \mathrm{m}$ (Portela, 1996). São encontrados em lagos, rios e oceanos e produzem seu próprio alimento a partir do processo da fotossíntese, onde ocorre a absorção da luz pela clorofila e a transformação de nutrientes em moléculas orgânicas. Os grupos que ocorrem com maior frequência são: cianobactérias, dinoflagelados e diatomáceas. No ecossistema aquático, é a fonte de alimento principal para diversas espécies aquáticas, desde zooplâncton até baleias. Alguns possuem certa capacidade de locomoção, porém são sujeitos ao fluxo da água em que vivem. Podem se deslocar verticalmente ao longo do dia em busca de luz ou para fugir de predadores.

O modelo assume que a concentração da clorofila é diretamente proporcional à concentração de carbono do fitoplâncton (Valiela, 2013). A razão entre carbono e clorofila

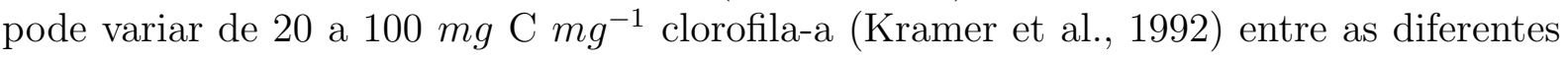
espécies.

\section{Limitação por nutriente}

O modelo considera nitrogênio e fósforo os nutrientes que limitam o crescimento do fitoplâncton. Essa limitação é expressa na fórmula de Michaelis-Menten, com a constante de meia saturação $K_{N}$.

No caso da amônia e nitrato, o modelo considera:

$$
\Psi(N)_{P h y}=\frac{N H_{4}+N O_{3}}{K_{N}+N H_{4}+N O_{3}}
$$

onde $\Psi(N)_{P h y}$ representa a limitação devida à presença de nitrogênio, $\mathrm{NH}_{4}$ e $\mathrm{NO}_{3}$ são as concentrações de amônia e nitrato em $\mathrm{mg} N \cdot L^{-1}$ e $K_{N}$ é a constante de meia saturação para a limitação por nitrogênio em mg $N \cdot L^{-1}$.

No caso do fósforo a equação toma a forma de:

$$
\Psi(P)_{P} h y=\frac{\mathrm{PO}_{4}}{K_{p}+P O_{4}}
$$

onde $\Psi(P)_{P h y}$ representa a limitação devida à presença de fósforo, $P O_{4}$ é a concentração de fósforo em mg $P . L^{-1}$ e $K_{p}$ a constante de meia saturação para a limitação por fósforo $\operatorname{mg} N . L^{-1}$.

Assim o mínimo entre $\Psi(N)_{P h y}$ e $\Psi(P)_{P h y}$ corresponde ao fator limitante.

\section{Limitação pela temperatura}

Para representar a limitação por temperatura, foi adotado a equação 7 (Thornton and Lessem, 1978):

$$
\Psi(T)=K_{A}(T) \cdot K_{B}(T)
$$


onde $K_{A}(T)$ é definido como:

$$
K_{A}(T)=\frac{K_{1} \cdot e^{\gamma_{1} \cdot\left(T-T_{m i n}\right)}}{1+K_{1} \cdot\left(e^{\gamma_{1} \cdot\left(T-T_{m i n}\right)}-1\right)}
$$

com

$$
\gamma_{1}=\frac{\operatorname{Ln} \frac{K_{2}\left(1-K_{1}\right)}{K_{1}\left(1-K_{2}\right)}}{\operatorname{Topt}_{\min }-T_{\min }}
$$

onde $K_{B}(T)$ é definido por:

$$
K_{B}(T)=\frac{K_{4} \cdot e^{\gamma_{2} \cdot\left(T_{\max }-T\right)}}{1+K_{4} \cdot\left(e^{\gamma_{2} \cdot\left(T_{\max }-T\right)}-1\right)}
$$

com

$$
\gamma_{2}=\frac{\operatorname{Ln} \frac{K_{3}\left(1-K_{4}\right)}{K_{4}\left(1-K_{3}\right)}}{T_{\max }-T_{o p t_{\max }}}
$$

Topt $_{\min }\left({ }^{\circ} \mathrm{C}\right)$ e $\operatorname{Topt}_{\max }\left({ }^{\circ} \mathrm{C}\right)$ representam o intervalo de temperatura ótima, e $T_{\max }\left({ }^{\circ} \mathrm{C}\right)$ e $T_{\min }\left({ }^{\circ} \mathrm{C}\right)$ a máxima e a mínima temperatura tolerável onde a fotossíntese é completamente inibida. As constantes remanescentes $\left(K_{1}, K_{2}, K_{3}\right.$ e $\left.K_{4}\right)$ controlam a forma da curva do efeito da temperatura.

\section{Limitação pela luz}

A fotossíntese ocorre somente quando a intensidade de luz está acima de uma determinada intensidade. Isso significa que o fitoplâncton está limitado às camadas superiores da coluna d'água, onde a intensidade de luz é suficiente. A profundidade em que a luz penetra na água e em que a produção pode ocorrer é dependente de fatores como absorção, reflexão e espalhamento que ocorrem na água, o comprimento de onda da luz, transparência da água, reflexão da superfície, reflexão das partículas, latitude e estação do ano.

A radiação solar depende de fatores como cobertura de nuvens, poeira na atmosfera e elevação do sol.

A taxa de fotossíntese é estritamente dependente da intensidade de luz. O aumento na intensidade de luz leva a taxas maiores até um certo limite. Acima desse limite, o aumento da intensidade de luz geralmente inibe a fotossíntese.

Os principais componentes que absorvem e espalham a luz na coluna d'água são: substâncias orgânicas dissolvidas, material planctônico vivo e morto, partículas suspensas inanimadas e a própria água.

$$
\begin{gathered}
E(z)=E_{0} \cdot e^{-k(p) \cdot z} \\
\Psi(E)=\frac{e}{k(p) \cdot z} \cdot\left(e^{-\frac{E_{0}}{E_{o p t}} \cdot e^{-k(p) \cdot z}}-e^{-\frac{E_{0}}{E_{o p t}}}\right)
\end{gathered}
$$

$E(z)$ representa a radiação solar em uma profundidade $z, E_{0}$ representa a radiação solar efetiva na superfície da água $\left(W \cdot m^{-2}\right), k(p)$ o fator de extinção da luz $\left(m^{-1}\right), E_{\text {opt }}$ a intensidade ótima para a fotossíntese e $z$ a profundidade $(m)$. 


\section{Equações}

Fitoplâncton é descrito em termos de concentração de carbono $(m g C / l)$. O modelo assume três fatores que limitam a taxa de crescimento do fitoplâncton: temperatura $\Psi(T)$, luz $\Psi(E)$ e nutriente (mínimo entre $\Psi(N)$ e $\Psi(P)$ ).

A simulação de fitoplâncton é desenvolvida com as seguintes considerações (Figura 2) o fitoplâncton consome nutrientes inorgânicos dependendo de sua disponibilidade; absorve luz para a produção de energia através da fotossíntese; durante o processo da fotossíntese, oxigênio dissolvido é produzido; o processo de respiração consome oxigênio e produz amônia; a excreção do fitoplâncton produz matéria orgânica dissolvida; quando morre o fitoplâncton aumenta a matéria orgânica dissolvida e particulada; a concentração de fitoplâncton diminui ao ser consumido pelo zooplâncton.

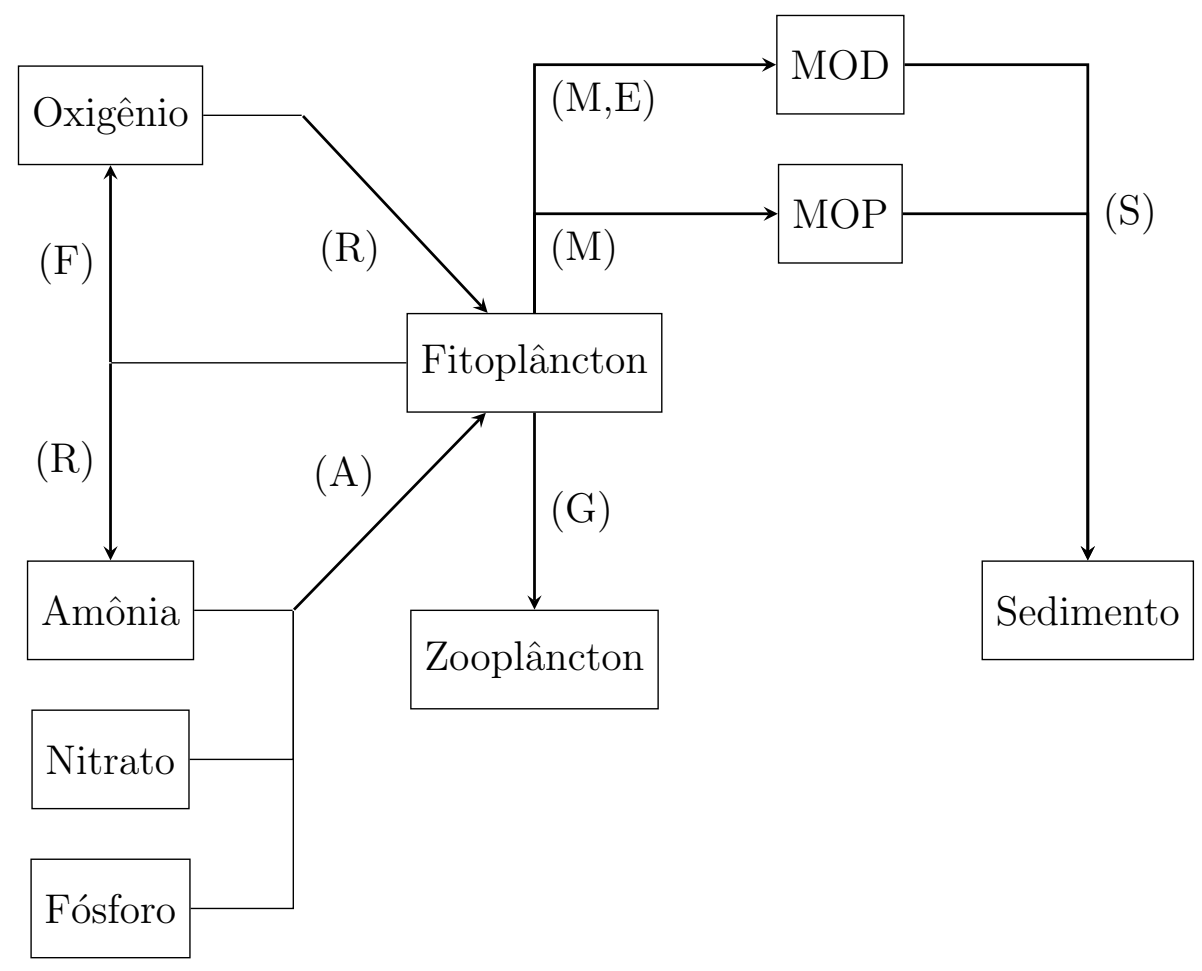

Figura 2: Esquema do fluxo interno do fitoplâncton (A - assimilação, F - fotossíntese, R - respiração, M - mortalidade, E - excreção, G - forrageio, S - deposição)

Equação da variação do fitoplâncton é representada como:

$$
\frac{\partial \Phi_{P h y}}{\partial t}=\left(\mu_{P h y}-r_{P h y}-e x_{P h y}-m_{P h y}\right) \cdot \Phi-G
$$

A taxa de crescimento, $\mu_{P h y}\left(d i a^{-1}\right)$ é dada por:

$$
\mu_{P h y}=\mu_{\max } \cdot \min (\Psi(N), \Psi(P)) \cdot \Psi(E) \cdot \Psi(T)
$$

onde $\mu_{\max }$ representa a taxa máxima de crescimento.

A respiração, $r_{P h y}\left(d i a^{-1}\right)$, é dada por:

$$
r_{P h y}=k_{e r} \cdot \exp (0.069 \cdot T)+k_{p} \cdot \mu_{P h y}
$$


onde $k_{e r}$ representa a constante de respiração endógena e $k_{p}$ o fator de fotorespiração.

A excreção,ex $x_{P h y}\left(d i a^{-1}\right)$, é dada por:

$$
e x_{P h y}=\varepsilon_{P h y} \cdot\left(1-\Psi(E)_{P h y}\right)
$$

A mortalidade natural, $m_{P h y}\left(d i a^{-1}\right)$, é dada por:

$$
m_{P h y}=m_{\max } \cdot \frac{\frac{\Phi_{P h y}}{\mu_{P h y}}}{K m+\frac{\Phi_{P h y}}{\mu_{P h y}}}
$$

onde $m_{\max }$ representa a mortalidade máxima e $K m$ a razão de mortalidade de meia saturação.

O grazing, $G$, é dado por:

$$
G=\frac{g_{z}}{E} \cdot \Phi_{z}
$$

onde $g_{z}$ representa a taxa bruta de crescimento do zooplâncton, $E$ a eficiência de assimilação e $\Phi_{z}$ a concentração de zooplâncton.

\section{Luz}

Na coluna d'água, a lei de Lambert-Beer define a atenuação da luz com a profundidade:

$$
I(z)=l_{0} e^{-k z}
$$

onde I $\left(W m^{-2}\right)$ é a intensidade em uma determinada profundidade $z, l_{0}$ é a intensidade de luz na superfície, e $k$ é o coeficiente de extinção da luz $\left(m^{-1}\right)$.

O coeficiente de extinção $k$ é calculado:

$$
k=k_{w}+k_{p} C_{p}+k_{s} C_{s}
$$

onde $C$ é a concentração e os índices $w, p$ e $s$ são água, fitoplâncton e sólido total na coluna d'água, respectivamente.

\subsubsection{Zooplâncton}

O zooplâncton é descrito em termos de concentração de carbono $(m g C / l)$. A respiração e a mortalidade natural, $r_{Z}$ e $m_{Z_{0}}$, são consideradas funções da temperatura. A mortalidade por predação, $G_{Z}$, depende da concentração de zooplâncton.

\section{Equações}

O crescimento do zooplâncton é dado por:

$$
\frac{\partial \Phi_{Z}}{\partial t}=\left(g_{Z}-r_{Z}-m_{Z}\right) \cdot \Phi_{Z} \cdot G_{Z}
$$


A taxa de crescimento, $g_{Z}\left(d i a^{-1}\right)$, é dada por:

$$
g_{Z}=g_{\text {max }} \cdot T_{r e f} \cdot \Psi(T)_{Z} \cdot\left(1-e^{-\Lambda\left(\Phi_{P h y}-\Phi_{P h y_{0}}\right)}\right)
$$

onde $g_{\max }$ representa o crescimento máximo, $\Lambda$ a constante de Ivlev, $\Phi_{P h y_{0}}$ a concentração mínima do fitoplâncton para o grazing. A limitação por temperatura é calculada da mesma forma que para o fitoplâncton, porém com constantes diferentes.

A mortalidade natural e a respiração, $r_{z}+m_{z}\left(d i a^{-1}\right)$, são dadas por:

$$
r_{Z}+m_{Z}=d_{Z} \cdot T_{r e f} \cdot \Psi(T)
$$

Grazing, $G_{z}\left(d_{i a^{-1}}\right)$, é dado por:

$$
G_{Z}=e_{Z} Z
$$

onde $e_{Z}$ representa a taxa de mortalidade por predação. 


\section{Métodos}

Os dados básicos necessários para processar o modelo são: grade numérica, batimetria, condições iniciais, condições de fronteira, forçantes meteorológicas, descargas de rios e tipos de fitoplâncton (Ribeiro, 2012). Esses dados estão disponíveis no Laboratório de Simulação e Previsão Numérica Hidrodinâmica (LABSIP), coordenado pelo Prof. Dr. Joseph Harari, no Instituto Oceanográfico da Universidade de São Paulo (IOUSP). Para sua utilização, os dados passaram por processo de adequação, com conversão e padronização para atender aos requisitos de formatos do software MOHID.

Nas simulações iniciais, foram feitos testes de conceito e calibração do modelo. Em seguida, foi feita a validação do modelo, com a comparação dos resultados obtidos com os dados de trabalhos anteriores, a fim de reproduzir as principais características hidrodinâmicas e biogeoquímicas na região estudada. Com o modelo calibrado, foram realizadas simulações para análise dos resultados, de modo a estabelecer as interações entre os processos hidrodinâmicos e biológicos.

\subsection{Grade Numérica}

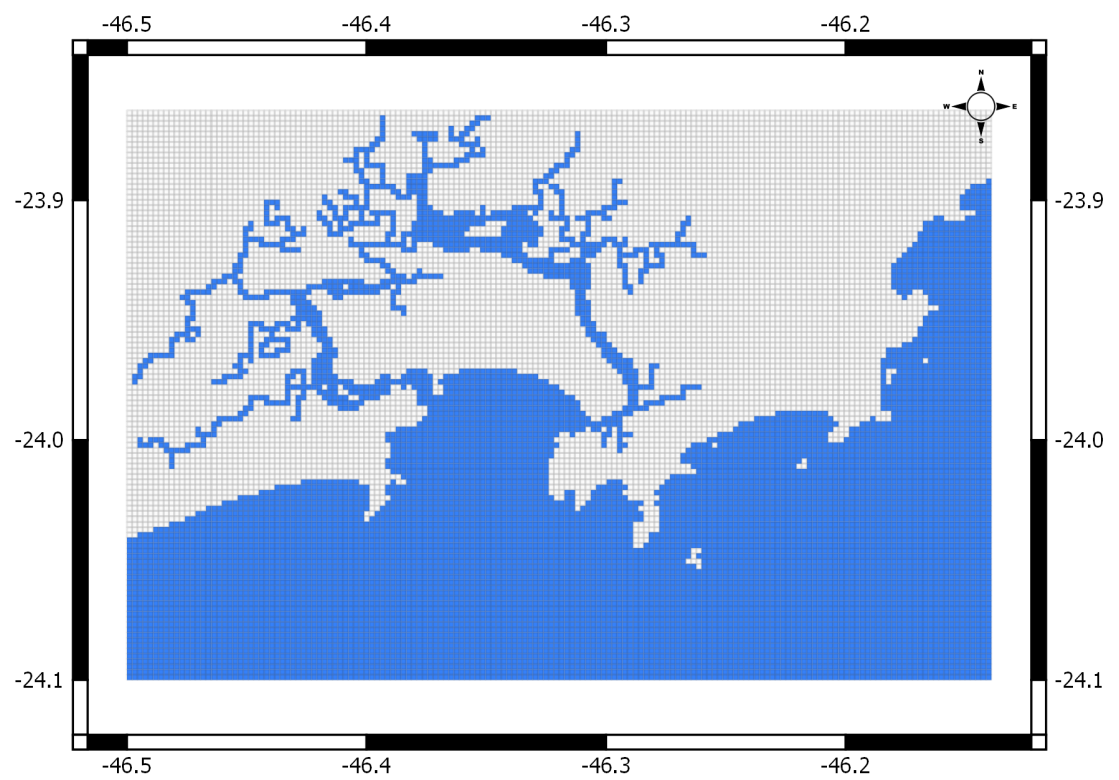

Figura 3: Grade numérica, com resolução horizontal de $0.0022^{\circ}$ $(x=223.5 m, y=244.6 m)$.

Utilizou-se uma grade de espaçamento regular com 108x164 pontos de cálculo e resolução horizontal de $0.0022^{\circ}$ (Figura 3). Na vertical, utilizou-se o sistema de coordenadas sigma com 10 camadas, esquematizado pela figura 4 . 


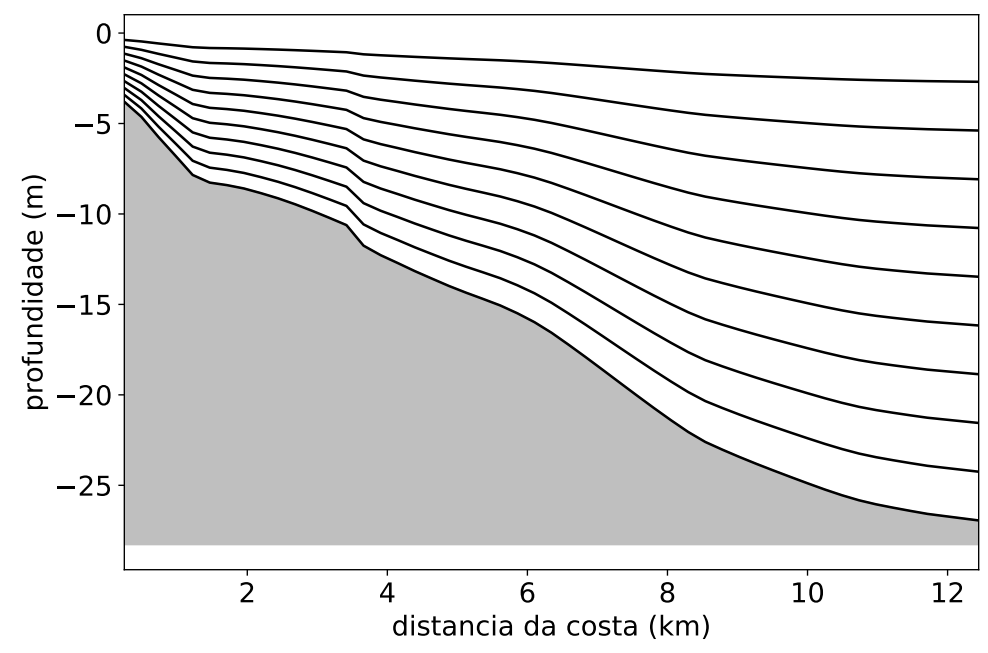

Figura 4: Coordenada vertical sigma com 10 camadas.

O sistema de coordenadas sigma otimiza a representação topográfica, permitindo o mesmo número de pontos de grade para todas as profundidades. Esta discretização é vantajosa para a simulação de fluxos, uma vez que o escoamento acompanha as linhas da grade e as trocas verticais advectivas entre as células são minimizadas (Martins et al., 2001).

\subsection{Grade Batimétrica}

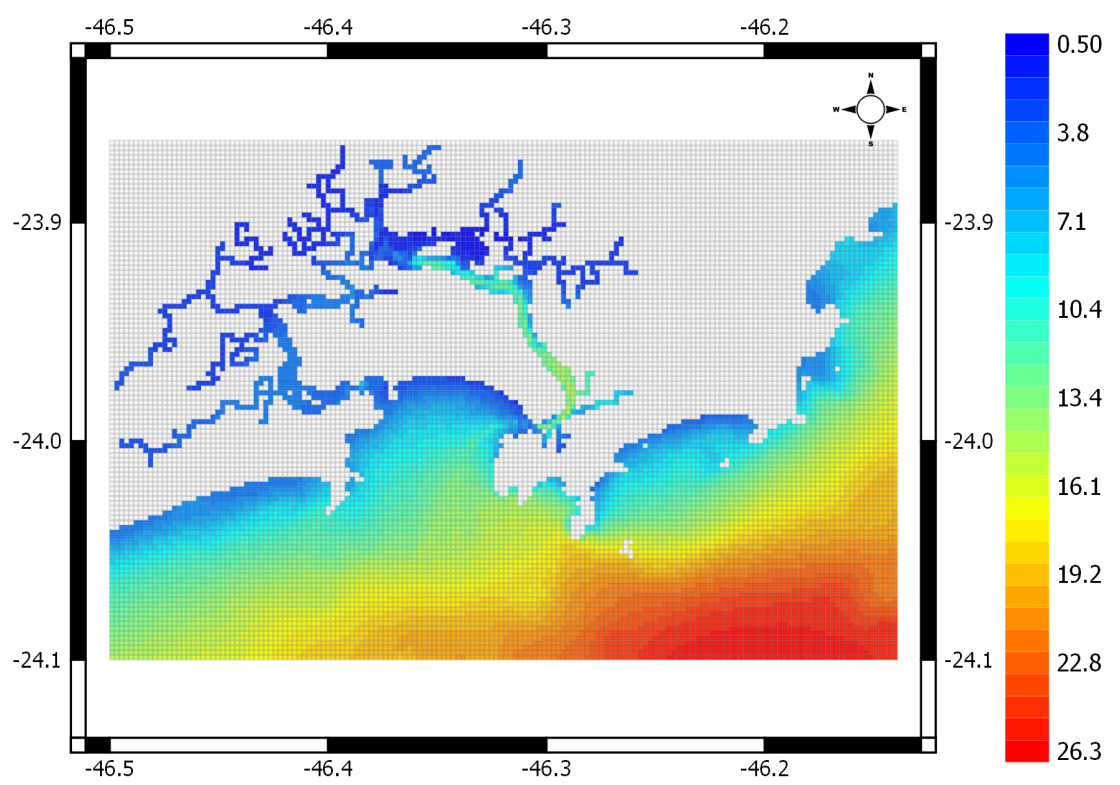

Figura 5: Grade batimétrica (m).

A grade batimétrica (Figura 5) foi estabelecida através de dados de profundidade e linha de costa das cartas náuticas no $n^{\circ}$ 1711, 1712 e 1713, produzidas pela Diretoria de Hidrografia da Marinha (DHN) por meio do Centro de Hidrografia da Marinha (CHM).

As Cartas Náuticas são documentos cartográficos que resultam de levantamentos de áreas oceânicas, mares, baías, rios, canais, lagos, lagoas, ou qualquer outra massa d'água 
navegável e que se destinam a servir de base à navegação; são geralmente construídas na Projeção de Mercator e representam os acidentes terrestres e submarinos, fornecendo informações sobre profundidades, perigos à navegação, natureza do fundo, fundeadouros e áreas de fundeio, auxílios à navegação, altitudes e pontos notáveis aos navegantes, linha de costa e de contorno das ilhas, elementos de marés, correntes e magnetismo e outras indicações necessárias à segurança da navegação. (Marinha, 2017)

Neste modelo, a profundidade em conjunto com dados de radiação solar, cobertura de nuvens e temperatura do ar definem o perfil vertical de temperatura da água; e a profundidade em conjunto com dados de velocidade de vento, nível do mar, nas bordas abertas do modelo, definem o perfil vertical de corrente.

Os dados de linha de costa foram utilizados para definir pontos onde o modelo não deve realizar cálculos e, assim, reduzir o tempo de processamento.

\subsection{Pontos de Série Temporal}

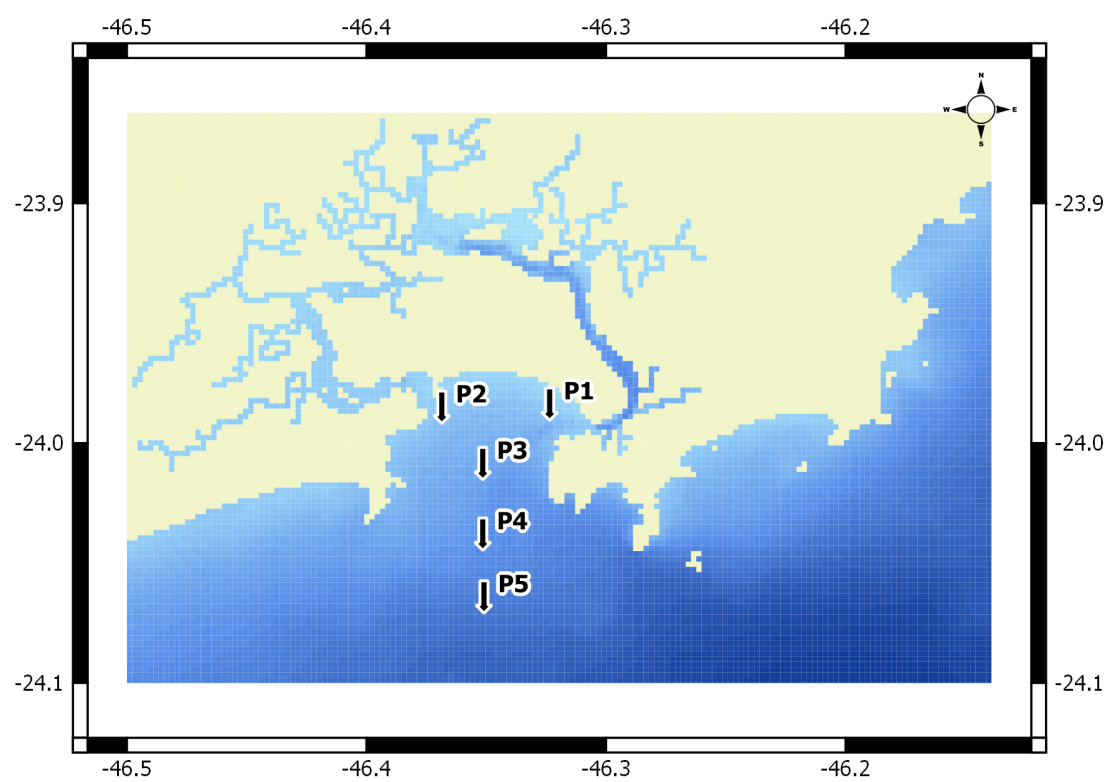

Figura 6: Posição dos pontos onde foram feitas séries temporais.

Além de salvar os resultados do modelo em todos os pontos de cálculo e para todas as camadas, cinco pontos foram escolhidos para salvar os resultados com uma frequência maior. A figura 6 indica as posições destes pontos de monitoramento, definidos aqui como pontos de séries temporais e a tabela 2 suas coordenadas. 
Tabela 2: Coordenadas geográficas dos pontos onde foram geradas séries temporais com os resultados do modelo. O ponto P1 próximo do Estuário de Santos, P2 próximo da Baía de São Vicente, P3 na Baía de Santos, P4 e P5 pontos distantes da costa.

\begin{tabular}{|c|c|c|}
\hline Nome & lat & long \\
\hline$\overline{\mathrm{P} 1}$ & S $23^{\circ} 59^{\prime} 27.96^{\prime \prime}$ & W $46^{\circ} 19^{\prime} 22.44^{\prime \prime}$ \\
\hline P2 & S $23^{\circ} 59^{\prime} 27.96^{\prime \prime}$ & $\mathrm{W} 46^{\circ} 22^{\prime} 08.76^{\prime \prime}$ \\
\hline P3 & $\mathrm{S} 24^{\circ} 00^{\prime} 55.08^{\prime \prime}$ & W $46^{\circ} 21^{\prime} 05.40^{\prime \prime}$ \\
\hline P4 & $\mathrm{S} 24^{\circ} 02^{\prime} 38.04^{\prime \prime}$ & W $46^{\circ} 21^{\prime} 05.40^{\prime \prime}$ \\
\hline P5 & $\mathrm{S} 24^{\circ} 04^{\prime} 13.08^{\prime \prime}$ & W $46^{\circ} 21^{\prime} 05.40^{\prime \prime}$ \\
\hline
\end{tabular}

O MOHID permite a realização de diversos cálculos estatísticos e também a realização de cálculos como massa total, transferência de massa, tempo de residência e taxas de processos ecológicos, úteis nas análises ambientais realizadas. Neste trabalho, além do cálculo da evolução das propriedades físicas e biogeoquímicas, foram feitos cálculos de produção bruta e limitação do crescimento do fitoplâncton por radiação solar, nutrientes e temperatura. Para a realização destes cálculos, é necessário definir regiões onde a integração deve ser feita. Estas regiões são representadas por caixas como pode ser visto na figura 7 .

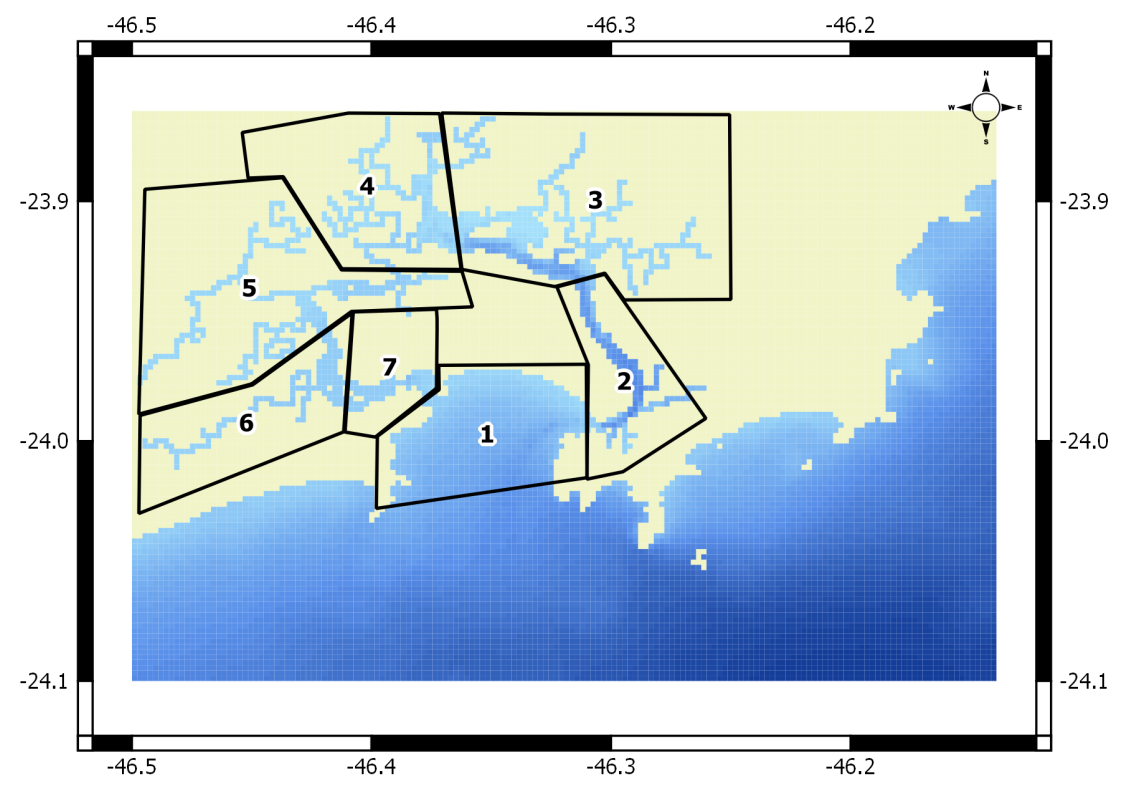

Figura 7: Representação das regiões, esquematizadas por caixas, onde foram feitas os cálculos de integração de propriedades físicas, biogeoquímicas, produção bruta e limitação do crescimento do fitoplâncton por radiação solar, nutrientes e temperatura.

Nas simulações foram definidas sete caixas de integração (Figura 7) baseadas em Mateus et al. (2008) e também utilizadas por Ribeiro (2012). Estas caixas incluem as distintas áreas do sistema estuarino de Santos-São Vicente que são: (1) Baía de Santos; (2) Canal de Santos; (3) Canal de Bertioga e Ilha Barnabé-Bagres; (4) Canal de Piaçaguera e Cubatão; (5) Largo da Pompeba e Rio Boturoca; (6) Rio Piaçabuçu e parte do Canal dos Barreiros; e (7) Canal dos Barreiros e Baía de São Vicente. 


\subsection{Condições iniciais e de fronteira}

Foram consideradas as bordas oceânicas da grade como as fronteiras abertas forçadas pela condição hidrodinâmica de elevação do nível do mar. Esta elevação foi calculada através de constantes harmônicas obtidas pelo TPXO Regional, o qual utiliza solução inversa para obter o melhor ajuste entre dados modelados, de satélite e de estações maregráficas.

O TPXO Regional é um produto concebido a partir de assimilação de vários dados altimétricos (TOPEX Poseidon, Topex Tandem, ERS, GFO) e de outros conjuntos de dados (estações maregráficas, ADCP). O TPXO Regional possui as mesmas magnitudes das soluções globais para o oceano aberto, porém a solução inversa regional geralmente se ajusta significativamente melhor para regiões com topografia complexa e para regiões rasas (Gary and Erofeeva, 2017).

Ao longo da borda aberta, foram selecionados pontos para extrair as constantes M2, S2, N2, K2, K1, O1, P1, Q1, M4, Ms4 e Mn4, através do software OTPS2 totalizando 11 componentes harmônicas de maré. A tabela 3 mostra as componentes utilizadas para um dos pontos da grade situado em $24^{\circ} 3^{\prime} 41^{\prime \prime} S$ e $46^{\circ} 29^{\prime} 39^{\prime \prime} W$.

Tabela 3: Constantes harmônicas das componentes de maré obtidas através do TPXO para o ponto na borda de coordenadas $24^{\circ} 6^{\prime} 0^{\prime \prime} S$ e $46^{\circ} 17^{\prime} 60^{\prime \prime} W$

\begin{tabular}{lcr}
\hline Harmônico & Amplitude $(\mathbf{m})$ & Fase (graus) \\
\hline M2 & 0.387 & 172.4 \\
S2 & 0.222 & -170.5 \\
N2 & 0.048 & -133.1 \\
K2 & 0.066 & -173.6 \\
K1 & 0.071 & -175.1 \\
O1 & 0.108 & 125.8 \\
P1 & 0.019 & 179.4 \\
Q1 & 0.030 & 105.9 \\
M4 & 0.008 & -41.7 \\
Ms4 & 0.026 & -26.3 \\
Mn4 & 0.013 & -67.2 \\
\hline
\end{tabular}


Tabela 4: Principais parâmetros utilizados no módulo qualidade da água.

\begin{tabular}{|c|c|c|c|}
\hline Variável & Descrição & Unidade & Valor \\
\hline$\mu_{\max }^{M \Delta}\left(T_{r e f}\right)$ & Taxa máxima de crescimento à temperatura de referência & | dia $^{-1}$ & 2.0 \\
\hline$I_{\text {opt }}$ & Intensidade de luz ótima para fitoplâncton & $W m^{-2}$ & 121.0 \\
\hline$K_{N}^{M \Delta}$ & Constante de meia saturação do nitrogênio & $m g N L^{-1}$ & 0.014 \\
\hline$K_{P}^{M \Delta}$ & Constante de meia saturação do fósforo & $m g P L^{-1}$ & 0.001 \\
\hline$K_{r e}^{M \Delta}$ & Constante de respiração endógena & $\mathrm{dia}^{-1}$ & 0.0175 \\
\hline$K_{e}^{M \Delta}$ & Constante de excreção & - & 0.07 \\
\hline$K_{\max }^{M \Delta}\left(T_{r e f}\right)$ & Taxa máxima de mortalidade à temperatura de referência & dia ${ }^{-1}$ & 0.02 \\
\hline$K_{m}^{M \Delta}$ & Taxa de mortalidade de meia saturação & $m g C L^{-1} \mathrm{dia}^{-1}$ & 0.3 \\
\hline$E$ & Eficiência de assimilação do fitoplâncton & - & 0.5 \\
\hline$\alpha_{N: C}$ & Razão nitrogênio/carbono do fitoplâncton (razão de redfield) & $m g N m g C^{-1}$ & 0.18 \\
\hline$\alpha_{P: C}$ & Razão fósforo/carbono do fitoplâncton (razão de redfield) & $m g P m g C^{-1}$ & 0.024 \\
\hline$K_{\text {deo }}^{N O P}\left(T_{r e f}\right)$ & Taxa de decomposição do NOP à temperatura de referência & $\mathrm{dia}^{-1}$ & 0.1 \\
\hline$K_{d e o}^{N O D}\left(T_{r e f}\right)$ & Taxa de mineralização do NOD à temperatura de referência & $d i a^{-1}$ & 0.1 \\
\hline$K_{d n i t}^{r e f}\left(T_{r e f}\right)$ & Taxa de denitrificação à temperatura de referência & $d i a^{-1}$ & 0.1 \\
\hline$K_{n i t}^{r e f}\left(T_{r e f}\right)$ & Taxa de nitrificação à temperatura de referência & $d i a^{-1}$ & 0.06 \\
\hline$K_{\text {deo }}^{F O P}\left(T_{r e f}\right)$ & Taxa de decomposição do FOP à temperatura de referência & $d i a^{-1}$ & 0.2 \\
\hline$K_{\min }^{F O D}\left(T_{r e f}\right)$ & Taxa de mineralização do FOD à temperatura de referência & dia ${ }^{-1}$ & 0.1 \\
\hline$\alpha_{O: N}^{N H_{3}}$ & Razão Oxigênio/Nitrogênio em nitrato & - & 3.43 \\
\hline$\alpha_{O: P}^{P}$ & Razão Oxigênio/Fósforo em fosfato & - & 2.06 \\
\hline
\end{tabular}

Tabela 5: Condições iniciais e de fronteira aberta.

\begin{tabular}{llcc}
\hline Propriedades & Unidade & Condições Iniciais & Condições na Borda \\
\hline Temperatura & $C^{\circ}$ & 22 & 22 \\
Salinidade & $p s u$ & 25 & 36 \\
Sedimentos Coesivos & $m g / l$ & 100 & 15 \\
Oxigênio & $m g O^{2} / l$ & 7.5 & 9.56 \\
\hline Amônia & $m g N / l$ & 0.002 & 0.002 \\
Nitrato & & 0.09 & 0.04 \\
Nitrito & & 0.003 & 0.001 \\
NODnr & & 0.02 & 0.002 \\
NODr & & 0.2 & 0.02 \\
NOP & 0.37 & 0.0009 \\
\hline Fósforo Inorgânico & $m g P / l$ & 0.03 & 0.03 \\
NODnr & & 0.0028 & 0.0002 \\
NODr & & 0.028 & 0.002 \\
FOP & & 0.05 & 0.005 \\
\hline Fitoplâncton & $m g C / l$ & 0.05 & 0.02 \\
Zooplâncton & & 0.03 & 0.01 \\
\hline
\end{tabular}




\subsection{Forçantes meteorológicas}

Para as forçantes meteorológicas foram utilizados dados do Climate Forecast System Reanalysis (CFSR) v2 do National Center for Environmental Prediction (NCEP). O CFSR foi implementado como um sistema global de alta resolução acoplando atmosfera, oceano, terra e gelo. Para a re-análise, o CFSR assimila dados de satélites, arquivos operacionais e históricos, dados de centros de pesquisa internacionais, observações de aeronaves, radiossondas, estações meteorológicas, entre outros (Saha et al., 2010).

Análises preliminares do CFSR indicaram ser um produto superior ao anterior, sendo este um dos mais utilizados da NCEP, o CFSR possui maior resolução espacial e temporal, cobre a atmosfera, oceano, gelo marinho e terra, e foi estabelecido com um sistema de assimilação e modelo de previsão mais moderno (Saha et al., 2010).

O propósito geral de conduzir re-análises é produzir representações gradeadas do estado da atmosfera através de modelo e um sistema de assimilação constante de informações. Embora a intenção de se fazer re-análises possa ser para estudos climáticos, esses dados também podem ser usados para gerar estados iniciais para começar integrações em modelos numéricos. Em particular, a análise em um dado instante de tempo $(t)$ é o resultado de uma previsão curta inicializada por uma análise anterior assimilando novas observações disponíveis em uma janela próxima centrada em $(t)$ (Saha et al., 2010).

Dentre os dados disponibilizados pelo CFSR, foram utilizadas as componente zonal e meridional do vento (Figura 14 e 15), temperatura do ar (Figura 10), umidade relativa (Figura 9), radiação solar (Figura 12) e cobertura de nuvens (Figura 8).



Figura 8: Evolução temporal da cobertura de nuvens para o mês de Fevereiro (vermelho) e Agosto (azul) de 2015, na posição $24^{\circ} 1^{\prime} 13.44^{\prime \prime} S$ e $46^{\circ} 13^{\prime} 37.2^{\prime \prime}$. O eixo inferior é referente ao mês de Fevereiro e superior ao mês de Agosto. 


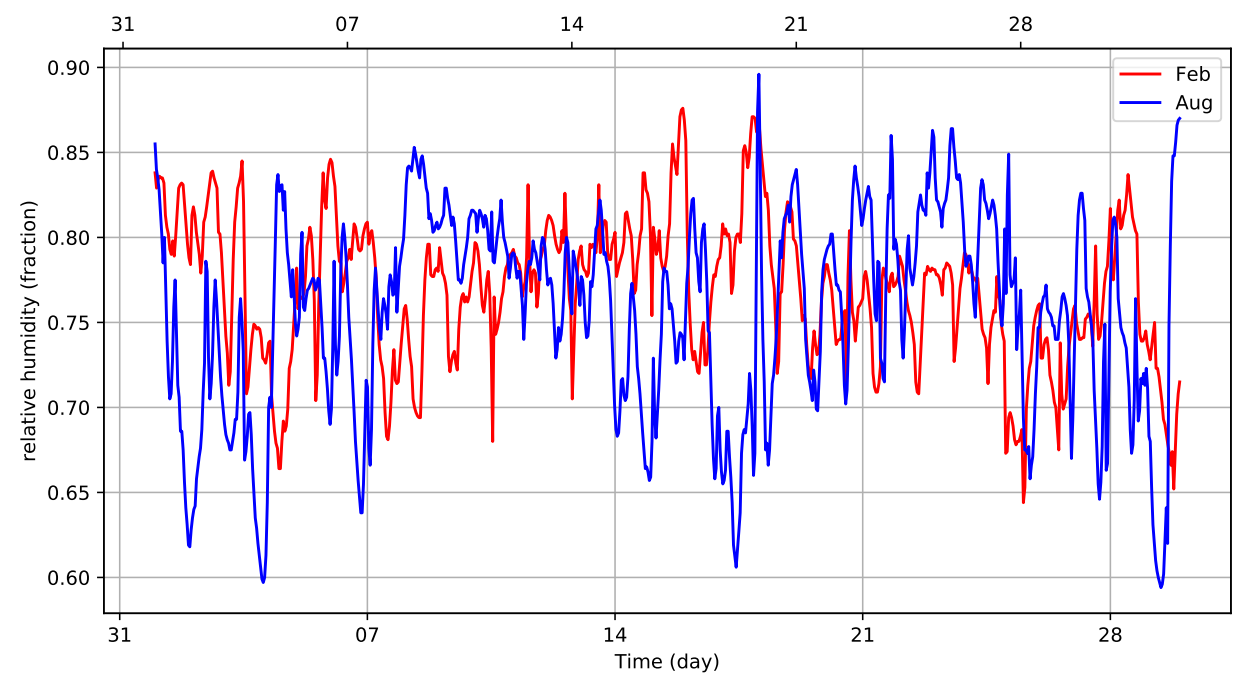

Figura 9: Evolução temporal da umidade relativa do ar para o mês de Fevereiro (vermelho) e Agosto (azul) de 2015, na posição $24^{\circ} 0^{\prime} 0.0^{\prime \prime} S$ e $46^{\circ} 0^{\prime} 0.0^{\prime \prime}$. O eixo inferior é referente ao mês de Fevereiro e superior ao mês de Agosto.

\subsubsection{Temperatura do Ar}

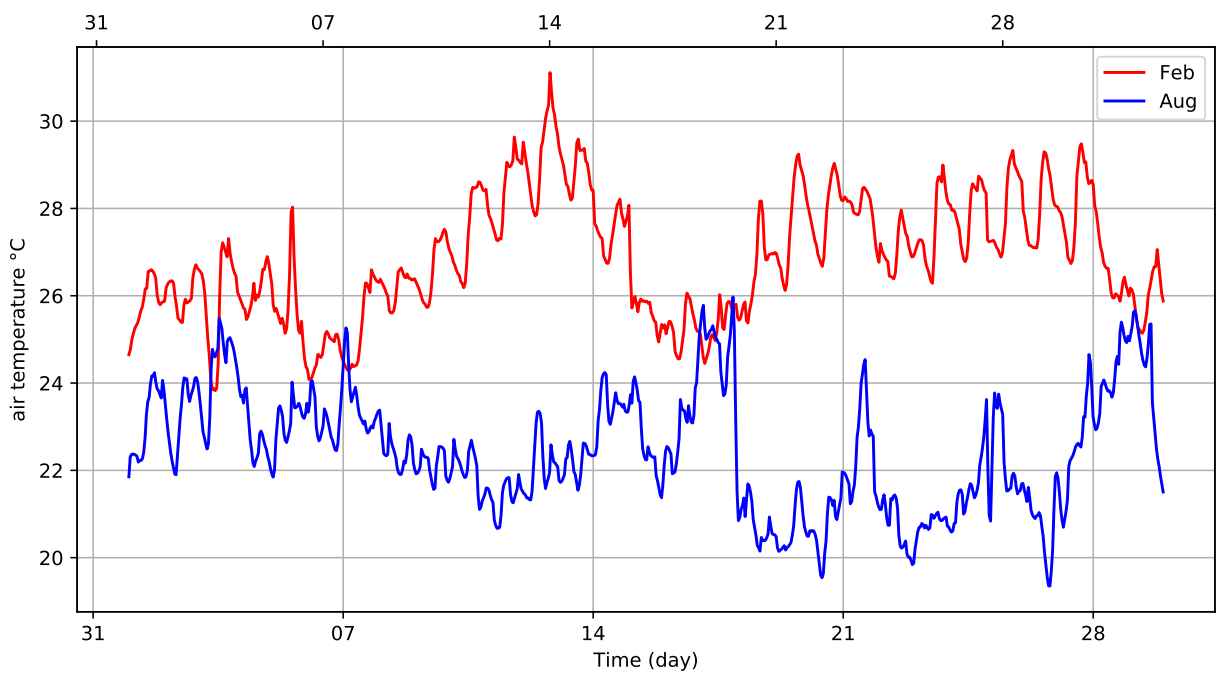

Figura 10: Evolução temporal da temperatura do ar $\left({ }^{\circ} \mathrm{C}\right)$ para o mês de Fevereiro (vermelho) e Agosto (azul) de 2015, na posição $24^{\circ} 1^{\prime} 13.44^{\prime \prime} S$ e $46^{\circ} 13^{\prime} 37.2^{\prime \prime}$. O eixo inferior é referente ao mês de Fevereiro e superior ao mês de Agosto. 




Figura 11: Evolução temporal da temperatura do ar $\left({ }^{\circ} \mathrm{C}\right)$ para o período de 2011 a 2016 (colorido) e a média mensal (preto), na posição $24^{\circ} 1^{\prime} 13.44^{\prime \prime} S$ e $46^{\circ} 13^{\prime} 37.2^{\prime \prime}$.

\subsubsection{Radiação Solar}

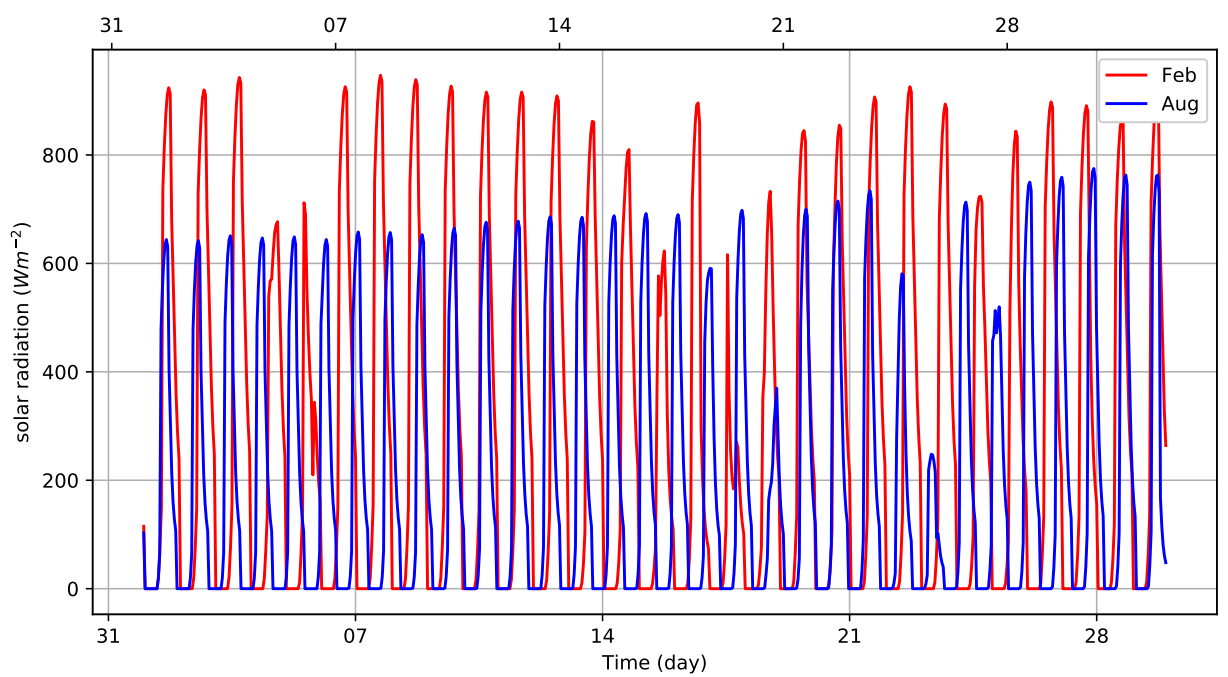

Figura 12: Evolução temporal da radiação solar para o mês de Fevereiro (vermelho) e Agosto (azul) de 2015 , na posição $24^{\circ} 1^{\prime} 13.44^{\prime \prime} S$ e $46^{\circ} 13^{\prime} 37.2^{\prime \prime}$. O eixo inferior é referente ao mês de Fevereiro e superior ao mês de Agosto. 


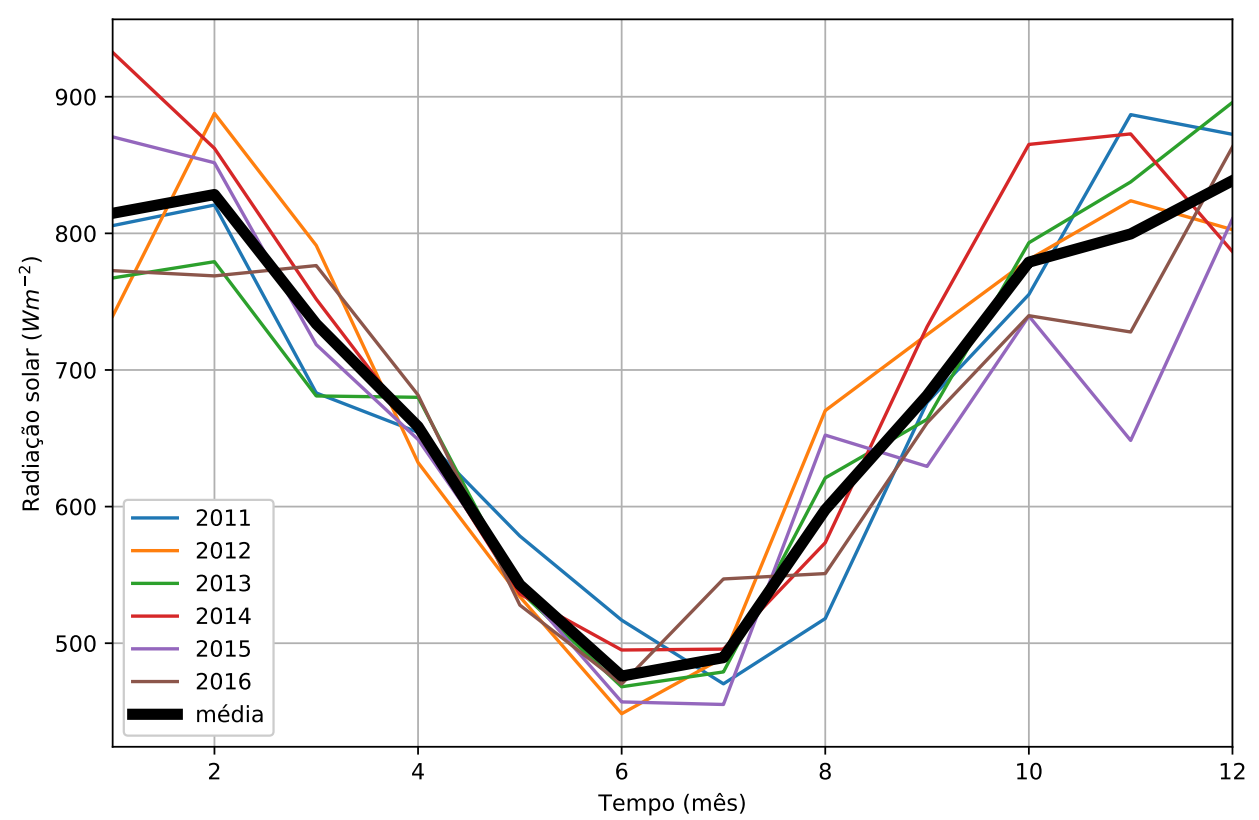

Figura 13: Evolução temporal da radiação solar média máxima $\left(W / m^{2}\right)$ para o período de 2011 a 2016 (colorido) e a média mensal (preto), na posição $24^{\circ} 1^{\prime} 13.44^{\prime \prime} S$ e $46^{\circ} 13^{\prime} 37.2^{\prime \prime}$.

\subsubsection{Velocidade do Vento}

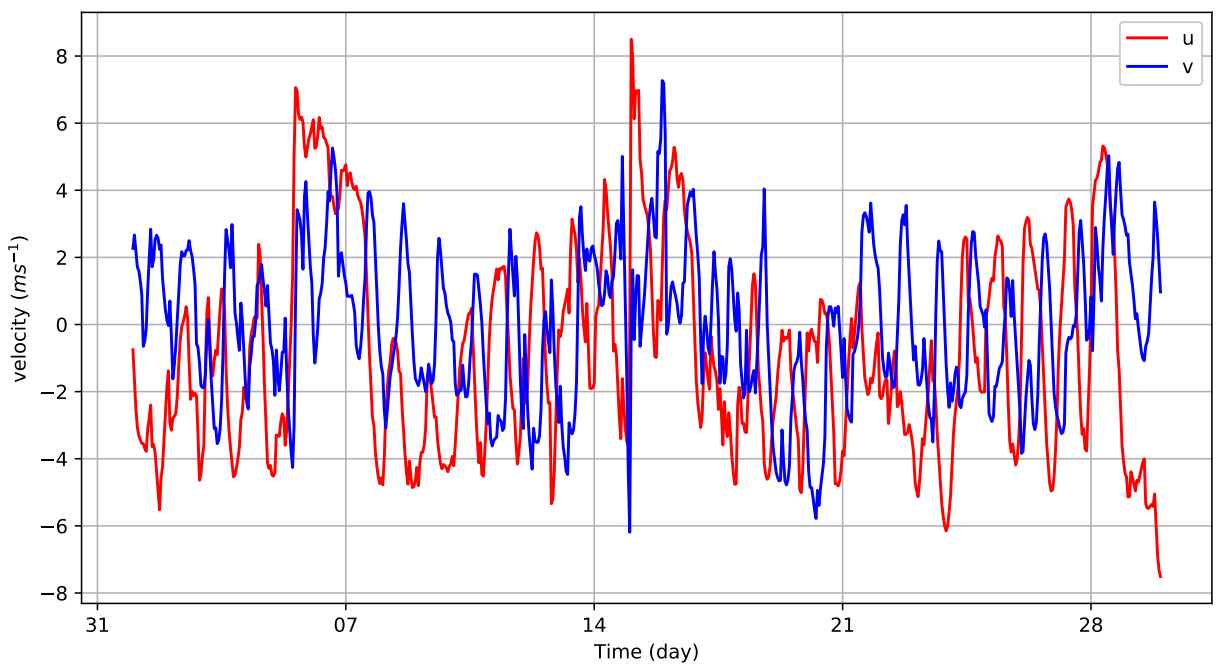

Figura 14: Evolução temporal da velocidade do vento $\left(m s^{-1}\right)$ para o mês de Fevereiro de 2015 , na posição $24^{\circ} 1^{\prime} 13.44^{\prime \prime} S$ e $46^{\circ} 13^{\prime} 37.2^{\prime \prime}$. 


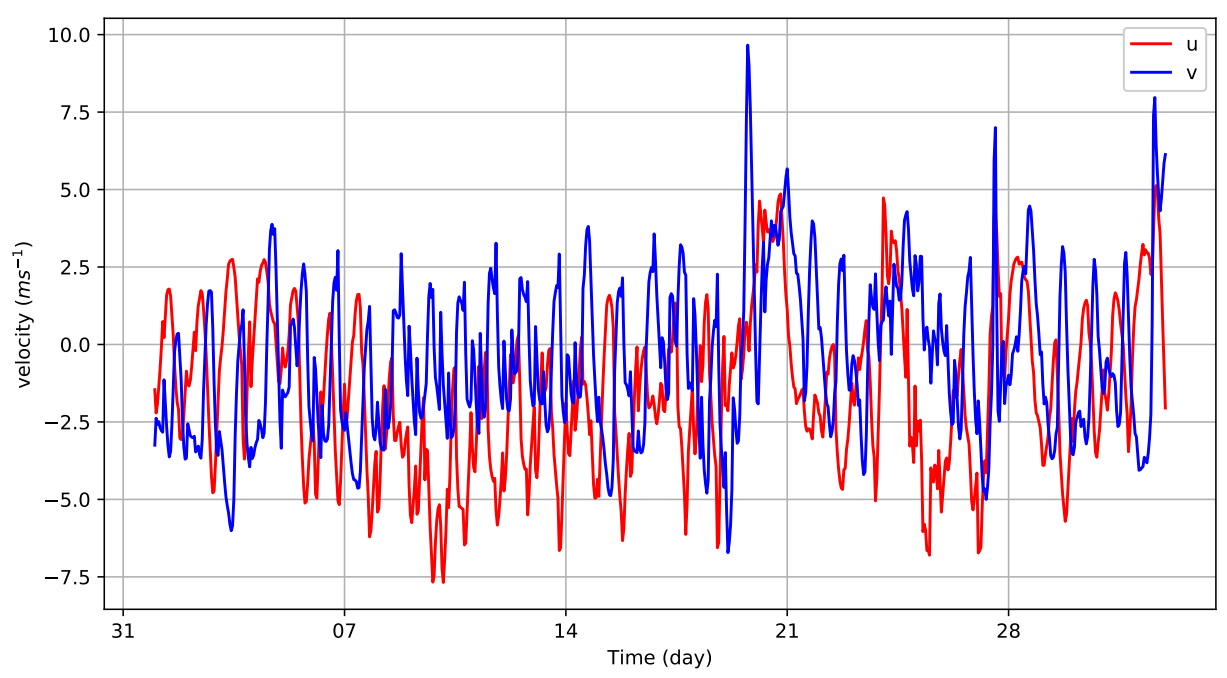

Figura 15: Evolução temporal da velocidade do vento $\left(m s^{-1}\right)$ para o mês de Agosto de 2015 , na posição $24^{\circ} 1^{\prime} 13.44^{\prime \prime} S$ e $46^{\circ} 13^{\prime} 37.2^{\prime \prime}$.

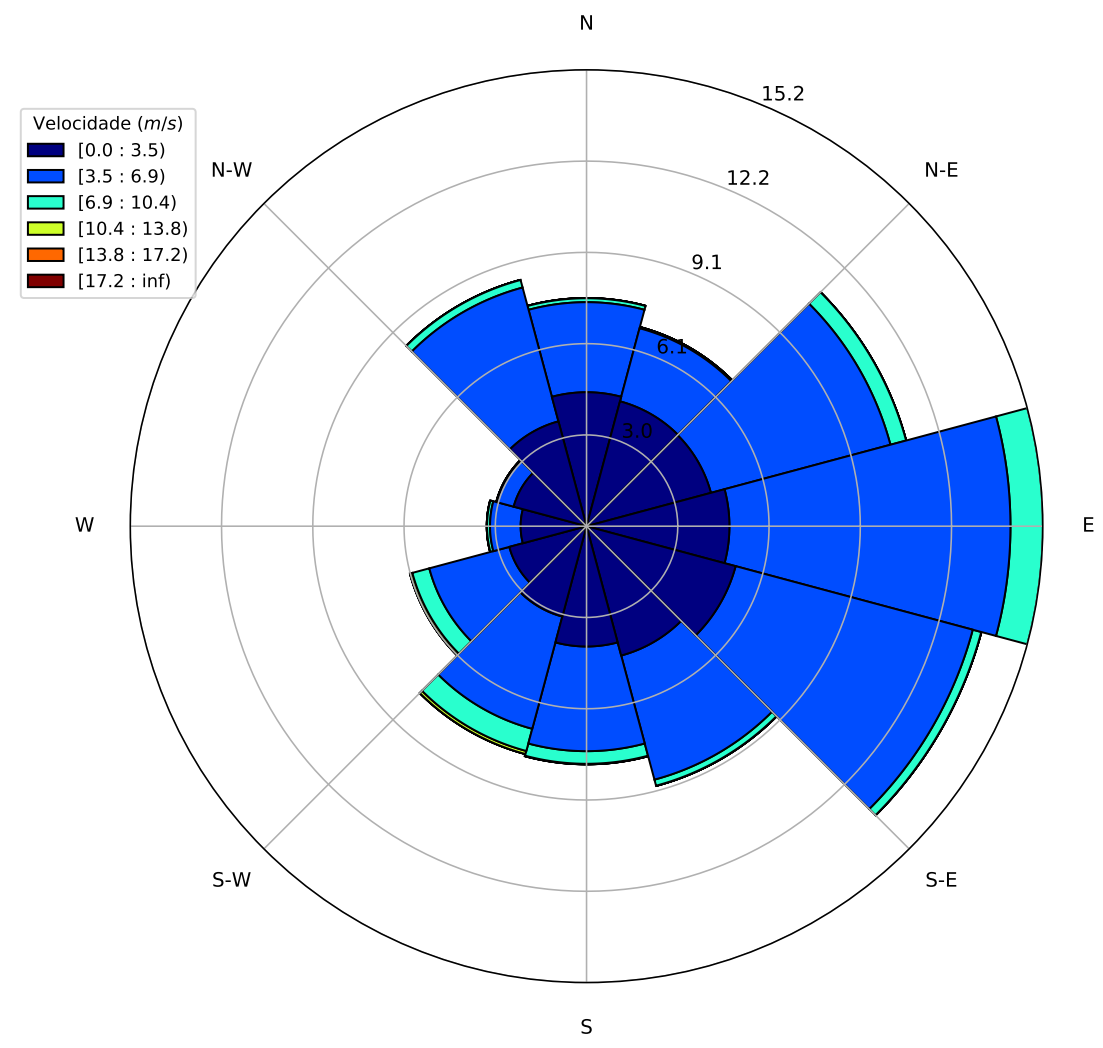

Figura 16: Rosa dos ventos para o período de 2011 a 2016 


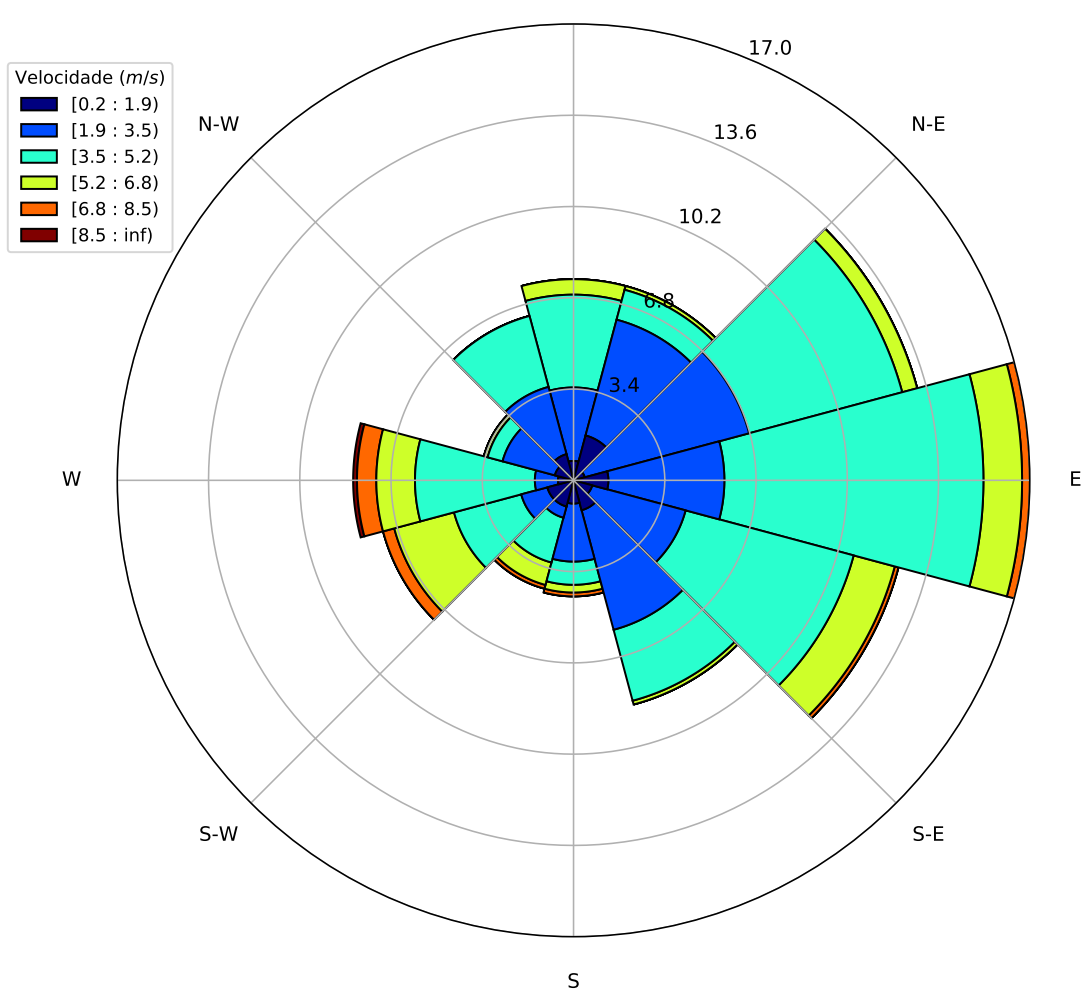

Figura 17: Rosa dos ventos para o mês de Fevereiro de 2015

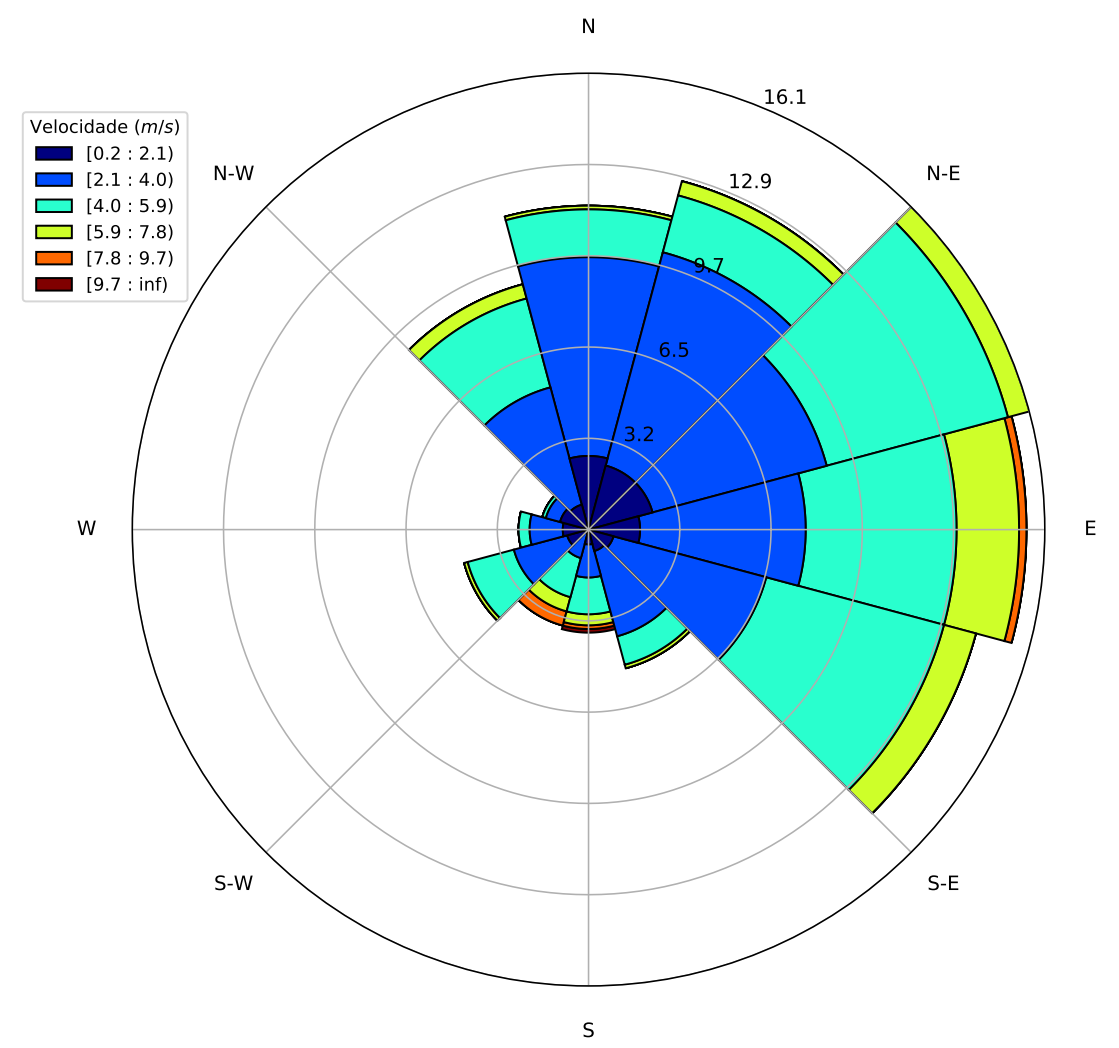

Figura 18: Rosa dos ventos para o mês de Agosto de 2015 




Figura 19: Evolução temporal do módulo da velocidade do vento $\left(m s^{-1}\right)$ para o mês de Fevereiro de 2015 , na posição $24^{\circ} 1^{\prime} 13.44^{\prime \prime} S$ e $46^{\circ} 13^{\prime} 37.2^{\prime \prime}$.

\subsection{Descargas de rios}

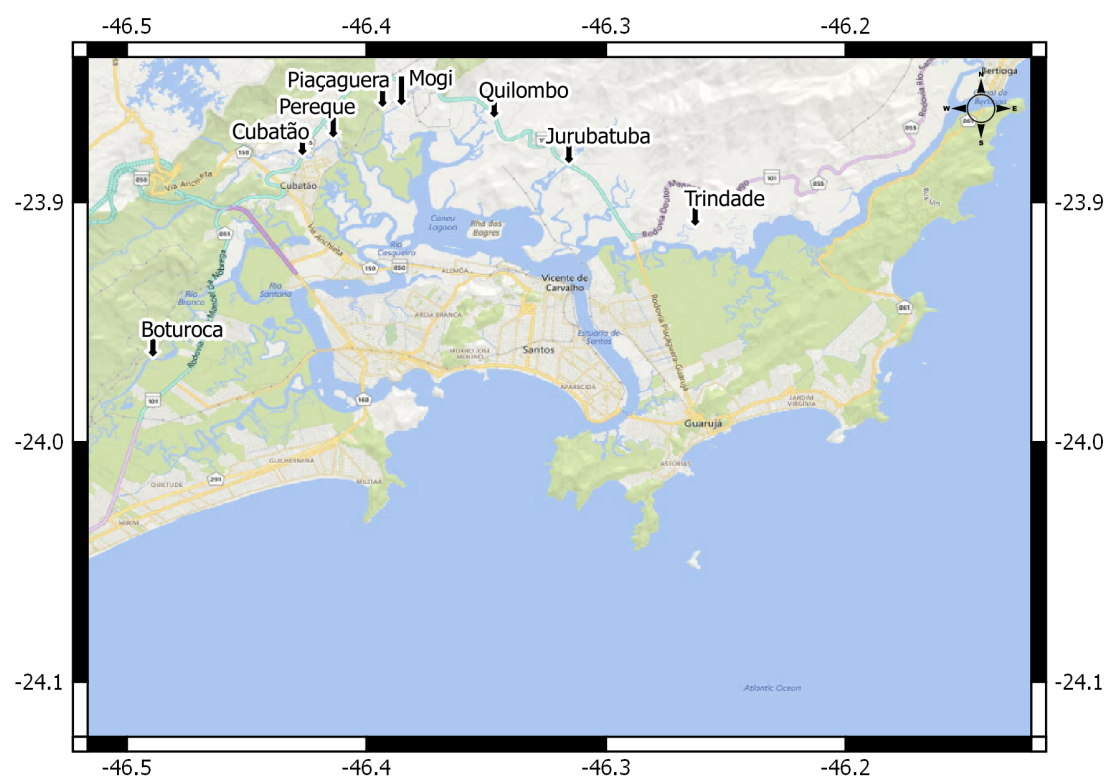

Figura 20: Localização dos rios utilizados no modelo. 


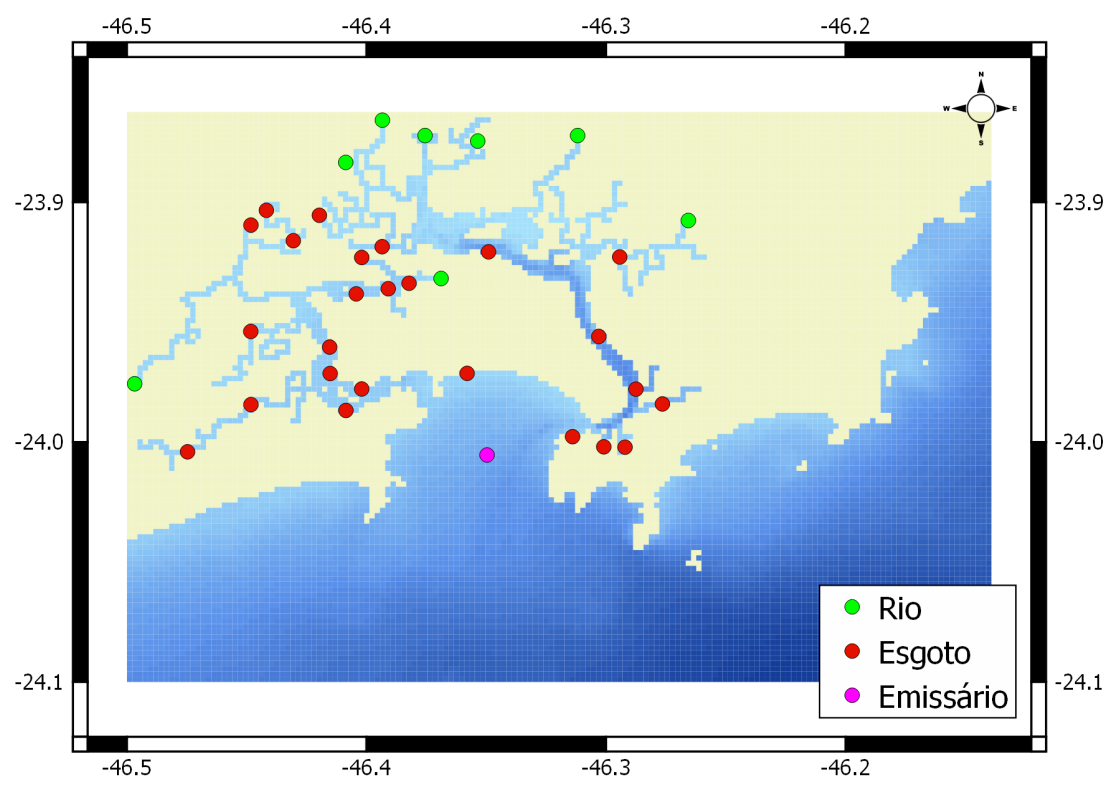

Figura 21: Localização dos pontos onde rios, esgoto e o emissário foram simulados.

Para a inclusão dos efeitos de descargas de rios na modelagem, foram utilizados valores de vazão média mensal a partir do Estudo de Impactos Ambientais da dragagem de aprofundamento do canal Porto de Santos (CODESP, 2008).

Tabela 6: Parâmetros utilizados nas descargas de rio, emissário e esgoto.

\begin{tabular}{llccc}
\hline Propriedades & Unidade & $\begin{array}{l}\text { Condições } \\
\text { dos Rios }\end{array}$ & $\begin{array}{c}\text { Condições } \\
\text { dos Esgotos }\end{array}$ & Emissário \\
\hline Volume & $m^{3} / s$ & Variável & 0.01 & 2 \\
Temperatura & $C^{\circ}$ & Variável & Variável & Variável \\
Salinidade & $p s u$ & 18 & 18 & 18 \\
Sedimentos Coesivos & $m g / l$ & 100 & 100 & 100 \\
Oxigênio & $m g O^{2} / l$ & 7 & 6 & 5 \\
\hline Amônia & $m g N / l$ & 0.09 & 1 & 5 \\
Nitrato & & 0.1 & 0.1 & 3 \\
Nitrito & & 0.005 & 0.005 & 2 \\
NODnr & & 0.002 & 0.002 & 0.002 \\
NODr & & 0.02 & 0.02 & 0.02 \\
NOP & 0.02 & 0.02 & 0.02 \\
\hline Fósforo Inorgânico & $m g P / l$ & 0.05 & 5 & 10 \\
NODnr & & 0.002 & 0.002 & 0.002 \\
NODr & & 0.02 & 0.02 & 0.02 \\
FOP & & 0.02 & 0.02 & 0.02 \\
\hline Fitoplâncton & $m g C / l$ & 0.02 & 0.02 & 0.02 \\
Zooplâncton & & 0.01 & 0.01 & 0.01 \\
\hline
\end{tabular}




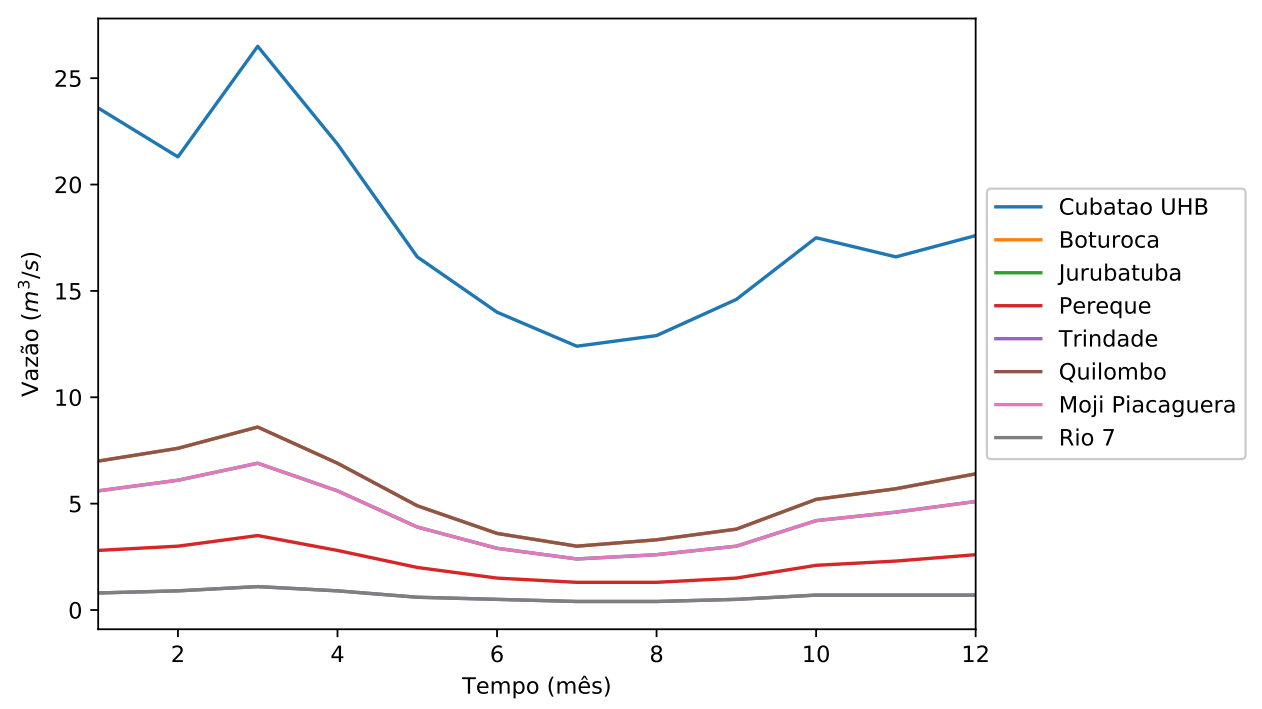

Figura 22: Variação da vazão dos rios utilizada no modelo.

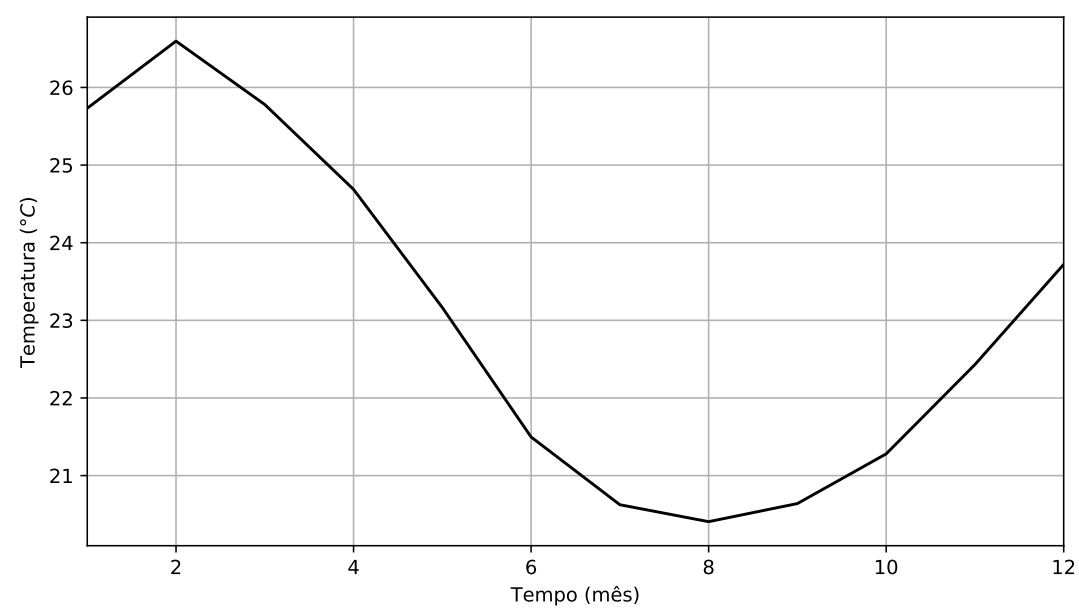

Figura 23: Variação da temperatura utilizada nas descargas de rios, esgotos e do emissário.

\subsection{Período de simulação e considerações}

Alguns trabalhos sugerem período de um ano para a estabilização de modelos de qualidade de água (Trancoso et al., 2005; Bernardes, 2007), porém simulações iniciais mostraram que em quatro meses as propriedades biogeoquímicas da água se estabilizavam, no entanto o modelo foi processado durante seis meses, para estabilizar as propriedades da água.

O modelo foi processado de duas formas, a primeira foi para o mês de Fevereiro e Agosto de 2015, com todas as características destas duas épocas do ano, de modo a avaliar os diferentes resultados gerados pelo modelo, principalmente o contraste entre verão e inverno. A segunda forma foi rodar o modelo para o mês de fevereiro de 2015 fazendo algumas alterações nas forçante, uma de cada vez, para analisar a resposta do fitoplâncton de forma isolada. 
Trancoso et al. (2005) sugere uma técnica para diminuir o tempo de processamento de um modelo para estabilizar as propriedades da água. Esta técnica consiste em gravar as condições hidrodinâmicas durante um período de M2 (12h 25min 30s) e rodar o módulo da qualidade da água utilizando este arquivo de forma cíclica. Outra forma de reduzir o tempo de processamento é realizar uma rodada inicial gravando os resultados hidrodinâmicos e nas rodadas subsequentes utilizar estes dados como informação de entrada. Estas técnicas não foram utilizadas, pois estas técnicas são úteis para modelos bem definidos, neste trabalho, dados de entrada foram alterados diversas vezes.

Um dos fatores que influenciam o tempo de simulação é a gravação dos dados gerados pelo modelo. O MOHID pode gerar resultados em forma de séries temporais, em determinados pontos e também na forma de distribuições espaciais, em arquivos Formato Hierárquico de Dados (HDF). Gravar resultados de distribuições espaciais consome mais tempo que gravar dados em séries temporais. Assim, para economizar tempo de simulação, dados de séries temporais foram gravados para todos os meses e de distribuição espacial foram gravados com maior frequência apenas para os meses de Fevereiro e Agosto. Apesar disto cada mês levou por volta de 8 horas para ser processado e uma estabilização de seis meses levou 51 horas para ser completado. Os resultados para os meses de Fevereiro e Agosto ocuparam em torno de 9 GB cada e um período de estabilização de seis meses 2 GB.

Outro fator que influencia o tempo de simulação é a capacidade do computador em que o modelo é rodado, mais precisamente a capacidade de seu processador. Uma forma de aumentar a capacidade de um processador é, ao invés de aumentar a capacidade de realizar operações por segundo, aumentar o número de núcleos de processamento. Assim, uma tarefa pode ser dividida entre mais núcleos e ser processada em menor tempo. Uma Unidade de Processamento Central (CPU) é composta por apenas alguns núcleos de processamento, já uma Unidade de Processamento Gráfico (GPU) é composta de centenas de núcleos de processamento. Em comparação, uma GPU pode realizar tarefas mais rápido sendo mais eficiente em termos de custo e consumo de energia.

O sistema de modelagem MOHID pode ser compilado para utilizar apenas um núcleo de processamento, mais de um núcleo (OpenMP), utilizando a capacidade de processamento da GPU (CUDA). Nenhuma versão CUDA está disponível no site oficial, mas seu código permite a compilação de um executável deste tipo. Neste trabalho foi utilizado a versão 17.06 do executável que utiliza apenas um núcleo de processamento e que roda em arquitetura x64. Este executável foi escolhido, pois apesar de processar simulações em um tempo mais longo, permite o processamento de mais de um cenário simultaneamente.

O modelo foi rodado em um computador com processador Intel $\mathrm{R}$. Core $^{\mathrm{TM}} \mathrm{i7}-4790 \mathrm{~K}$ 4,00HZ com 16 GB de RAM. 


\section{Resultados: Parte I}

\subsection{Hidrodinâmico}

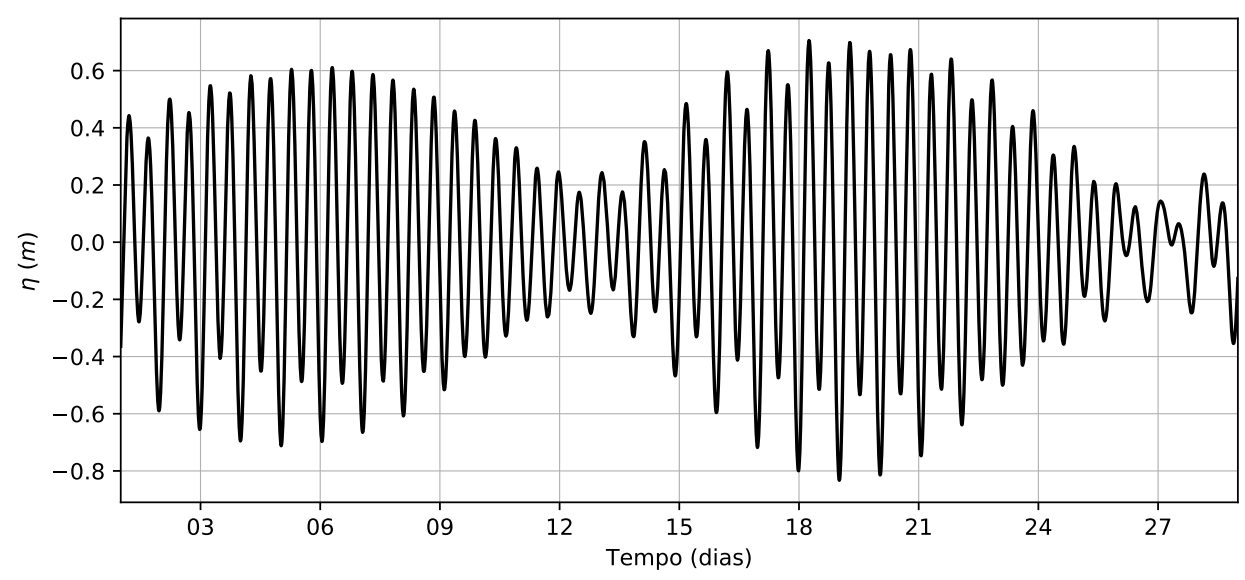

Figura 24: Série temporal da variação do nível do mar $(\eta[\mathrm{m}])$, no ponto P3, para o período de Fevereiro de 2015.

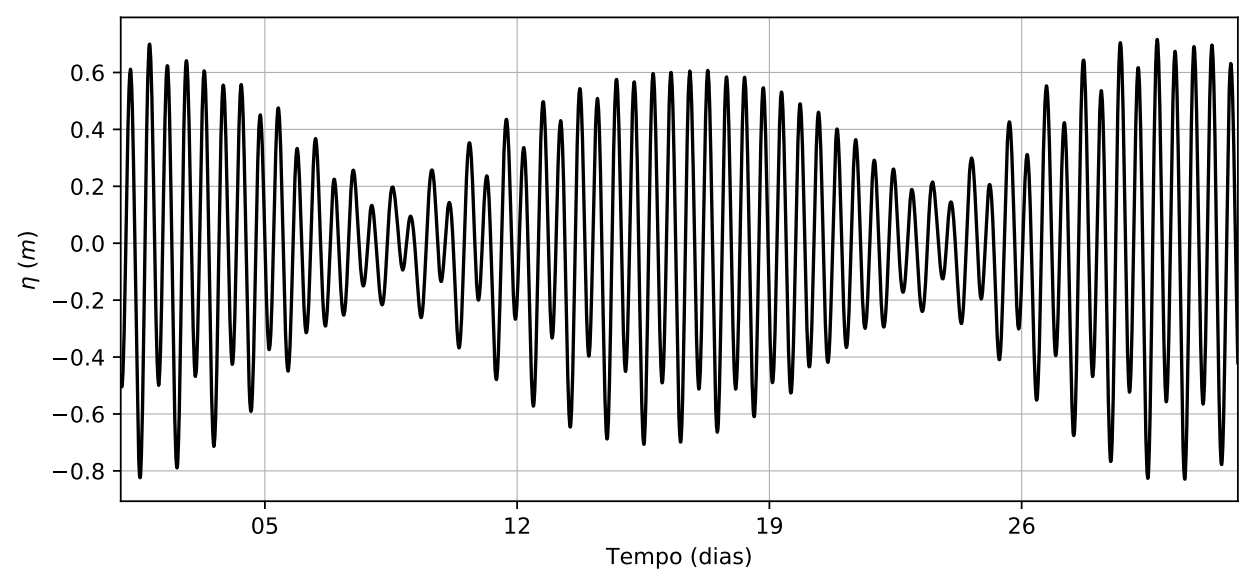

Figura 25: Série temporal da variação do nível do mar $(\eta[\mathrm{m}])$, no ponto P3, para o período de Agosto de 2015.

As figuras 24 e 25 mostram a variação do nível do mar $(\eta[\mathrm{m}])$ para o período de Fevereiro e Agosto de 2015. É possível observar que a amplitude na maré de sizígia foi de $0.8 \mathrm{~m}$ e na maré de quadratura foi de $0.2 \mathrm{~m}$, estas amplitudes estão de acordo com a amplitude esperada para a região. 


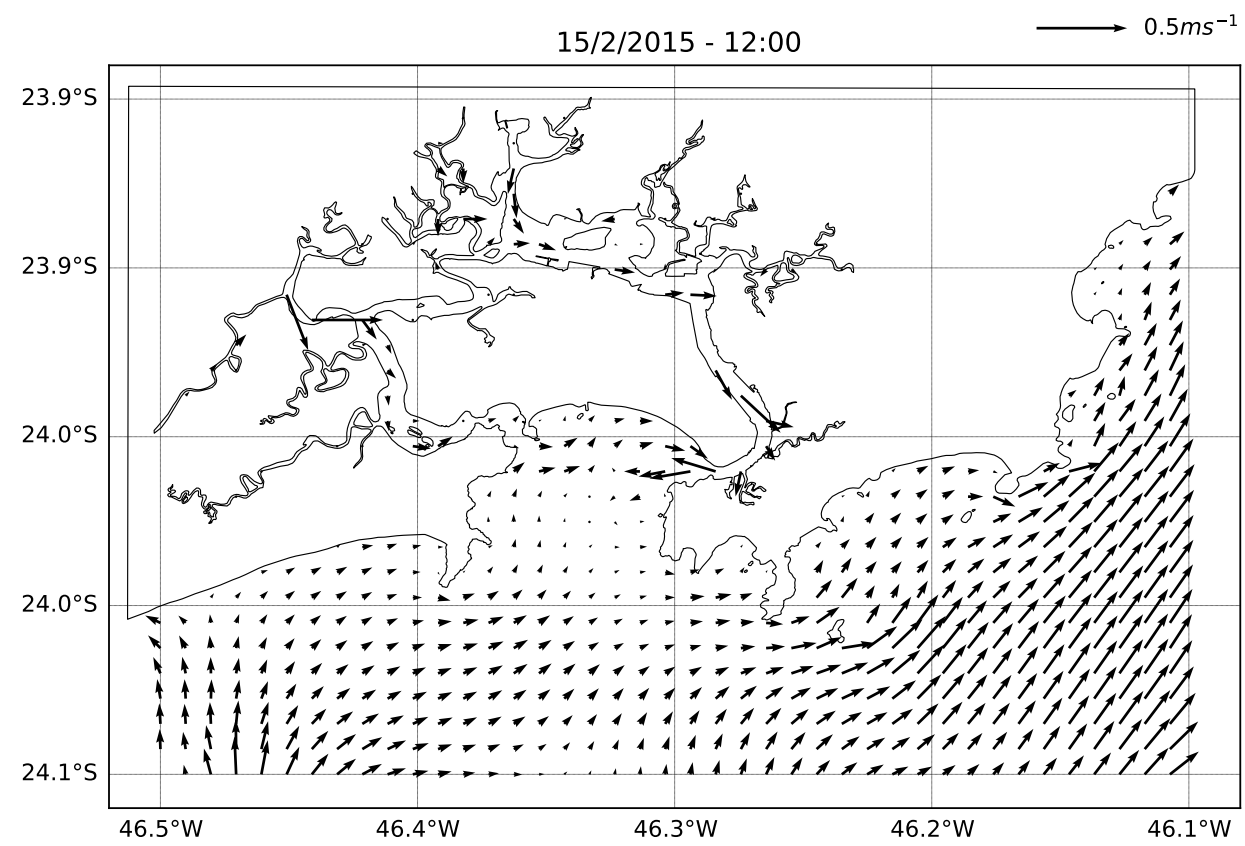

Figura 26: Campo de velocidade $(\mathrm{m} / \mathrm{s})$ referente à camada superficial para o dia 15 de Fevereiro de 2015.

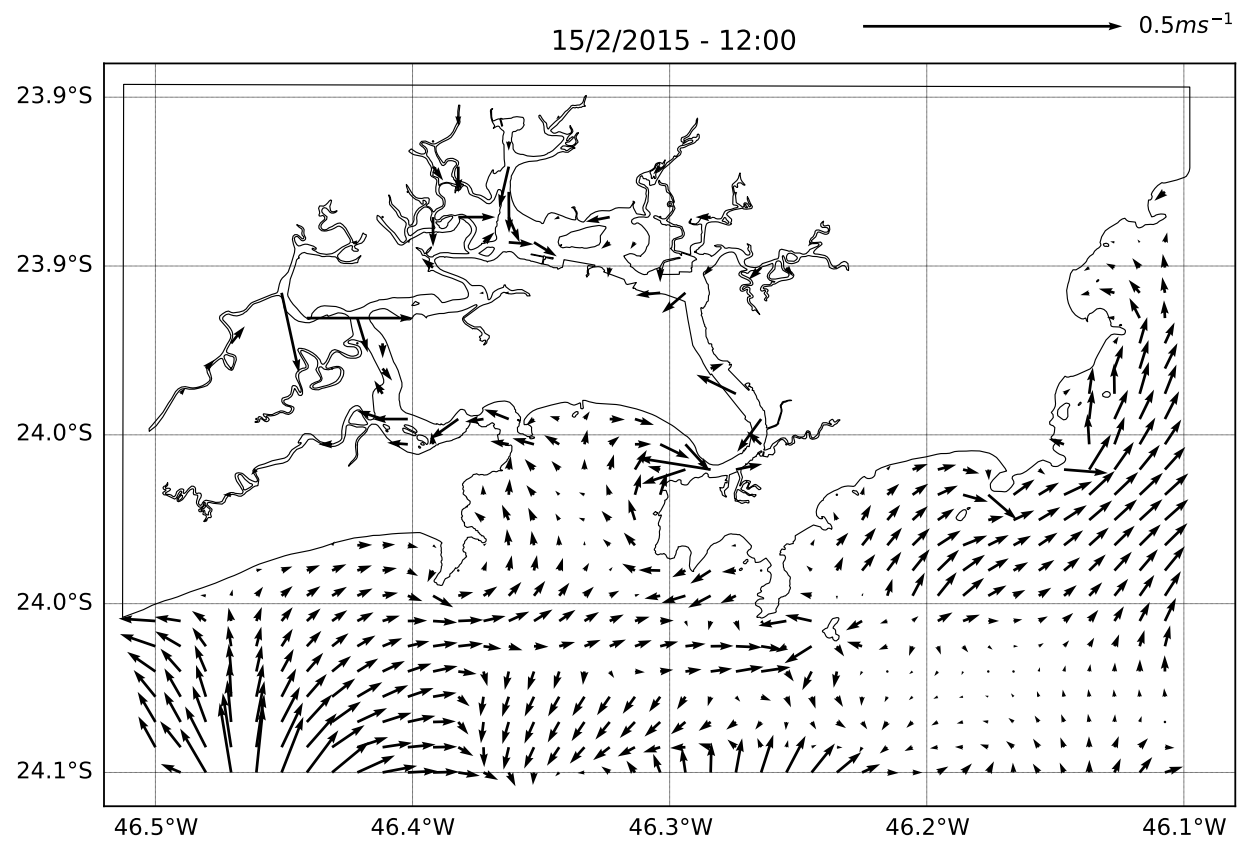

Figura 27: Campo de velocidade $(\mathrm{m} / \mathrm{s})$ referente à camada de fundo para o dia 15 de Fevereiro de 2015.

As figuras 26 e 27 representam o campo de velocidade $(\mathrm{m} / \mathrm{s})$ para o período de Fevereiro para as camadas de superfície e fundo, respectivamente. Nas 12 horas do dia 15 temos início de maré enchente, na superfície temos correntes saindo do Estuário de Santos e no fundo temos correntes entrando na Baía de São Vicente e no Estuário de Santos. É possível observar que fora da Baía de Santos o padrão de velocidade entre superfície e fundo é semelhante, porém a intensidade de corrente na superfície é maior. 


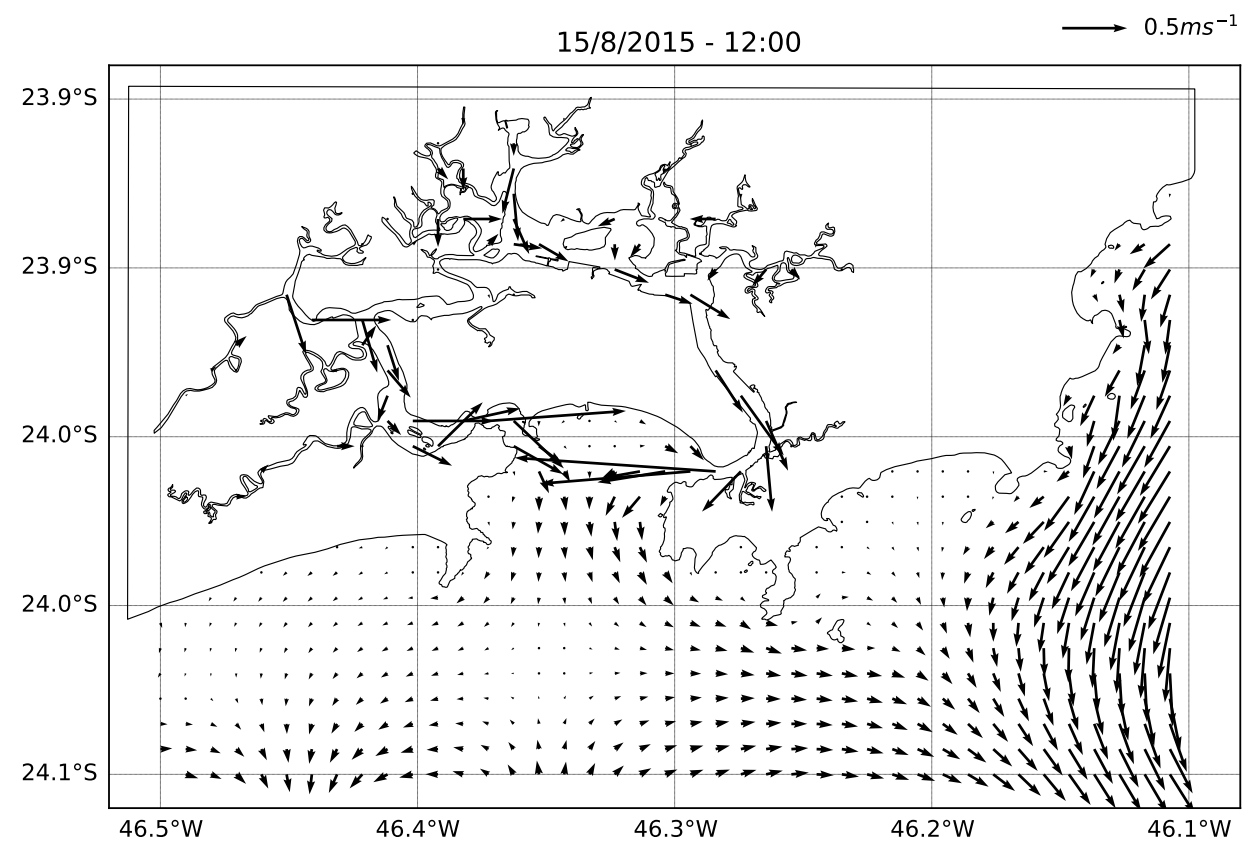

Figura 28: Campo de velocidade $(\mathrm{m} / \mathrm{s})$ referente à camada superficial para o dia 15 de Agosto de 2015.

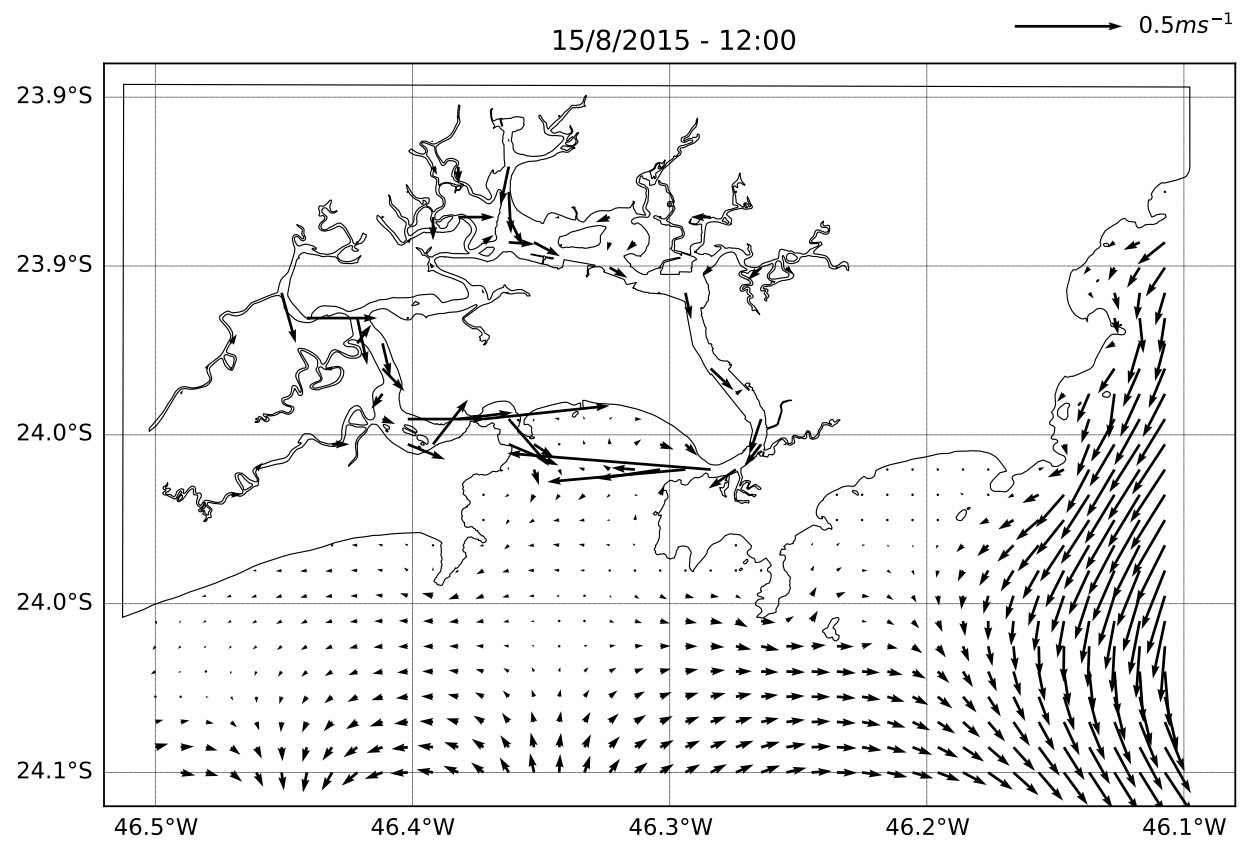

Figura 29: Campo de velocidade $(\mathrm{m} / \mathrm{s})$ referente à camada de fundo para o dia 15 de Agosto de 2015.

As figuras 28 e 29 representam o campo de velocidade $(\mathrm{m} / \mathrm{s})$ para o período de Agosto para as camadas de superfície e fundo, respectivamente. Nas 12 horas do dia 15 temos fim de maré vazante, tanto na superfície quanto no fundo temos correntes saindo da Baía de São Vicente e do Estuário de Santos. Fora da Baía de Santos o padrão de velocidade entre superfície e fundo é semelhante, porém com intensidade de corrente maior na superfície. 


\subsection{Qualidade da Água}

A seguir serão apresentados e discutidos os resultados do modelo referentes à qualidade da água. Para avaliar os resultados obtidos com o modelo, foram feitas comparações na forma de série temporal e gráfico de distribuição horizontal de propriedades. Segundo Legates and McCabe (1999) este tipo de comparação é importante para uma avaliação adequada do modelo.

\subsubsection{Temperatura}

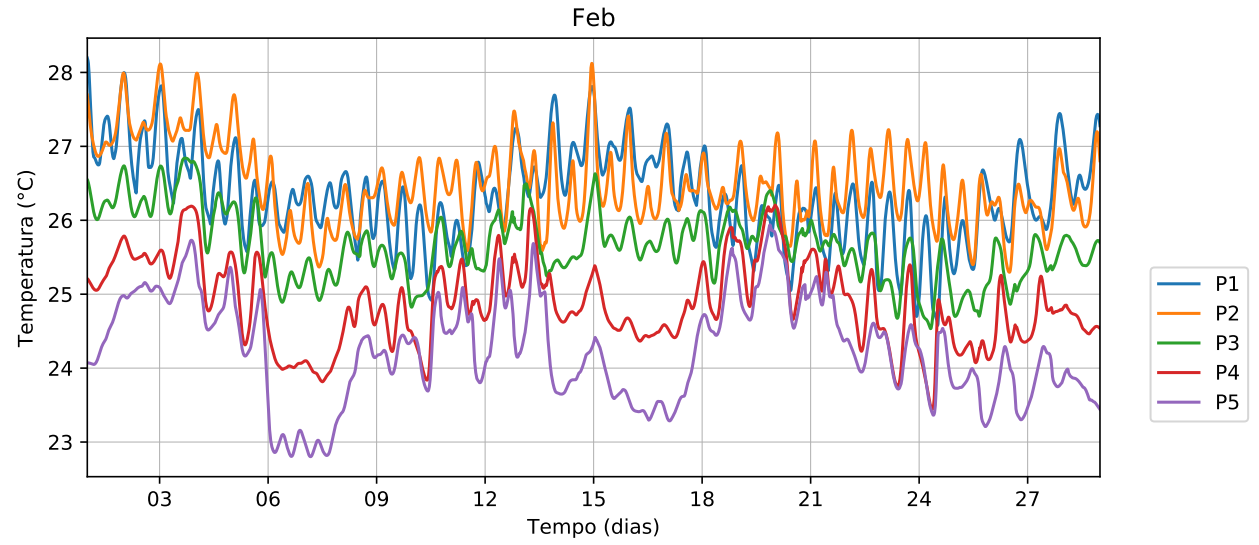

Figura 30: Série temporal da temperatura da água $\left({ }^{\circ} \mathrm{C}\right)$, para o período de Fevereiro de 2015.

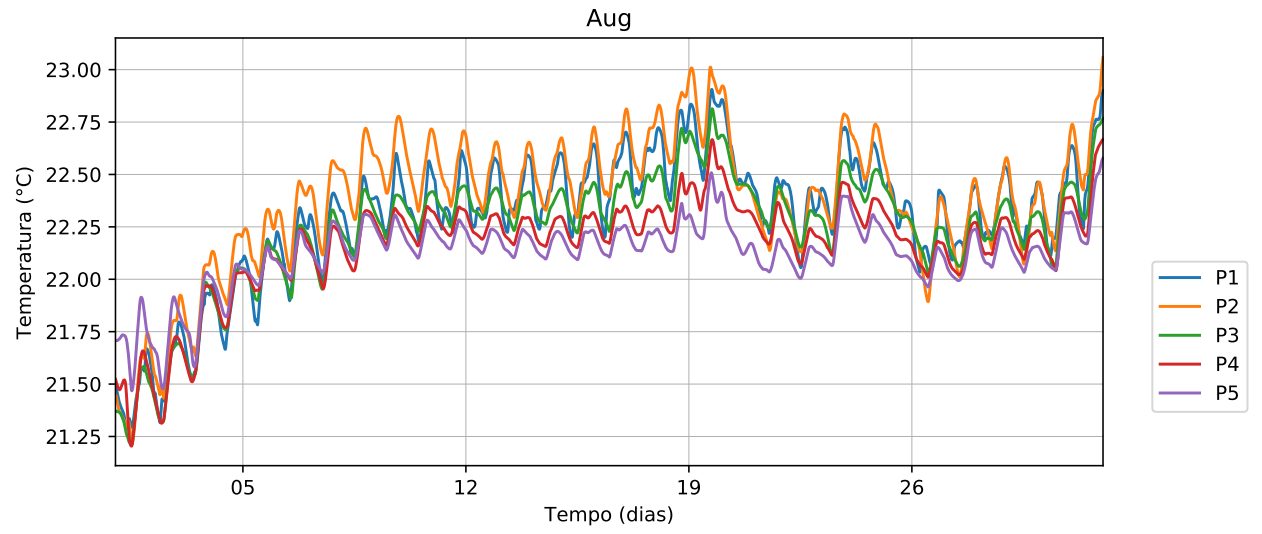

Figura 31: Série temporal da temperatura da água $\left({ }^{\circ} \mathrm{C}\right)$, para o período de Agosto de 2015.

As figuras 30 e 31 representam a variação da temperatura ao longo dos meses de Fevereiro e Agosto. Para o mês de Fevereiro temos temperaturas mais altas $\left(26^{\circ} \mathrm{C}\right)$ próximo da Baía de Santos e temperaturas mais baixas a medida que nos afastamos da costa $\left(23.5^{\circ} \mathrm{C}\right)$. Já para o mês de Agosto, a temperatura varia menos ao se distanciar da costa $\left(22.25^{\circ} \mathrm{C}\right)$. 

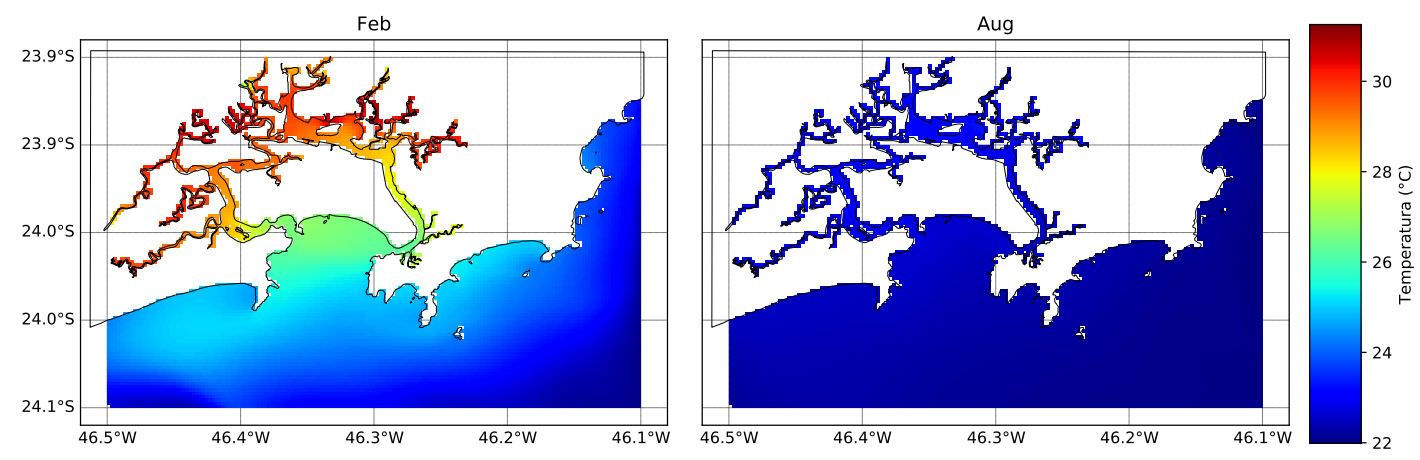

Figura 32: Temperatura da água $\left({ }^{\circ} \mathrm{C}\right)$ referente à camada superficial para o dia 12 de Fevereiro e Agosto de 2015.
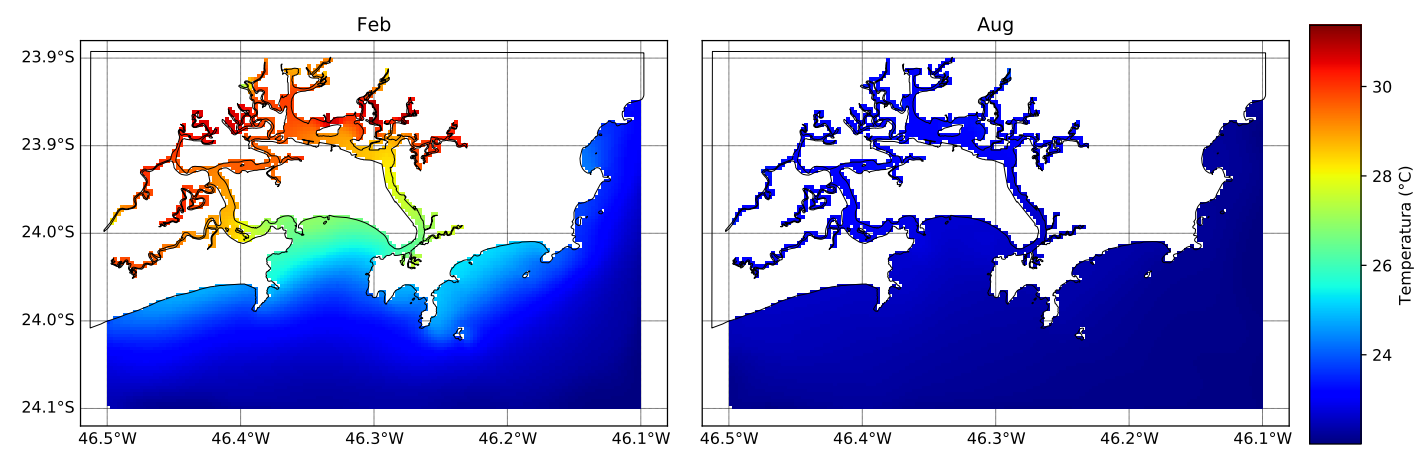

Figura 33: Temperatura da água $\left({ }^{\circ} \mathrm{C}\right)$ referente à camada de fundo para o dia 12 de Fevereiro e Agosto de 2015.

As figuras 32 e 33 mostram a variação da temperatura para o período de Fevereiro e Agosto para as camadas de superfície e fundo. No verão houve maior variação de temperatura tanto entre superfície e fundo quanto próximo e longe da costa. No inverno a temperatura foi mais baixa $\left(>24^{\circ} \mathrm{C}\right)$ e a variação espacial de temperatura foi mais homogênea.

Os resultados do modelo para temperatura da água na região da Baía de Santos foram semelhantes à resultados de outros trabalhos. $\mathrm{O}$ modelo conseguiu representar estratificação na coluna d'água, principalmente em regiões distantes da costa. Apesar do sombreamento imposto no modelo, para representar o sombreamento causado pela copa das árvores, a parte interna apresentou temperaturas altas $\left(>26^{\circ} \mathrm{C}\right)$ durante o verão.

Entretanto, é possível afirmar que o modelo foi capaz de representar de forma satisfatória a temperatura da água tanto para o mês de Fevereiro quanto para o mês de Agosto.

\subsubsection{Salinidade}




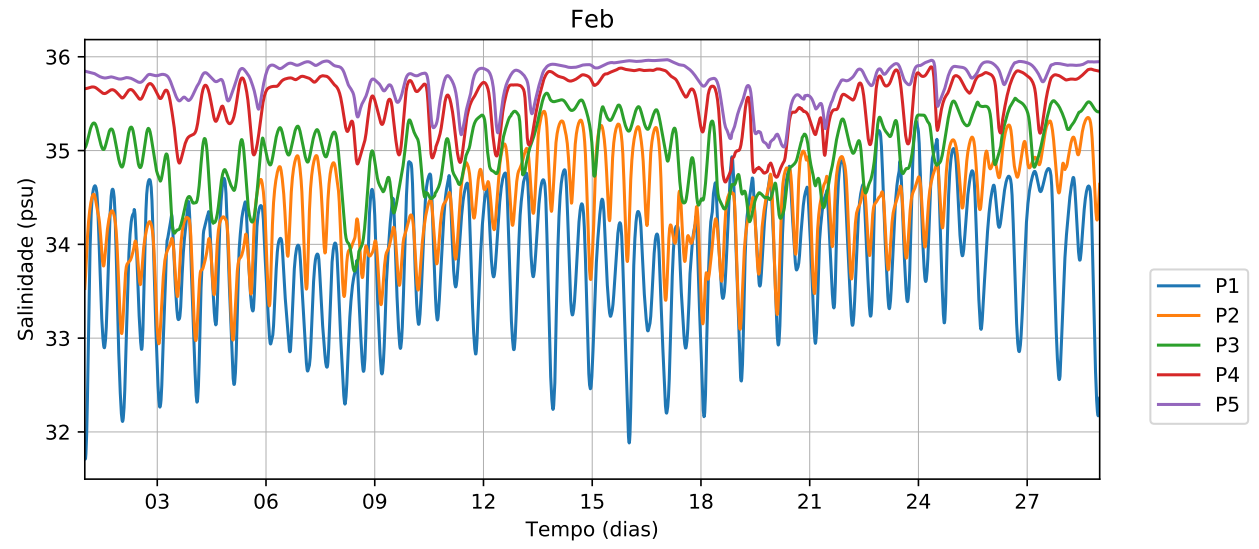

Figura 34: Série temporal da salinidade da água ( $p s u)$, para o período de Fevereiro de 2015.

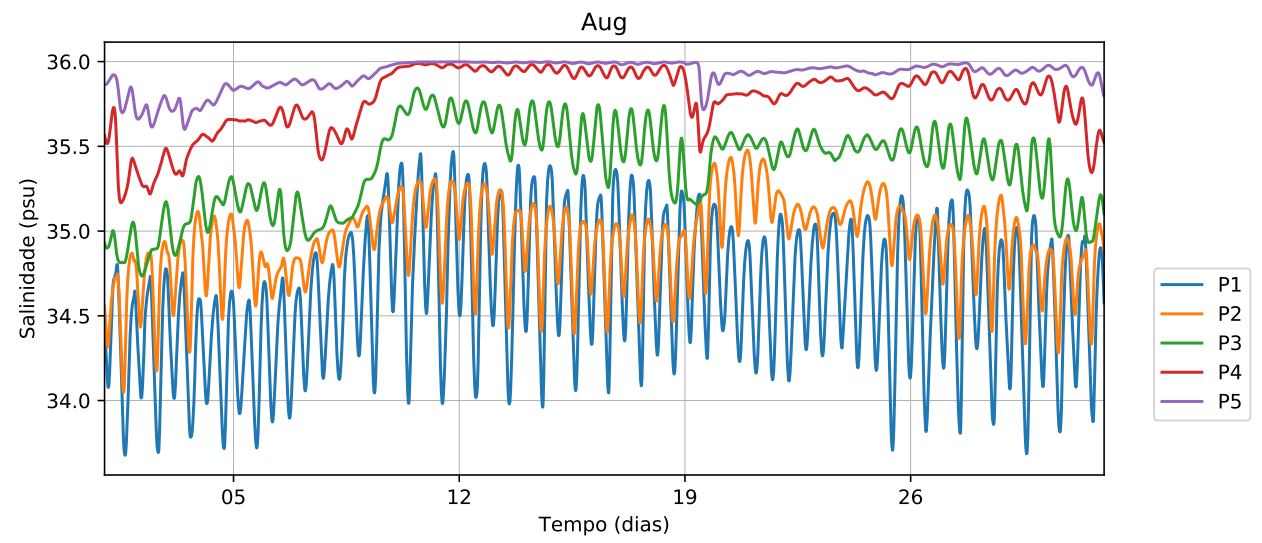

Figura 35: Série temporal da salinidade da água ( $p s u)$, para o período de Agosto de 2015.

As figuras 34 e 35 representam a variação temporal da salinidade para os meses de Fevereiro e Agosto. A partir destas figuras é possível observar de forma clara a influência da maré na salinidade da Baía de São Vicente e Estuário de Santos, e também o aumento da salinidade ao se distanciar da costa.
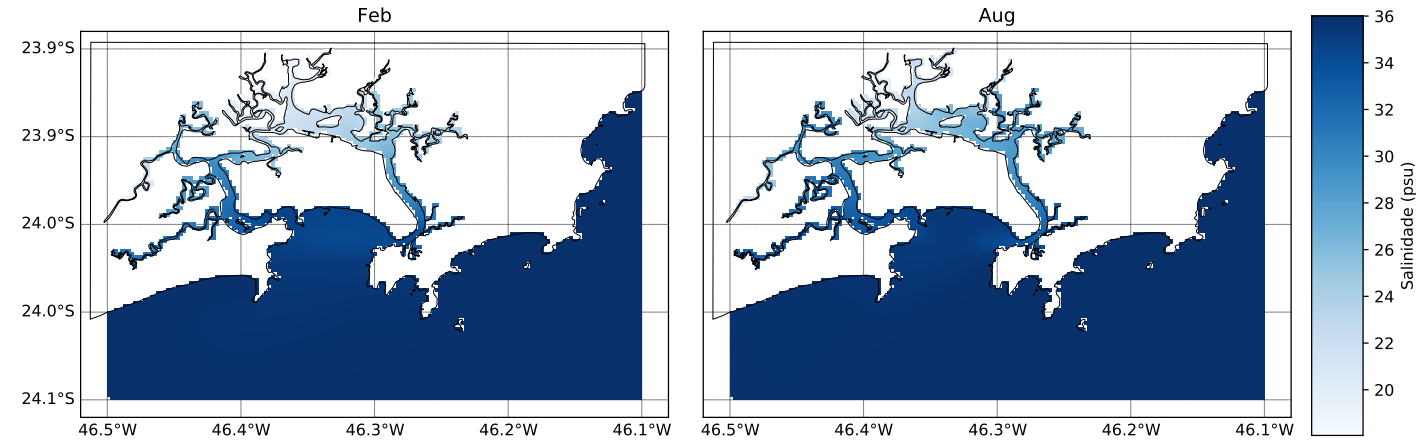

Figura 36: Salinidade da água ( $p s u$ ) referente à camada superficial para o dia 12 de Fevereiro e Agosto de 2015. 

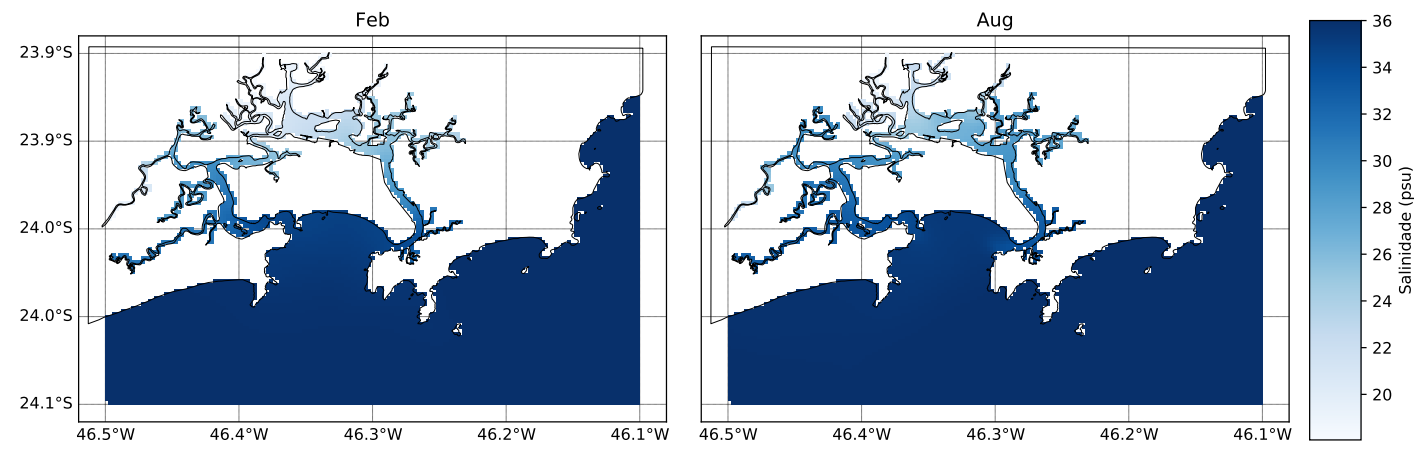

Figura 37: Salinidade da água (psu) referente à camada de fundo para o dia 12 de Fevereiro e Agosto de 2015.

As figuras 36 e 37 mostram a variação espacial da salinidade ( $p s u$ ) para os meses de Fevereiro e Agosto, tanto na superfície quanto no fundo. É possível observar uma ligeira variação de salinidade entre superfície e fundo e salinidades mais baixas $(<30)$ na região interna da grade.

Os resultados do modelo para salinidade na região da Baía de Santos foram semelhantes aos dados de trabalhos anteriores. Com relação à região do Canal de Barreiros os resultados do modelo foram superiores (> $30 \mathrm{psu}$ ) à de trabalhos anteriores.

As simulações consideraram as descargas dos principais rios da região, porém algumas diferenças podem ser observadas, uma vez que foram utilizados valores médios mensais de dados pluviométricos.

Entretanto o modelo foi capaz de representar de forma satisfatória a salinidade e sua variação sazonal e espacial nas regiões internas (20 psu), no canal de Santos (31 psu) e no Canal de São Vicente (33 psu).

\subsubsection{Oxigênio}

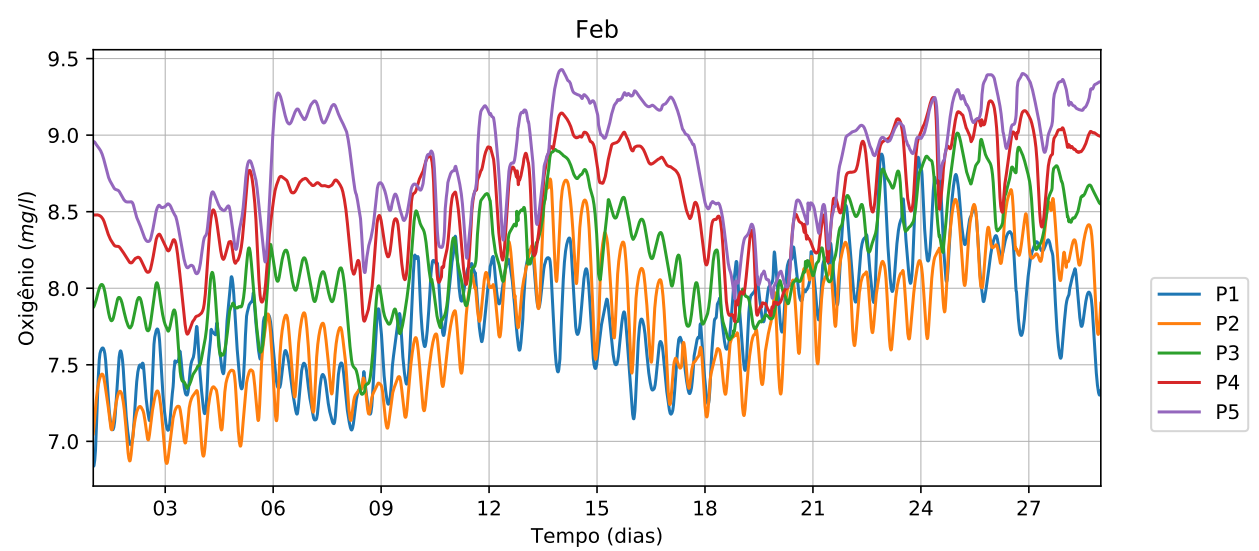

Figura 38: Série temporal da concentração de oxigênio $(m g / l)$, para o período de Fevereiro de 2015. 




Figura 39: Série temporal da concentração de oxigênio $(m g / l)$, para o período de Agosto de 2015.

As figuras 38 e 39 mostram a variação temporal da concentração de oxigênio $(m g / l)$ para o mês de Fevereiro e Agosto. É possível observar que a concentração de oxigênio oscilou mais no mês de Fevereiro e que a concentração de oxigênio aumenta ao se afastar da costa.
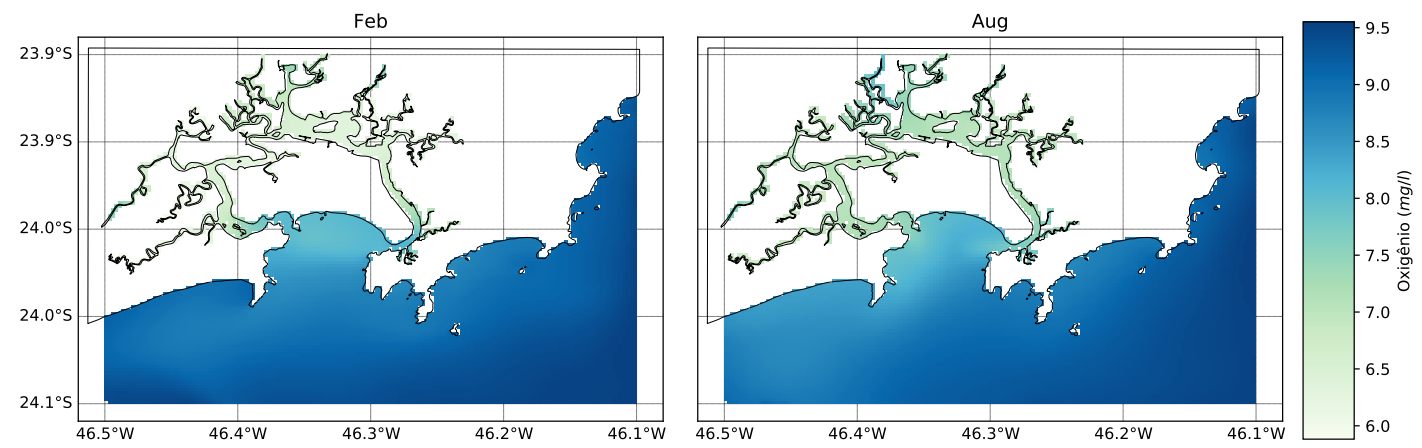

Figura 40: Concentração de oxigênio $(m g / l)$ referente à camada superficial para o dia 12 de Fevereiro e Agosto de 2015.
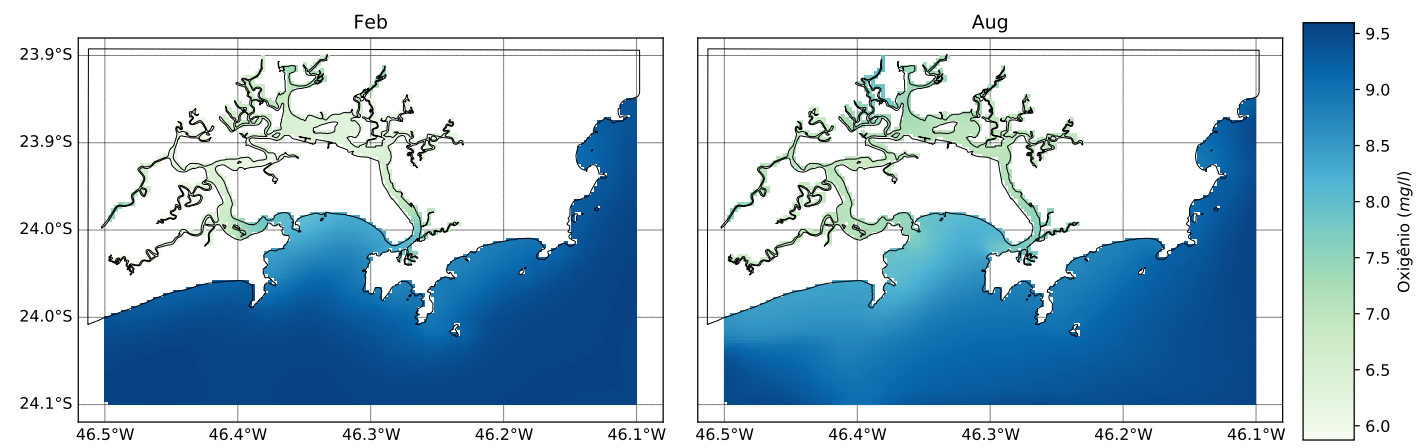

Figura 41: Concentração de oxigênio $(m g / l)$ referente à camada de fundo para o dia 12 de Fevereiro e Agosto de 2015.

As figuras 40 e 41 mostram a variação espacial da concentração de oxigênio na superfície e fundo para os meses de Fevereiro e Agosto. Na parte interna do modelo é possível observar menor concentração de oxigênio e concentrações menores durante o verão. Fora da região interna, maiores concentrações de oxigênio foram encontradas no fundo e no mês de Fevereiro. 
O oxigênio tem um papel importante, pois participa de reações químicas e biológicas que constituem a dinâmica do ecossistema. Sua solubilidade depende de fatores como temperatura, pressão atmosférica, pressão de vapor e salinidade. O efeito das ondas, atividades fotossintéticas, respiração dos organismos e decomposição de matéria orgânica também influenciam a concentração de oxigênio na água.

Baixas concentrações são esperadas no mês de verão, pois o aporte dos rios é maior neste período, e que introduz altas concentrações de nutrientes, principalmente fósforo através dos rios Moji e Piaçaguera, resultando em maiores quantidades de material orgânico e consequentemente maior decomposição e consumo de oxigênio (Gianesella and Saldanha-Corrêa, 2007).

\subsubsection{Nutrientes}

Nutrientes são essenciais na produção primária. Estudos mostram que os principais nutrientes que limitam o crescimento dos produtores primários são o nitrogênio e o fósforo (Smith et al., 1999).

Nas simulações foram considerados o nitrogênio na sua forma inorgânica (amônia, nitrato e nitrito) e orgânica (nitrogênio orgânico dissolvido e particulado), quanto ao fósforo foi considerado fósforo inorgânico, fósforo orgânico dissolvido e particulado.

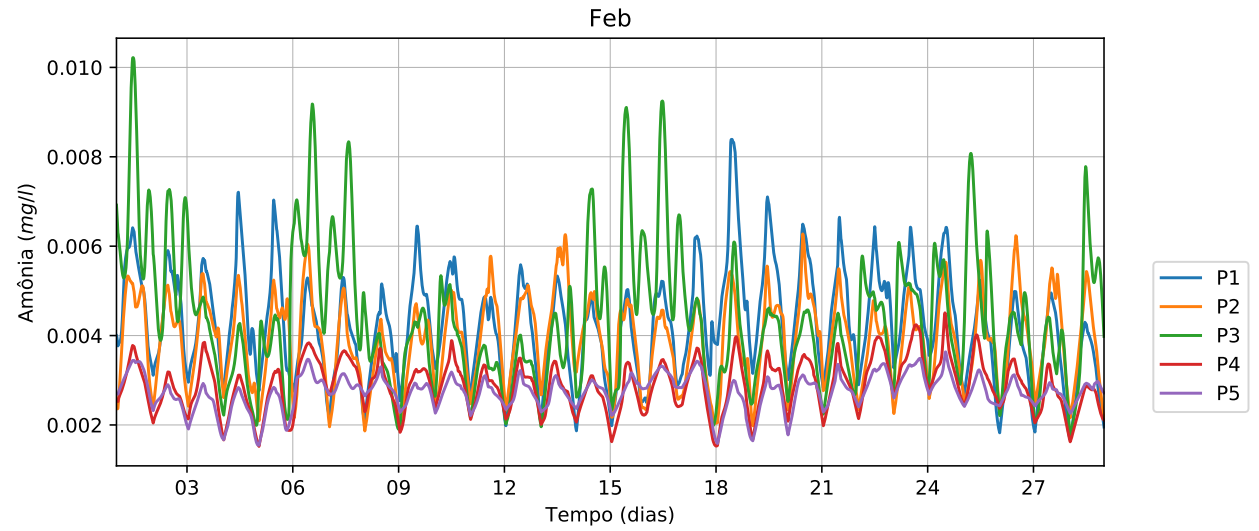

Figura 42: Série temporal da concentração de amônia $(m g / l)$, para o período de Fevereiro de 2015.

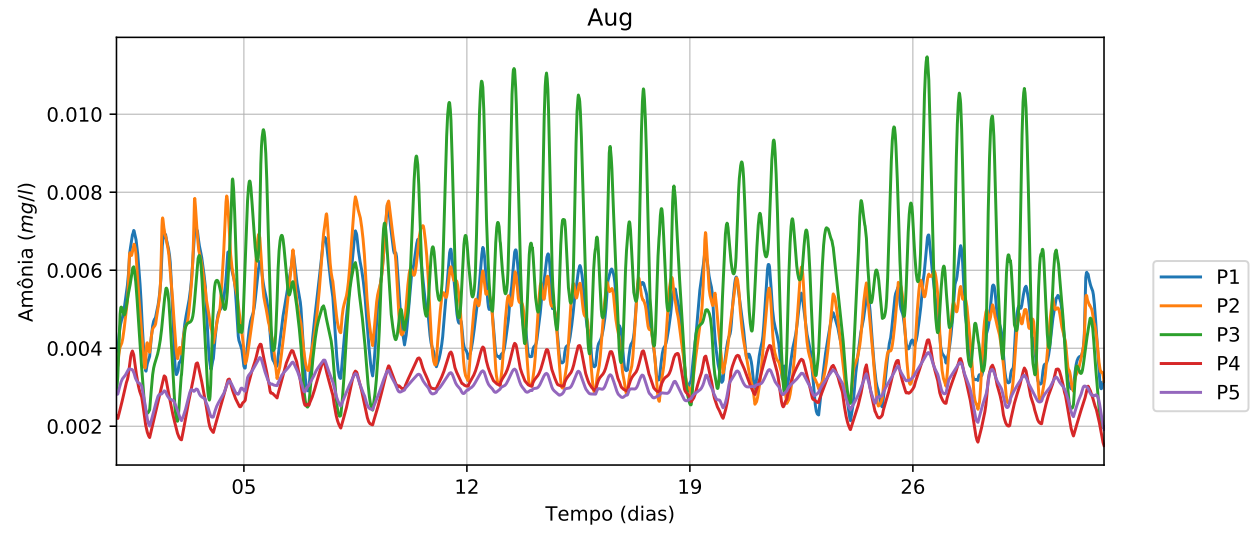

Figura 43: Série temporal da concentração de amônia $(m g / l)$, para o período de Agosto de 2015. 
As figuras 42 e 43 mostram a variação temporal da concentração de amônia $(m g / l)$ para os meses de Fevereiro e Agosto. A partir destas figuras é possível observar que a concentração de amônia foi de aproximadamente $0.004 \mathrm{mg} / \mathrm{l}$ e o mês de Agosto teve maiores concentrações $(0.01 \mathrm{mg} / \mathrm{l})$.
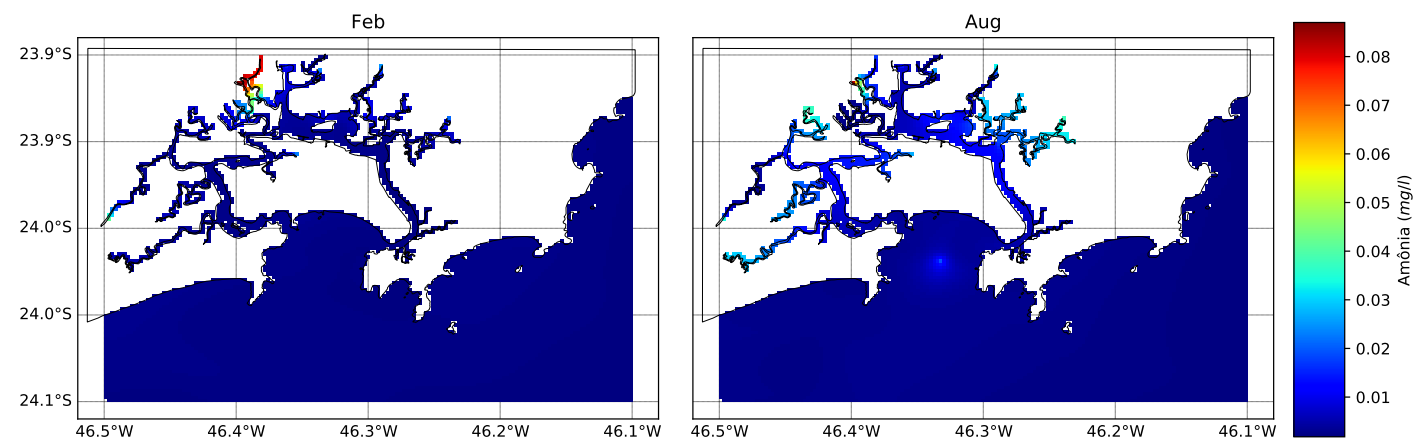

Figura 44: Concentração de amônia $(m g / l)$ referente à camada superficial para o dia 12 de Fevereiro e Agosto de 2015.
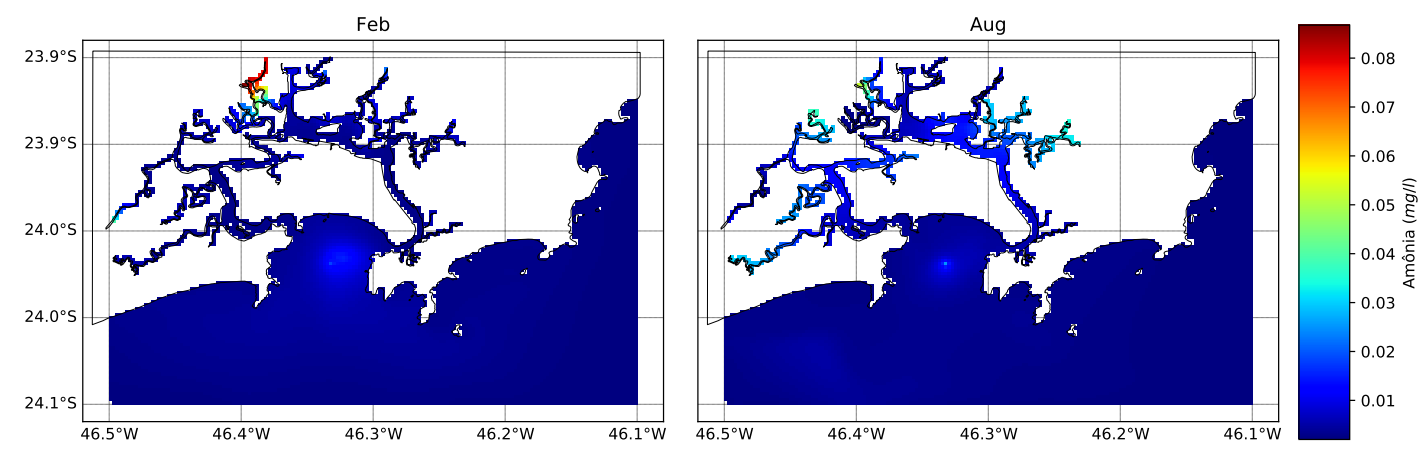

Figura 45: Concentração de amônia $(m g / l)$ referente à camada de fundo para o dia 12 de Fevereiro e Agosto de 2015.

As figuras 44 e 45 representam a variação espacial da concentração de amônia $(m g / l)$ nos meses de Fevereiro e Agosto, para a superfície e fundo. A partir desta figura é possível observar que as maiores concentrações ocorreram próximas dos pontos de aporte fluvial, esgoto e emissário submarino. Na região do emissário, é possível observar maiores concentrações na camada de fundo.

Apesar de representar variação espacial para as diferentes regiões do estuário e variações sazonais adequadas, as concentrações de amônia foram baixas $(<0.01 \mathrm{mg} / \mathrm{l})$ comparado à outros trabalhos $(0.1 \mathrm{mg} / \mathrm{l})$. 


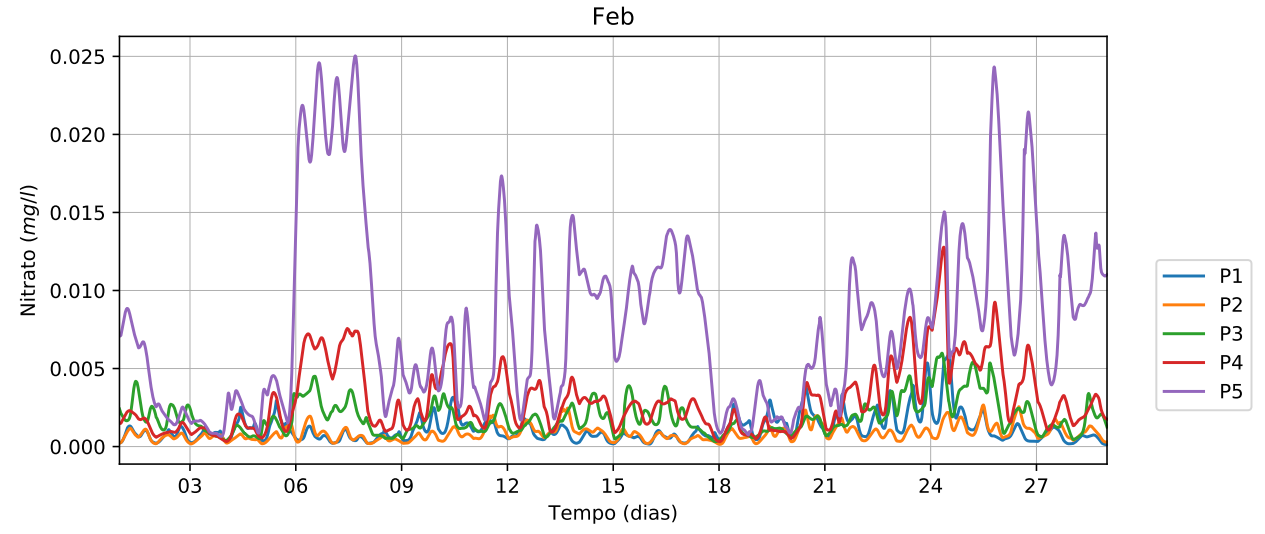

Figura 46: Série temporal da concentração de nitrato $(m g / l)$, para o período de Fevereiro de 2015.

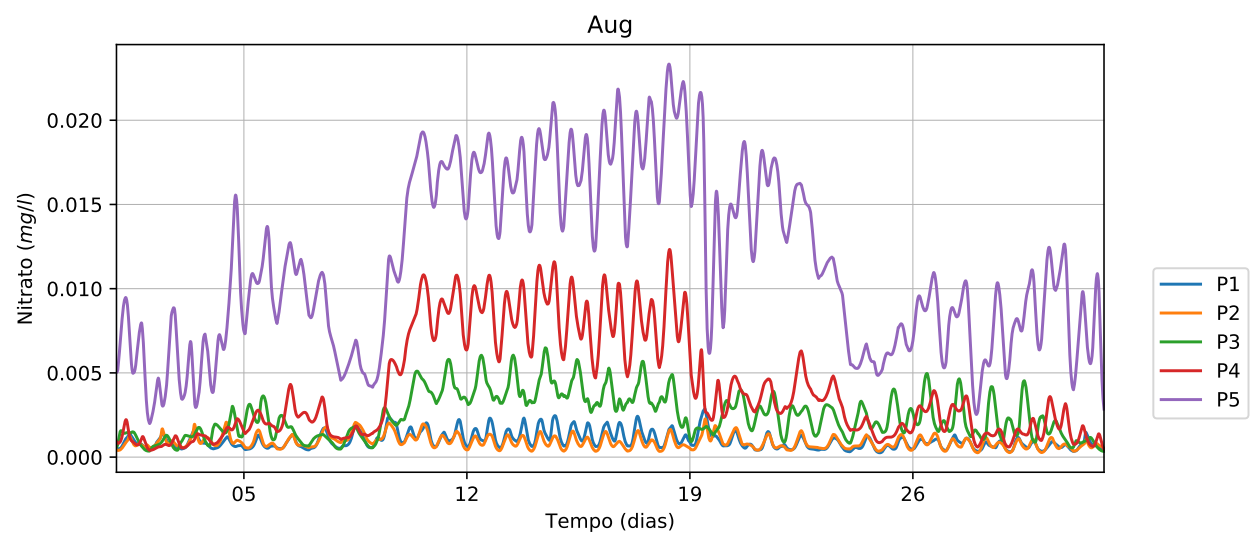

Figura 47: Série temporal da concentração de nitrato $(m g / l)$, para o período de Agosto de 2015.

As figuras 46 e 47 mostram a variação temporal da concentração de nitrato $(m g / l)$ para os meses de Fevereiro e Agosto. É possível observar maiores concentrações no período de Agosto e em regiões distantes da costa.
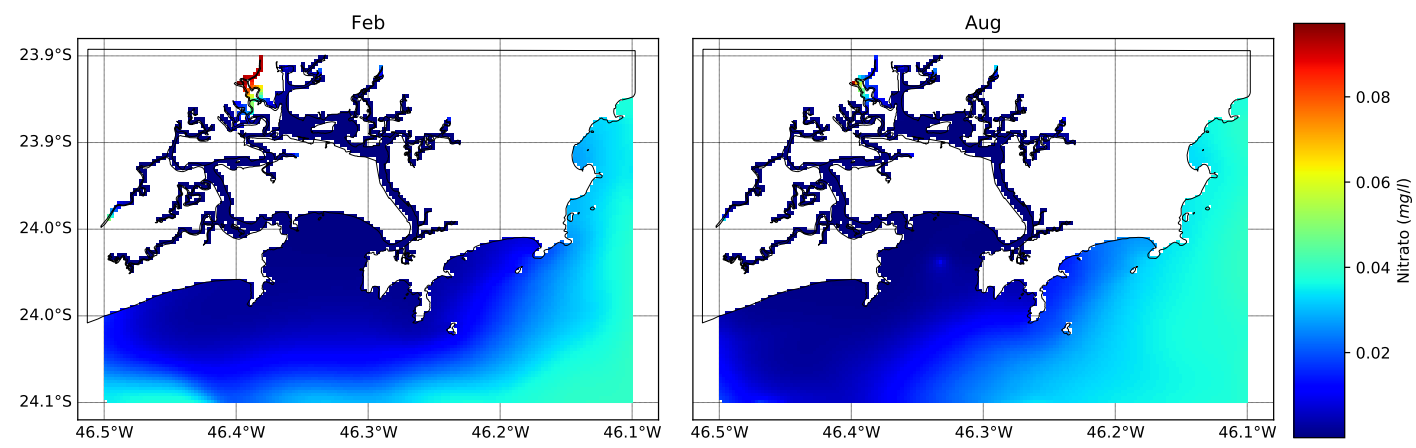

Figura 48: Concentração de nitrato $(m g / l)$ referente à camada superficial para o dia 12 de Fevereiro e Agosto de 2015. 

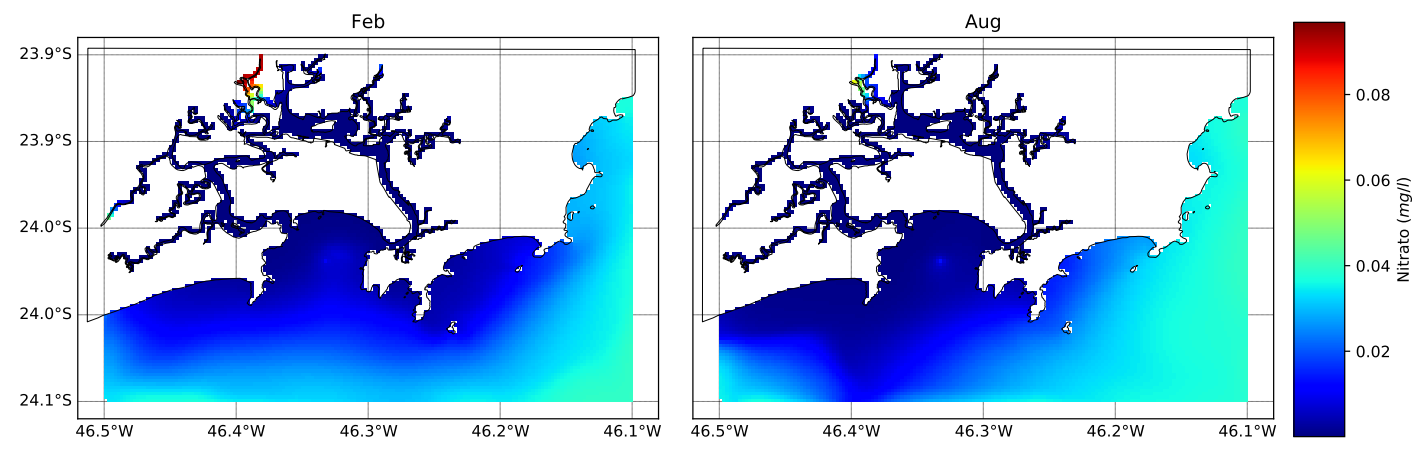

Figura 49: Concentração de nitrato $(\mathrm{mg} / \mathrm{l})$ referente à camada de fundo para o dia 12 de Fevereiro e Agosto de 2015.

As figuras 48 e 49 representam a variação espacial da concentração de nitrato nos meses de Fevereiro e Agosto, para a superfície e fundo. É possível observar maiores concentrações de nitrato na fronteira aberta do modelo, na região do emissário submarino e em alguns pontos de aporte fluvial.

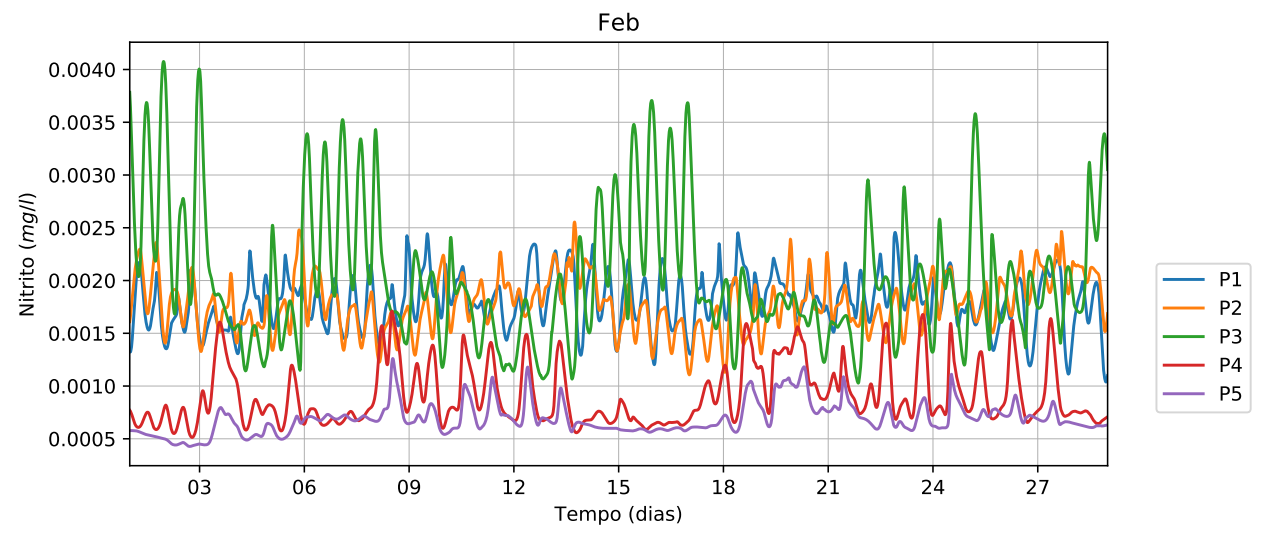

Figura 50: Série temporal da concentração de nitrito $(m g / l)$, para o período de Fevereiro de 2015.

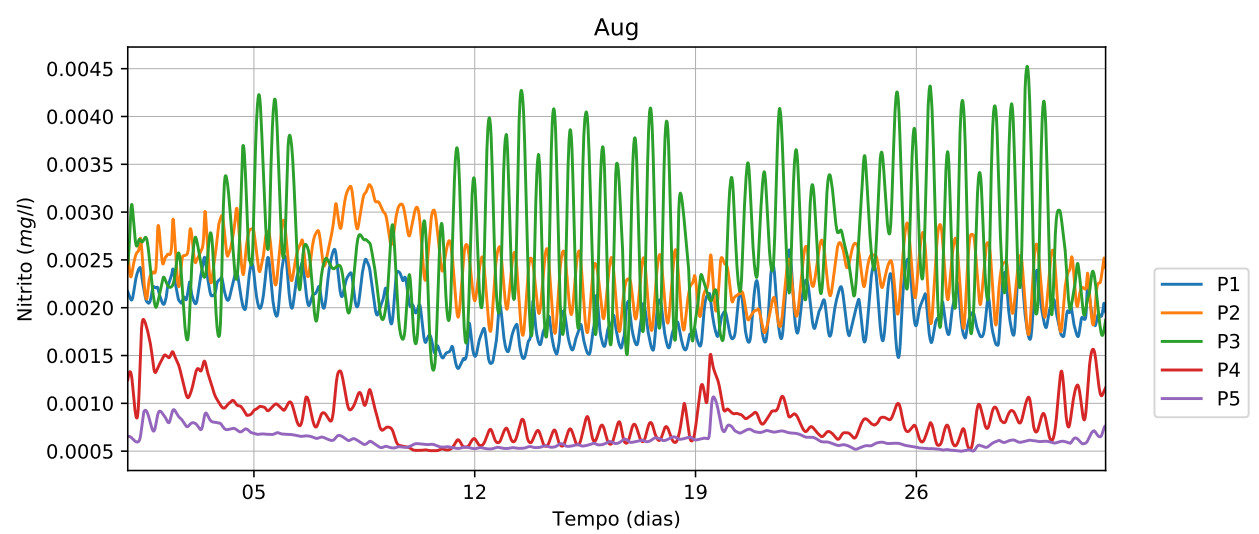

Figura 51: Série temporal da concentração de nitrito $(m g / l)$, para o período de Fevereiro de 2015.

As figuras 50 e 51 representam a variação temporal da concentração de nitrito $(m g / l)$ para os meses de Fevereiro e Agosto. A partir destes gráficos é possível observar maiores concentrações de nitrito no mês de Agosto e em regiões mais distantes da costa. 

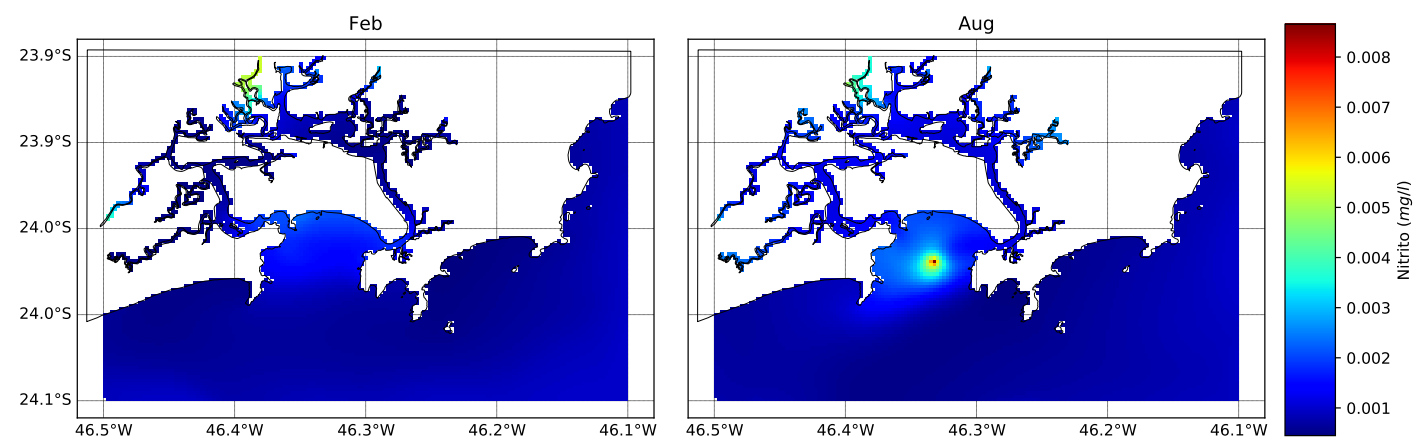

Figura 52: Concentração de nitrito $(m g / l)$ referente à camada superficial para o dia 12 de Fevereiro e Agosto de 2015.
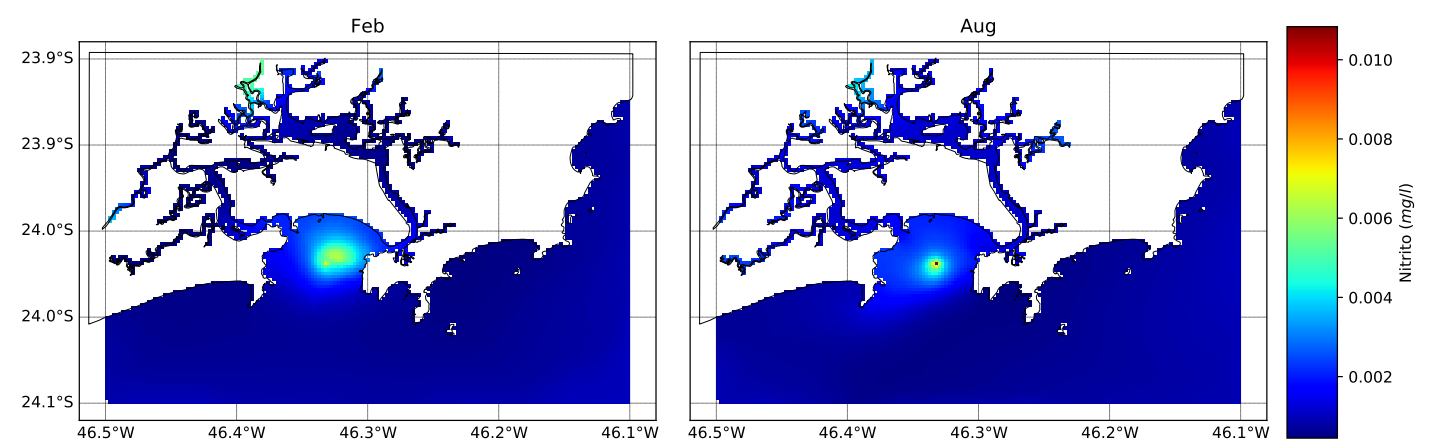

Figura 53: Concentração de nitrito $(m g / l)$ referente à camada de fundo para o dia 12 de Fevereiro e Agosto de 2015.

As figuras 52 e 53 são distribuições espaciais da concentração de nitrito para os meses de Fevereiro e Agosto, para a superfície e fundo. É possível observar maiores concentrações em alguns pontos de aporte fluvial e emissário, e maiores concentrações no fundo.

Os resultados para a concentração de nitrito e nitrato foram satisfatórias, quanto à distribuição espacial e variação sazonal, porém foram baixas $(<0.03 \mathrm{mg} / \mathrm{l})$ comparado à outros trabalhos $(<0.2 \mathrm{mg} / \mathrm{l})$.

As altas concentrações próximas de esgotos também foram observados por Braga et al. (2000) e Sampaio (2010), e o acúmulo de nutrientes pode ser justificado não só pela baixa energia de correntes como também pela elevada carga de efluentes domésticos.

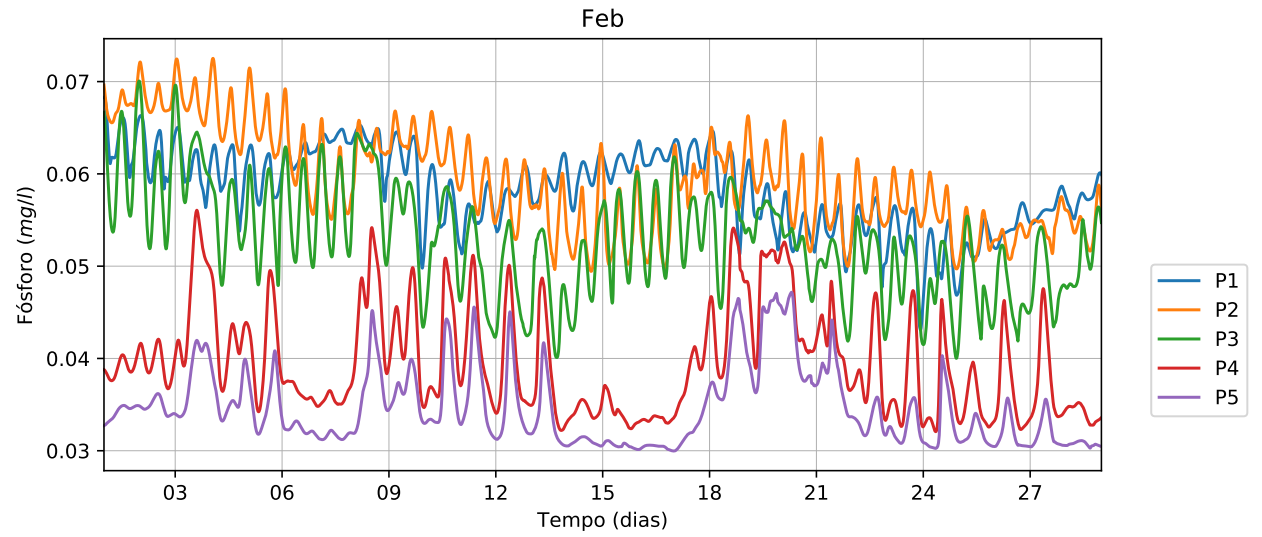

Figura 54: Série temporal da concentração de fósforo inorgânico $(\mathrm{mg} / \mathrm{l})$, para o período de Fevereiro de 2015. 


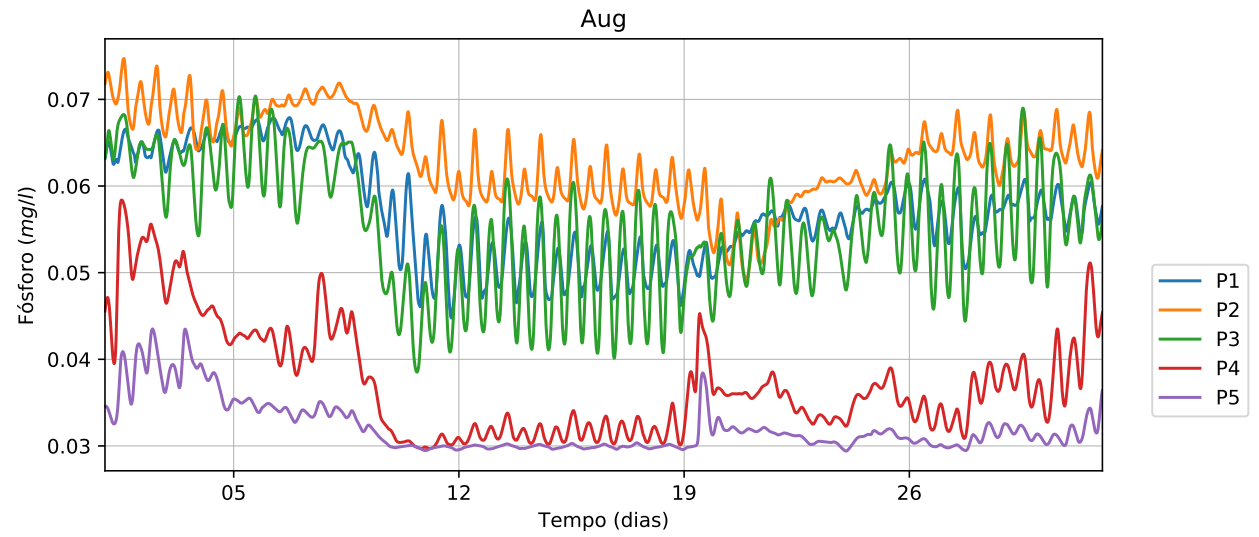

Figura 55: Série temporal da concentração de fósforo inorgânico $(\mathrm{mg} / \mathrm{l})$, para o período de Agosto de 2015.

As figuras 54 e 55 representam a variação temporal da concentração de fósforo inorgânico $(m g / l)$ para os meses de Fevereiro e Agosto. Tanto para o mês de Fevereiro quanto Agosto, a variação da concentração de fósforo foi parecida entre estes meses e as concentrações foram maiores próximo da costa.
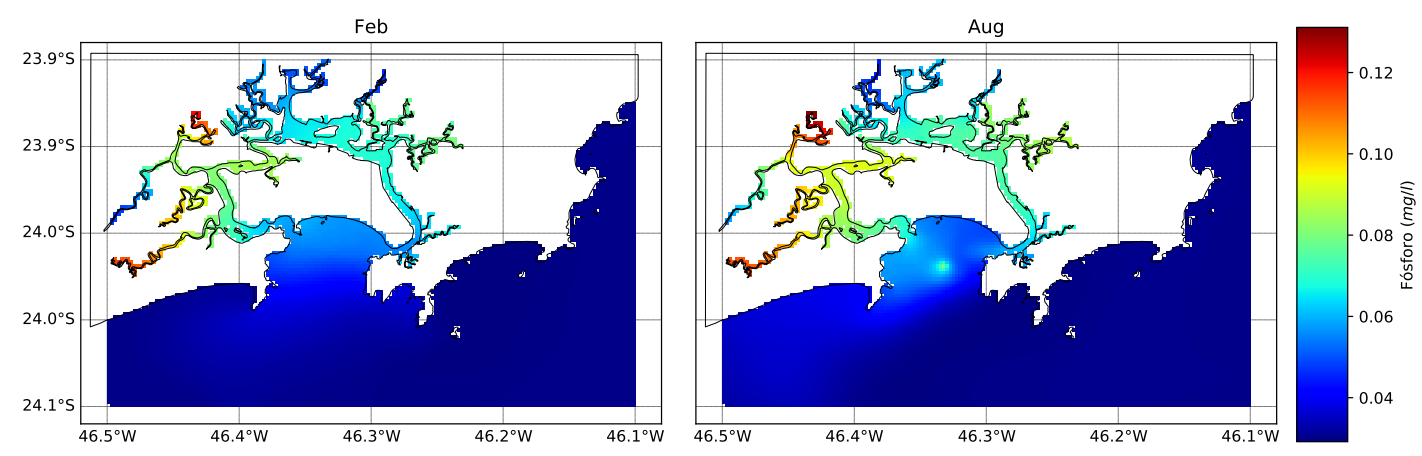

Figura 56: Concentração de fósforo inorgânico $(\mathrm{mg} / \mathrm{l})$ referente à camada superficial para o dia 12 de Fevereiro e Agosto de 2015.
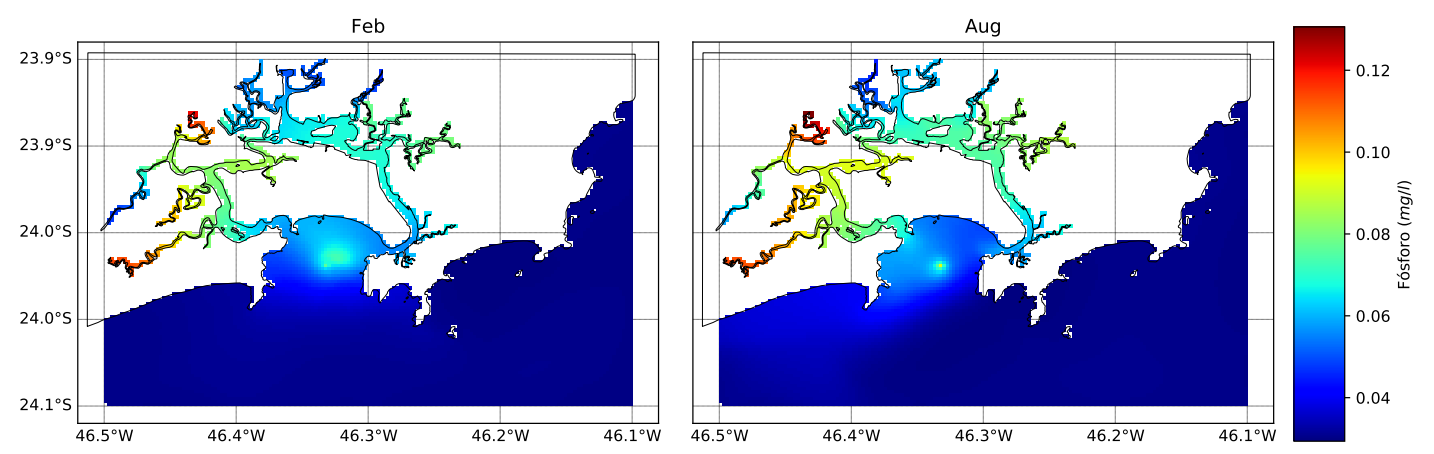

Figura 57: Concentração de fósforo inorgânico $(m g / l)$ referente à camada de fundo para o dia 12 de Fevereiro e Agosto de 2015.

As figuras 56 e 57 mostram a variação espacial da concentração de fósforo inorgânico $(\mathrm{mg} / \mathrm{l})$ para os meses de Fevereiro e Agosto, para a superfície e para o fundo. É possível observar que as maiores concentrações foram dentro do estuário, próximo da costa e próximo do emissário.

Os resultados para a concentração de fósforo inorgânico foram satisfatórias, quanto à distribuição espacial, porém foram baixas $(<0.1 \mathrm{mg} / \mathrm{l})$ comparado à outros trabalhos $(<0.8 \mathrm{mg} / \mathrm{l})$. 


\subsubsection{Fitoplâncton e Zooplâncton}

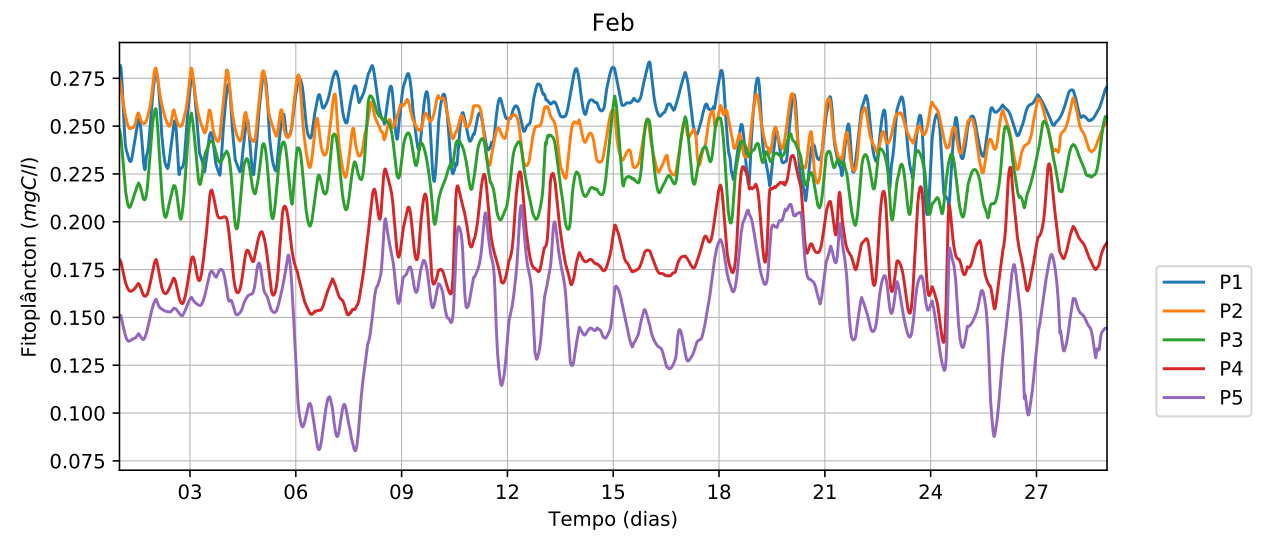

Figura 58: Série temporal da concentração de fitoplâncton $(m g C / l)$, para o período de Fevereiro de 2015.

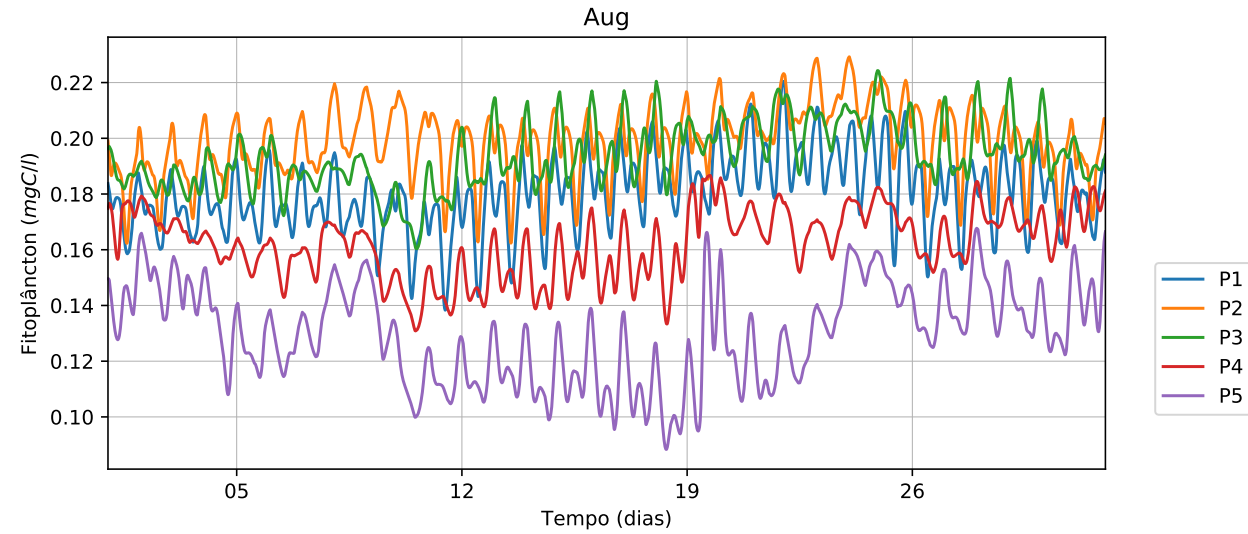

Figura 59: Série temporal da concentração de fitoplâncton $(m g C / l)$, para o período de Agosto de 2015.

As figuras 58 e 59 mostram a evolução temporal da concentração de fitoplâncton $(m g C / l)$ para os meses de Fevereiro e Agosto. É possível observar maiores concentrações de fitoplâncton em regiões próximas da costa e maiores concentrações durante o mês de Fevereiro.
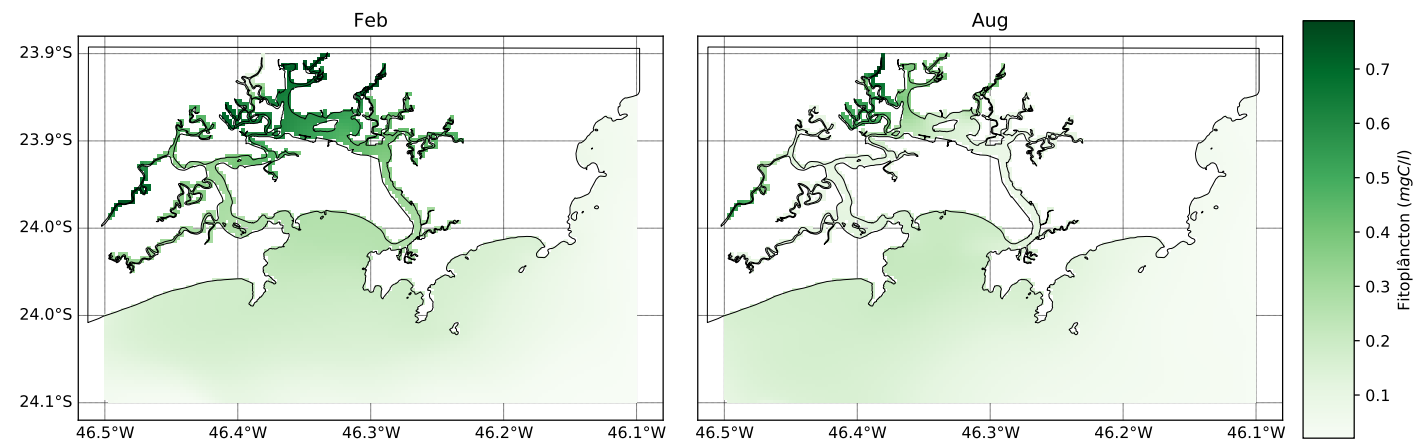

Figura 60: Concentração de fitoplâncton $(m g C / l)$ referente à camada superficial para o dia 12 de Fevereiro e Agosto de 2015. 



Figura 61: Concentração de fitoplâncton $(m g C / l)$ referente à camada de fundo para o dia 12 de Fevereiro e Agosto de 2015.

As figuras 60 e 61 representam a distribuição espacial da concentração de fitoplâncton $(m g C / l)$ para os meses de Fevereiro e Agosto, na superfície e fundo. É possível observar que maiores concentrações ocorrem na porção interna do estuário, na superfície e para o período de verão.

De forma geral os resultados obtidos com a modelagem foram próximos de trabalhos anteriores. A distribuição espacial foi concordante com resultados de MOSER (2002), Gianesella and Saldanha-Corrêa (2008) e Ribeiro (2012), que observaram maiores concentrações nas regiões internas do sistema. Apesar de concentrações de nutrientes ligeiramente maiores no mês de inverno, a concentração de fitoplâncton no verão foi ligeiramente maior, tal sazonalidade na concentração de fitoplâncton também foi observada por Gianesella and Saldanha-Corrêa (2008) e Ribeiro (2012). MOSER (2002) observou o mesmo padrão na concentração de fitoplâncton, porém apenas na região interna do estuário.

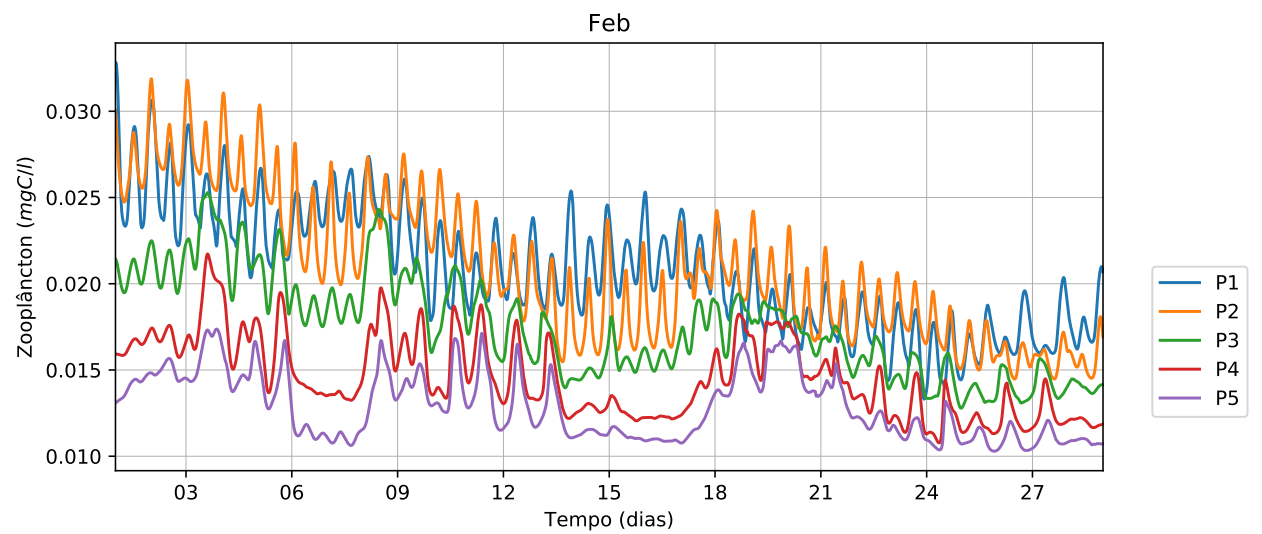

Figura 62: Série temporal da concentração de zooplâncton $(m g C / l)$, para o período de Fevereiro de 2015. 


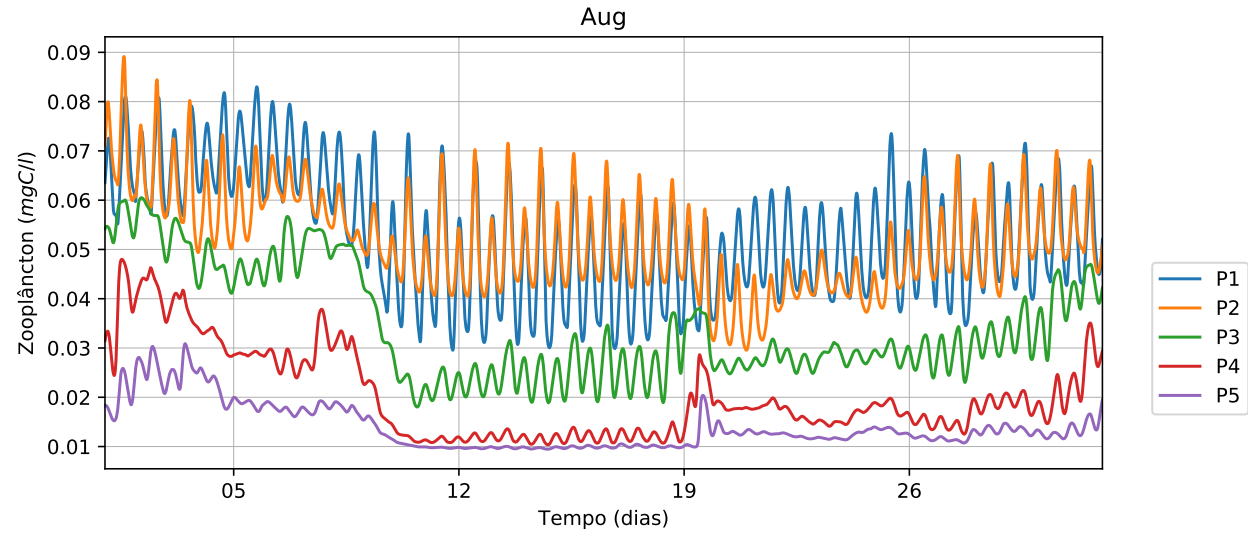

Figura 63: Série temporal da concentração de zooplâncton $(m g C / l)$, para o período de Agosto de 2015.

As figuras 62 e 63 mostram a evolução temporal da concentração de zooplâncton $(m g C / l)$ para os meses de Fevereiro e Agosto. É possível observar que maiores concentrações ocorrem próximo da costa e durante o mês de Agosto.
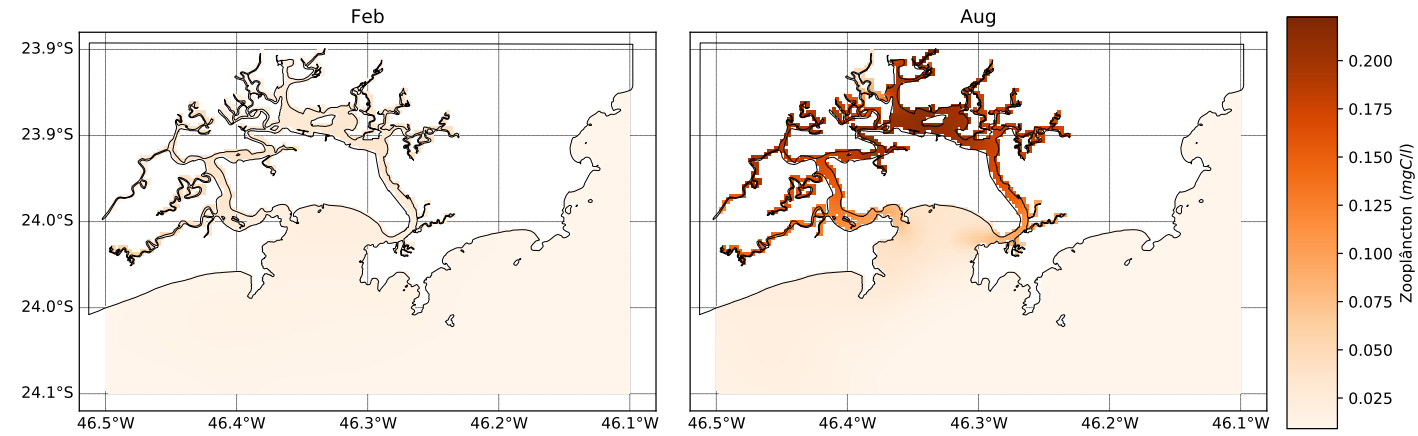

Figura 64: Concentração de zooplâncton $(m g C / l)$ referente à camada superficial para o dia 12 de Fevereiro e Agosto de 2015.
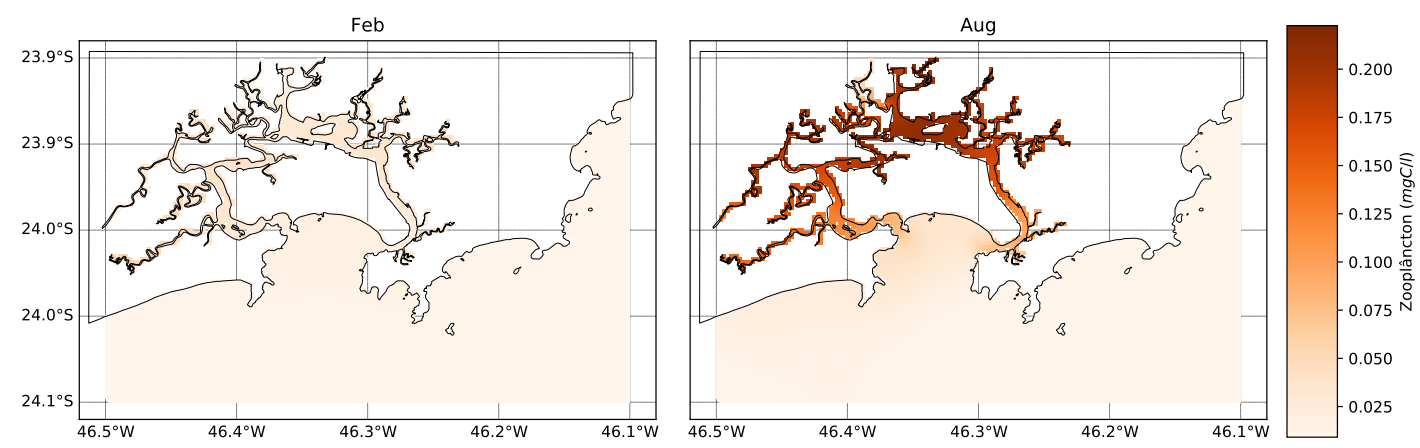

Figura 65: Concentração de zooplâncton $(m g C / l)$ referente à camada de fundo para o dia 12 de Fevereiro e Agosto de 2015.

As figuras 64 e 65 representam a distribuição espacial da concentração de zooplâncton $(m g C / l)$ para os meses de Fevereiro e Agosto, para superfície e fundo. É possível observar maiores concentrações de zooplâncton na região interna do estuário, no mês de Agosto e na superfície.

Alimentação realizada pelo zooplâncton é um processo ativo que envolve: localizar, selecionar, capturar, ingerir, digerir e assimilar alimento. Quantidade reduzida de 
alimento pode dificultar a captura e quantidade em excesso pode provocar morte por inanição. Outros fatores que afetam o crescimento do zooplâncton são: temperatura, salinidade, teor de oxigênio, turbulência, turbidez, pH.

Tendo em vista os resultados da concentração de fitoplâncton, espera-se que maiores concentrações de zooplâncton ocorram no período de verão, entretanto este resultado não foi obtido pelo modelo. Uma das variáveis que influencia o crescimento do zooplâncton é a temperatura máxima do intervalo de crescimento ótimo do zooplâncton, esta variável indica que acima de seu valor $\left(25^{\circ} \mathrm{C}\right)$ a temperatura afeta negativamente o crescimento. Como os resultados de temperatura do modelo foram altos comparados à outros trabalhos, pode-se inferir que a temperatura foi responsável para essa diferença entre verão e inverno. 


\section{Resultados: Parte II}

Para avaliar a influência dos parâmetros físicos na concentração de fitoplâncton, a simulação para o período de Fevereiro foi repetida alterando algumas características de forçantes que influenciam o crescimento ou distribuição espacial do fitoplâncton. Como visto anteriormente, o fitoplâncton dependente da luz para realizar fotossíntese e produzir matéria orgânica; sua a taxa metabólica é afetada pela temperatura da água; e por ser um tipo de organismo com baixa ou nenhuma capacidade natatória, não consegue vencer correntes marinhas. Assim, foram realiza simulações adicionais com diferentes temperaturas do ar, radiação solar e direção do vento.

\subsection{Temperatura do Ar}

Analisando a figura 11 é possível observar que a temperatura média do ar variou de $27^{\circ} \mathrm{C}$ a $20.5^{\circ} \mathrm{C}$ ao longo do ano. Para analisar a influência da temperatura do ar na concentração e distribuição espacial do fitoplâncton, a simulação para o mês de fevereiro foi repetida utilizando temperatura do ar constante de $26^{\circ} \mathrm{C}$ (T26) em uma simulação e $21^{\circ} \mathrm{C}$ (T21) em outra.
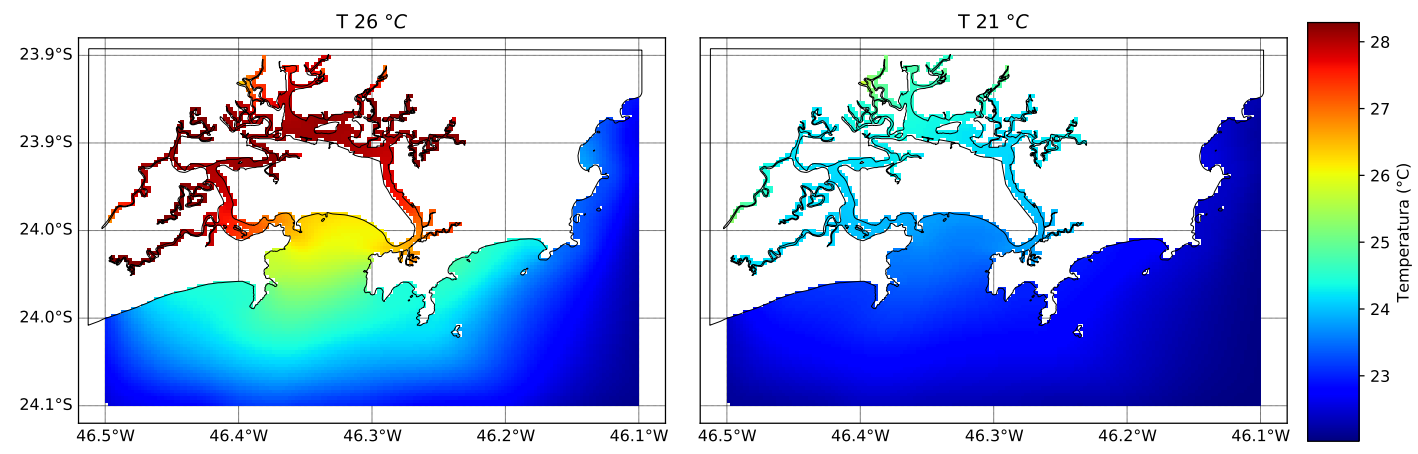

Figura 66: Temperatura média da água $\left({ }^{\circ} \mathrm{C}\right)$ referente à camada superficial para o mês de Fevereiro sobre influência da temperatura do ar de $26^{\circ} \mathrm{C}$ e $21^{\circ} \mathrm{C}$ constantes durante a simulação.

A figura 66 representa a temperatura média da água superficial para o mês de Fevereiro. Para a forçante T26, é possível observar que a temperatura da água foi alta tanto na região interna do estuário quanto para a Baía de Santos. Para a forçante T21, a temperatura média da água foi de 24.2 para a região interna e $23.5^{\circ} \mathrm{C}$ para a Baía de Santos. 

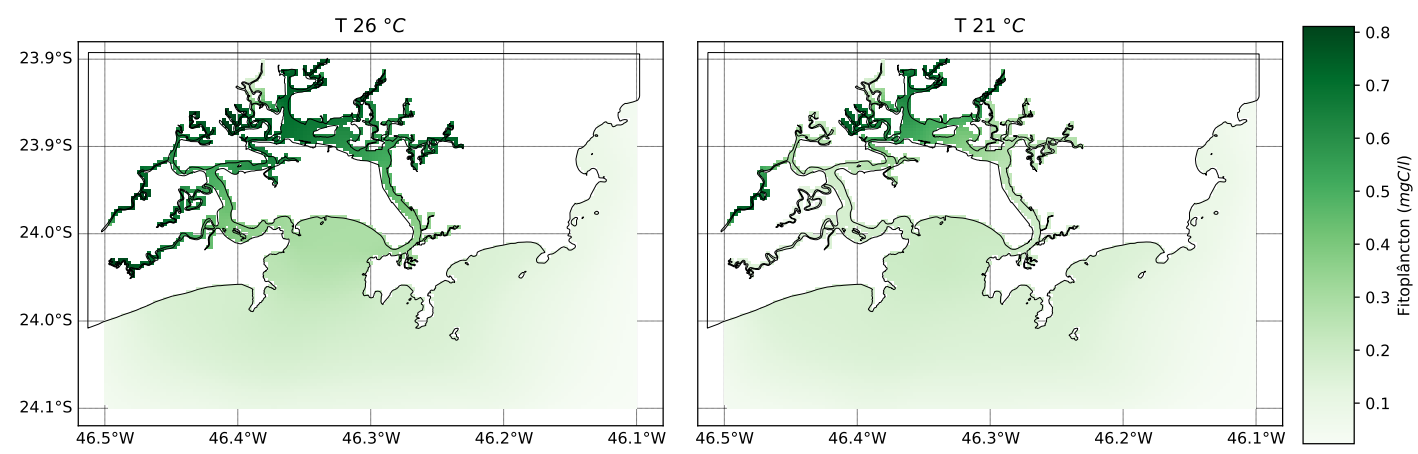

Figura 67: Concentração média de fitoplâncton $(m g C / l)$ referente à camada superficial para o mês de Fevereiro sobre influência da temperatura do ar de $26^{\circ} \mathrm{C}$ e $21^{\circ} \mathrm{C}$ constantes durante a simulação.

A figura 67 representa a concentração média de fitoplâncton na superfície para o mês de Fevereiro. O fitoplâncton apresentou maiores concentrações na região interna do estuário podendo atingir concentração de $0.8 \mathrm{mg} C / l$ e maiores concentrações na simulação com maior temperatura (T26), com média de $0.57 \mathrm{mgC} / \mathrm{l}$ na região interna do estuário e $0.27 m g C / l$ na Baía de Santos.
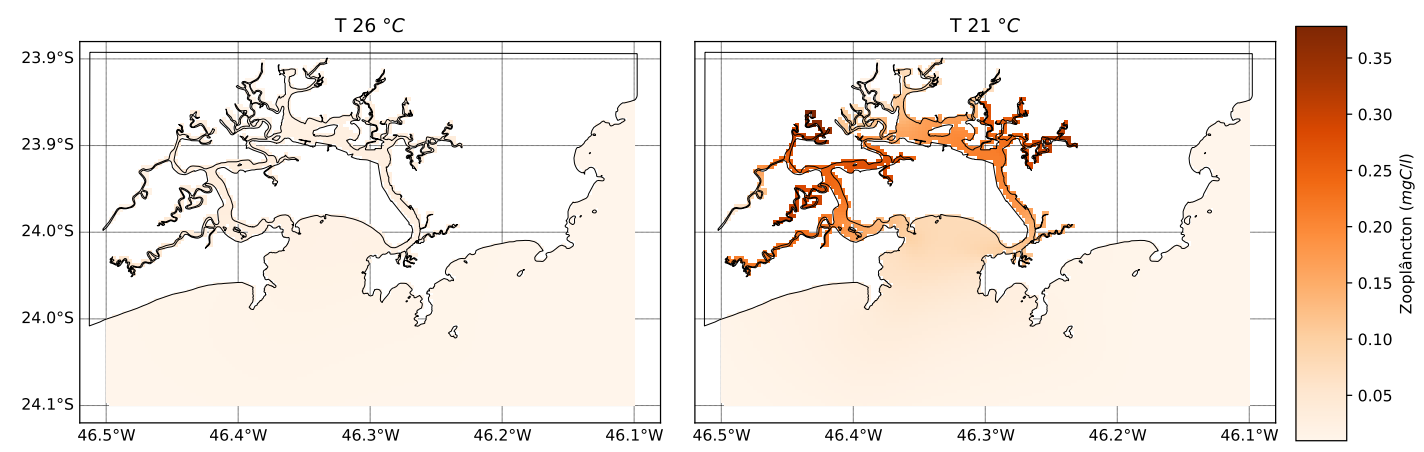

Figura 68: Concentração média de zooplâncton $(m g C / l)$ referente à camada superficial para o mês de Fevereiro sobre influência da temperatura do ar de $26^{\circ} \mathrm{C}$ e $21^{\circ} \mathrm{C}$ constantes durante a simulação.

A figura 68 representa a concentração média de zooplâncton na superfície para o mês de Fevereiro. É possível observar maior concentração na região interna do estuário $(0.37 \mathrm{mgC} / \mathrm{l})$ e na simulação com menor temperatura (T21). Novamente a temperatura da água atuou de forma a inibir o crescimento da população de zooplâncton. 
Tabela 7: Resultados da simulação para o mês de Fevereiro sob forçante de temperatura do ar de $26^{\circ} \mathrm{C}$. "all"são resultados para todo o domínio, "int"refere à região interna e "C1" à Baía de Santos

\begin{tabular}{|c|c|c|c|c|c|c|}
\hline Propriedade & Unidade & Região & $\min$ & $\max$ & mean & std \\
\hline \multirow[t]{3}{*}{ Temperatura } & \multirow[t]{3}{*}{${ }^{\circ} \mathrm{C}$} & all & 22.0841 & 28.2876 & 24.2006 & 1.6611 \\
\hline & & int & 26.3140 & 28.2876 & 27.8361 & 0.4557 \\
\hline & & $\mathrm{C} 1$ & 24.8612 & 26.5646 & 25.8145 & 0.3616 \\
\hline \multirow[t]{3}{*}{ Salinidade } & \multirow[t]{3}{*}{ psu } & all & 18.0544 & 35.9999 & 34.4358 & 3.8757 \\
\hline & & int & 18.0544 & 33.9813 & 25.1982 & 4.5280 \\
\hline & & $\mathrm{C} 1$ & 33.0296 & 35.4722 & 34.5187 & 0.4399 \\
\hline \multirow[t]{3}{*}{ Oxigênio } & \multirow[t]{3}{*}{$\mathrm{mg} / \mathrm{l}$} & all & 5.5003 & 9.5263 & 8.6213 & 0.9366 \\
\hline & & int & 5.5003 & 7.4416 & 6.4553 & 0.4279 \\
\hline & & $\mathrm{C} 1$ & 7.3713 & 8.4137 & 7.8234 & 0.2189 \\
\hline \multirow[t]{3}{*}{ Amônia } & \multirow[t]{3}{*}{$\mathrm{mg} / \mathrm{l}$} & all & 0.0020 & 0.0856 & 0.0035 & 0.0045 \\
\hline & & int & 0.0035 & 0.0856 & 0.0084 & 0.0114 \\
\hline & & $\mathrm{C} 1$ & 0.0029 & 0.0082 & 0.0041 & 0.0007 \\
\hline \multirow[t]{3}{*}{$\overline{\text { Nitrato }}$} & \multirow[t]{3}{*}{$\mathrm{mg} / \mathrm{l}$} & all & 0.0000 & 0.0958 & 0.0144 & 0.0126 \\
\hline & & int & 0.0000 & 0.0958 & 0.0038 & 0.0142 \\
\hline & & $\mathrm{C} 1$ & 0.0005 & 0.0036 & 0.0011 & 0.0004 \\
\hline \multirow[t]{3}{*}{ Nitrito } & \multirow[t]{3}{*}{$\mathrm{mg} / \mathrm{l}$} & all & 0.0004 & 0.0052 & 0.0009 & 0.0005 \\
\hline & & int & 0.0005 & 0.0052 & 0.0011 & 0.0008 \\
\hline & & $\mathrm{C} 1$ & 0.0009 & 0.0038 & 0.0020 & 0.0004 \\
\hline \multirow[t]{3}{*}{ Fósforo inorgânico } & \multirow[t]{3}{*}{$\mathrm{mg} / \mathrm{l}$} & all & 0.0300 & 0.1126 & 0.0389 & 0.0144 \\
\hline & & int & 0.0463 & 0.1126 & 0.0695 & 0.0118 \\
\hline & & $\mathrm{C} 1$ & 0.0416 & 0.0667 & 0.0579 & 0.0050 \\
\hline \multirow[t]{3}{*}{ Fitoplâncton } & \multirow[t]{3}{*}{$\mathrm{mgC} / \mathrm{l}$} & all & 0.0235 & 0.8109 & 0.1852 & 0.1686 \\
\hline & & int & 0.0643 & 0.8109 & 0.5748 & 0.1509 \\
\hline & & $\mathrm{C} 1$ & 0.2035 & 0.3103 & 0.2707 & 0.0225 \\
\hline \multirow[t]{3}{*}{ Zooplâncton } & \multirow[t]{3}{*}{$\mathrm{mgC} / \mathrm{l}$} & all & 0.0096 & 0.0545 & 0.0138 & 0.0062 \\
\hline & & int & 0.0103 & 0.0545 & 0.0270 & 0.0076 \\
\hline & & $\mathrm{C} 1$ & 0.0149 & 0.0220 & 0.0186 & 0.0013 \\
\hline
\end{tabular}


Tabela 8: Resultados da simulação para o mês de Fevereiro sob forçante de temperatura do ar de $21^{\circ} \mathrm{C}$. "all"são resultados para todo o domínio, "int" refere à região interna e "C1" à Baía de Santos

\begin{tabular}{|c|c|c|c|c|c|c|}
\hline Propriedade & Unidade & Região & $\min$ & $\max$ & mean & std \\
\hline \multirow[t]{3}{*}{ Temperatura } & \multirow[t]{3}{*}{${ }^{\circ} \mathrm{C}$} & all & 22.0198 & 25.7828 & 22.8253 & 0.6716 \\
\hline & & int & 23.7566 & 25.7828 & 24.2579 & 0.2703 \\
\hline & & $\mathrm{C} 1$ & 23.2035 & 23.8268 & 23.5276 & 0.1496 \\
\hline \multirow[t]{3}{*}{ Salinidade } & \multirow[t]{3}{*}{ psu } & all & 18.0417 & 36.0000 & 34.3944 & 3.8913 \\
\hline & & int & 18.0417 & 33.7527 & 25.1060 & 4.4730 \\
\hline & & $\mathrm{C} 1$ & 32.7939 & 35.3002 & 34.3062 & 0.4594 \\
\hline \multirow[t]{3}{*}{ Oxigênio } & \multirow[t]{3}{*}{$\mathrm{mg} / \mathrm{l}$} & all & 6.1192 & 9.5354 & 8.6715 & 0.8197 \\
\hline & & int & 6.1192 & 7.7026 & 6.9027 & 0.3266 \\
\hline & & $\mathrm{C} 1$ & 7.4679 & 8.2347 & 7.7827 & 0.1733 \\
\hline \multirow[t]{3}{*}{ Amônia } & \multirow[t]{3}{*}{$\mathrm{mg} / \mathrm{l}$} & all & 0.0020 & 0.1343 & 0.0049 & 0.0096 \\
\hline & & int & 0.0042 & 0.1343 & 0.0183 & 0.0227 \\
\hline & & $\mathrm{C} 1$ & 0.0035 & 0.0111 & 0.0058 & 0.0010 \\
\hline \multirow[t]{3}{*}{ Nitrato } & \multirow[t]{3}{*}{$\mathrm{mg} / \mathrm{l}$} & all & 0.0001 & 0.0965 & 0.0144 & 0.0128 \\
\hline & & int & 0.0001 & 0.0965 & 0.0045 & 0.0140 \\
\hline & & $\mathrm{C} 1$ & 0.0006 & 0.0044 & 0.0011 & 0.0004 \\
\hline \multirow[t]{3}{*}{ Nitrito } & \multirow[t]{3}{*}{$\mathrm{mg} / \mathrm{l}$} & all & 0.0004 & 0.0098 & 0.0010 & 0.0008 \\
\hline & & int & 0.0008 & 0.0098 & 0.0019 & 0.0014 \\
\hline & & $\mathrm{C} 1$ & 0.0011 & 0.0048 & 0.0023 & 0.0004 \\
\hline \multirow[t]{3}{*}{ Fósforo inorgânico } & \multirow[t]{3}{*}{$\mathrm{mg} / \mathrm{l}$} & all & 0.0299 & 0.1112 & 0.0393 & 0.0146 \\
\hline & & int & 0.0446 & 0.1112 & 0.0682 & 0.0130 \\
\hline & & $\mathrm{C} 1$ & 0.0454 & 0.0734 & 0.0615 & 0.0049 \\
\hline \multirow[t]{3}{*}{ Fitoplâncton } & \multirow[t]{3}{*}{$\mathrm{mgC} / \mathrm{l}$} & all & 0.0234 & 0.7535 & 0.1452 & 0.1102 \\
\hline & & int & 0.0551 & 0.7535 & 0.3421 & 0.1867 \\
\hline & & $\mathrm{C} 1$ & 0.1774 & 0.2194 & 0.2042 & 0.0084 \\
\hline \multirow[t]{3}{*}{ Zooplâncton } & \multirow[t]{3}{*}{$\mathrm{mgC} / \mathrm{l}$} & all & 0.0097 & 0.3781 & 0.0426 & 0.0639 \\
\hline & & int & 0.0125 & 0.3781 & 0.1889 & 0.0760 \\
\hline & & $\mathrm{C} 1$ & 0.0420 & 0.1066 & 0.0725 & 0.0124 \\
\hline
\end{tabular}

\subsection{Radiação Solar}

A figura 13 mostra a média da radiação solar máxima ao longo do ano, para o período de 2011 a 2016. A média da radiação máxima variou de $838 \mathrm{Wm}^{-2}$ a $475 \mathrm{Wm}^{-2}$ ao longo do ano. Para analisar a influência da radiação solar na concentração e distribuição espacial do fitoplâncton, a simulação para o mês de fevereiro foi repetida, porém com radiação limitada à $838 \mathrm{Wm}^{-2}(\mathrm{R} 838)$ e a outra à $475 \mathrm{Wm}^{-2}$ (R475). Diferente da temperatura do ar, esta forçante não foi imposta de forma constante e sim de modo a respeitar a variação diária causada pela rotação da Terra. 

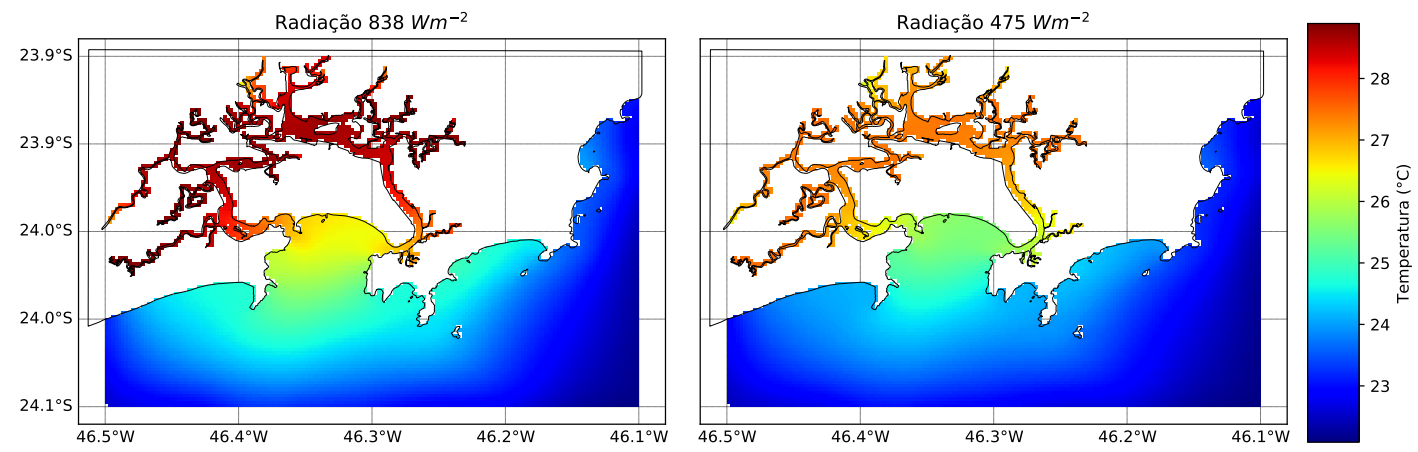

Figura 69: Temperatura média da água $\left({ }^{\circ} \mathrm{C}\right)$ referente à camada superficial para o mês de Fevereiro sobre influência da radiação solar limitadas à $838 \mathrm{Wm}^{-2}$ e à $475 \mathrm{Wm}^{-2}$.

Uma vez que a radiação solar também influencia a temperatura da água, a simulação com maior incidência solar apresentou maior temperatura da água. Para a simulação R838 a região interna do estuário e a região da Baía de Santos apresentaram valores altos de temperatura da água $\left(>26^{\circ} \mathrm{C}\right)$, já a média para todo o domínio ficou em $24.4^{\circ} \mathrm{C}$. Na simulação R475 a temperatura da água também foi alta $\left(>25^{\circ} \mathrm{C}\right)$ para a região interna e Baía de Santos e média de $23.9^{\circ} \mathrm{C}$ para toda a região modelada.
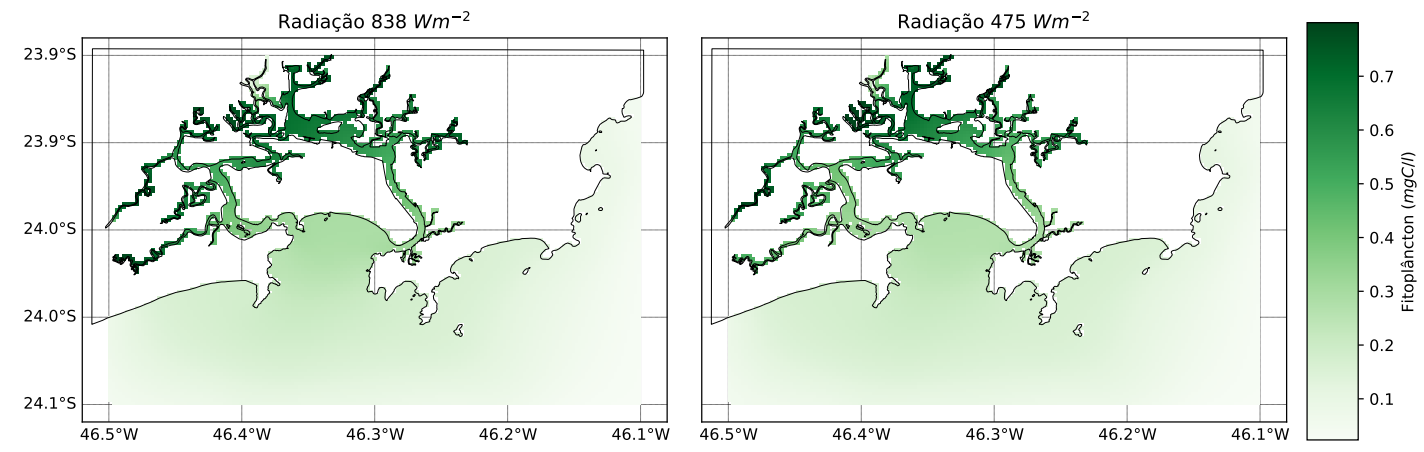

Figura 70: Concentração média de fitoplâncton $(m g C / l)$ referente à camada superficial para o mês de Fevereiro sobre influência da radiação solar limitadas à $838 \mathrm{Wm}^{-2}$ e à $475 \mathrm{Wm}^{-2}$.

Não é possível identificar variação significativa na concentração ou distribuição espacial da concentração de fitoplâncton a partir da figura 70, porém analisando os dados da tabela 9 e 10 podemos ver que a concentração de fitoplâncton foi ligeiramente maior na simulação com maior radiação.
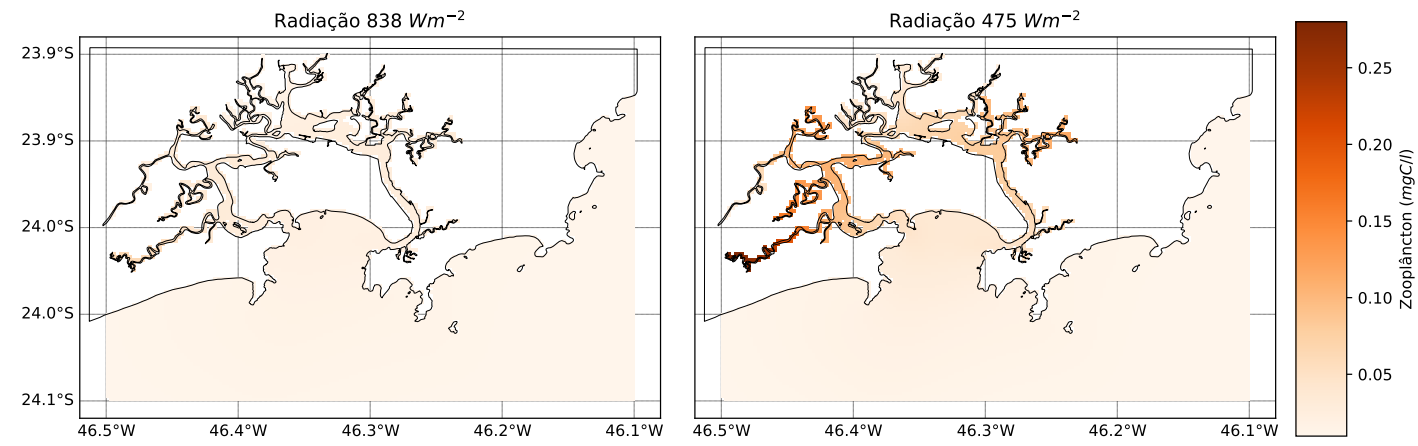

Figura 71: Concentração média de zooplâncton $(m g C / l)$ referente à camada superficial para o mês de Fevereiro sobre influência da radiação solar limitadas à $838 \mathrm{Wm}^{-2}$ e à $475 \mathrm{Wm}^{-2}$. 
A figura 71 indica que houve maior concentração de zooplâncton na simulação com menor radiação solar. A luminosidade estimula a atividade do zooplâncton podendo fazer com que ele vá a procura de alimento, apesar disto a simulação com maior radiação apresentou menor concentração de zooplâncton, este resultado pode ser explicado pelo aumento da temperatura causada pela radiação solar, que acima da temperatura ótima de crescimento, pode começar a prejudicar o crescimento deste organismo.

Tabela 9: Resultados da simulação para o mês de Fevereiro sob forçante de radiação solar limitada à $838 \mathrm{Wm}^{-2}$. "all" são resultados para todo o domínio, "int" refere à região interna e "C1"à Baía de Santos

\begin{tabular}{|c|c|c|c|c|c|c|}
\hline Propriedade & Unidade & Região & $\min$ & $\max$ & mean & std \\
\hline \multirow[t]{3}{*}{ Temperatura } & ${ }^{\circ} \mathrm{C}$ & all & 22.1023 & 28.8944 & 24.4254 & 1.8005 \\
\hline & & int & 26.4101 & 28.8944 & 28.3632 & 0.5169 \\
\hline & & $\mathrm{C} 1$ & 25.1288 & 26.9706 & 26.1709 & 0.3849 \\
\hline \multirow[t]{3}{*}{ Salinidade } & $\mathrm{psu}$ & all & 18.0558 & 35.9999 & 34.4392 & 3.8747 \\
\hline & & int & 18.0558 & 33.9938 & 25.2031 & 4.5280 \\
\hline & & $\mathrm{C} 1$ & 33.0549 & 35.4817 & 34.5361 & 0.4368 \\
\hline \multirow[t]{3}{*}{ Oxigênio } & $\mathrm{mg} / \mathrm{l}$ & all & 5.4233 & 9.5249 & 8.6073 & 0.9546 \\
\hline & & int & 5.4233 & 7.4091 & 6.3950 & 0.4355 \\
\hline & & $\mathrm{C} 1$ & 7.3372 & 8.3994 & 7.7987 & 0.2227 \\
\hline \multirow[t]{3}{*}{ Amônia } & $\mathrm{mg} / \mathrm{l}$ & all & 0.0020 & 0.0859 & 0.0037 & 0.0048 \\
\hline & & int & 0.0038 & 0.0859 & 0.0100 & 0.0116 \\
\hline & & $\mathrm{C} 1$ & 0.0030 & 0.0082 & 0.0043 & 0.0007 \\
\hline \multirow[t]{3}{*}{ Nitrato } & $\mathrm{mg} / \mathrm{l}$ & all & 0.0001 & 0.0959 & 0.0145 & 0.0126 \\
\hline & & int & 0.0001 & 0.0959 & 0.0041 & 0.0145 \\
\hline & & $\mathrm{C} 1$ & 0.0006 & 0.0036 & 0.0012 & 0.0004 \\
\hline \multirow[t]{3}{*}{ Nitrito } & $\mathrm{mg} / \mathrm{l}$ & all & 0.0004 & 0.0053 & 0.0009 & 0.0005 \\
\hline & & int & 0.0006 & 0.0053 & 0.0012 & 0.0008 \\
\hline & & $\mathrm{C} 1$ & 0.0009 & 0.0037 & 0.0019 & 0.0004 \\
\hline \multirow[t]{3}{*}{ Fósforo inorgânico } & $\mathrm{mg} / \mathrm{l}$ & all & 0.0300 & 0.1151 & 0.0390 & 0.0147 \\
\hline & & int & 0.0471 & 0.1151 & 0.0705 & 0.0120 \\
\hline & & $\mathrm{C} 1$ & 0.0415 & 0.0662 & 0.0577 & 0.0050 \\
\hline \multirow[t]{3}{*}{ Fitoplâncton } & $\mathrm{mgC} / \mathrm{l}$ & all & 0.0235 & 0.7965 & 0.1838 & 0.1659 \\
\hline & & int & 0.0627 & 0.7965 & 0.5673 & 0.1473 \\
\hline & & $\mathrm{C} 1$ & 0.2022 & 0.3081 & 0.2684 & 0.0224 \\
\hline \multirow[t]{3}{*}{ Zooplâncton } & $\mathrm{mgC} / \mathrm{l}$ & all & 0.0097 & 0.0645 & 0.0140 & 0.0066 \\
\hline & & int & 0.0103 & 0.0645 & 0.0276 & 0.0089 \\
\hline & & $\mathrm{C} 1$ & 0.0152 & 0.0229 & 0.0191 & 0.0014 \\
\hline
\end{tabular}


Tabela 10: Resultados da simulação para o mês de Fevereiro sob forçante de radiação solar limitada à $475 \mathrm{Wm}^{-2}$. "all" são resultados para todo o domínio, "int" refere à região interna e "C1"à Baía de Santos

\begin{tabular}{|c|c|c|c|c|c|c|}
\hline Propriedade & Unidade & Região & $\min$ & $\max$ & mean & std \\
\hline \multirow[t]{3}{*}{ Temperatura } & \multirow[t]{3}{*}{${ }^{\circ} \mathrm{C}$} & all & 22.0834 & 27.5141 & 23.9297 & 1.4531 \\
\hline & & int & 25.7844 & 27.5141 & 27.1411 & 0.4109 \\
\hline & & $\mathrm{C} 1$ & 24.4532 & 25.9269 & 25.2890 & 0.3041 \\
\hline \multirow[t]{3}{*}{ Salinidade } & \multirow[t]{3}{*}{$\mathrm{psu}$} & all & 18.0519 & 35.9999 & 34.4413 & 3.8714 \\
\hline & & int & 18.0519 & 34.0010 & 25.2106 & 4.5205 \\
\hline & & $\mathrm{C} 1$ & 33.0762 & 35.4843 & 34.5473 & 0.4332 \\
\hline \multirow[t]{3}{*}{ Oxigênio } & \multirow[t]{3}{*}{$\mathrm{mg} / \mathrm{l}$} & all & 5.6968 & 9.5268 & 8.6595 & 0.9100 \\
\hline & & int & 5.6968 & 7.5747 & 6.5528 & 0.4185 \\
\hline & & $\mathrm{C} 1$ & 7.4576 & 8.4556 & 7.8915 & 0.2090 \\
\hline \multirow[t]{3}{*}{ Amônia } & \multirow[t]{3}{*}{$\mathrm{mg} / \mathrm{l}$} & all & 0.0020 & 0.0827 & 0.0032 & 0.0035 \\
\hline & & int & 0.0035 & 0.0827 & 0.0073 & 0.0086 \\
\hline & & $\mathrm{C} 1$ & 0.0028 & 0.0081 & 0.0040 & 0.0007 \\
\hline \multirow[t]{3}{*}{ Nitrato } & \multirow{3}{*}{$\mathrm{mg} / 1$} & all & 0.0000 & 0.0940 & 0.0137 & 0.0121 \\
\hline & & int & 0.0000 & 0.0940 & 0.0031 & 0.0122 \\
\hline & & C1 & 0.0005 & 0.0036 & 0.0012 & 0.0005 \\
\hline \multirow[t]{3}{*}{ Nitrito } & \multirow[t]{3}{*}{$\mathrm{mg} / \mathrm{l}$} & all & 0.0004 & 0.0049 & 0.0009 & 0.0005 \\
\hline & & int & 0.0005 & 0.0049 & 0.0011 & 0.0008 \\
\hline & & $\mathrm{C} 1$ & 0.0009 & 0.0038 & 0.0020 & 0.0004 \\
\hline \multirow[t]{3}{*}{ Fósforo Inorgânico } & \multirow[t]{3}{*}{$\mathrm{mg} / \mathrm{l}$} & all & 0.0296 & 0.1116 & 0.0386 & 0.0141 \\
\hline & & int & 0.0448 & 0.1116 & 0.0684 & 0.0117 \\
\hline & & $\mathrm{C} 1$ & 0.0413 & 0.0658 & 0.0572 & 0.0049 \\
\hline \multirow[t]{3}{*}{ Fitoplâncton } & \multirow[t]{3}{*}{$\mathrm{mgC} / \mathrm{l}$} & all & 0.0240 & 0.7996 & 0.1793 & 0.1503 \\
\hline & & int & 0.0866 & 0.7996 & 0.5193 & 0.1520 \\
\hline & & $\mathrm{C} 1$ & 0.1966 & 0.2752 & 0.2518 & 0.0183 \\
\hline \multirow[t]{3}{*}{ Zooplâncton } & \multirow[t]{3}{*}{$\mathrm{mgC} / \mathrm{l}$} & all & 0.0097 & 0.2800 & 0.0232 & 0.0282 \\
\hline & & int & 0.0111 & 0.2800 & 0.0829 & 0.0439 \\
\hline & & $\mathrm{C} 1$ & 0.0212 & 0.0497 & 0.0337 & 0.0049 \\
\hline
\end{tabular}

\subsection{Vento}

A figura 16 mostra a frequência da direção dos ventos, sua intensidade e a frequência de cada intensidade. A partir dela podemos observar que os ventos mais frequentes são de leste e as intensidades mais frequentes são de 0 a $6.9 m s-1$. Com base nos dados desta figura, foram realizadas simulações com quatro regimes de vento: ventos de norte, de leste, de sul e de sudoeste. Nestas simulações apenas a direção do vento foi mantida e o módulo da velocidade foi variável com o tempo (Figura 19.) 


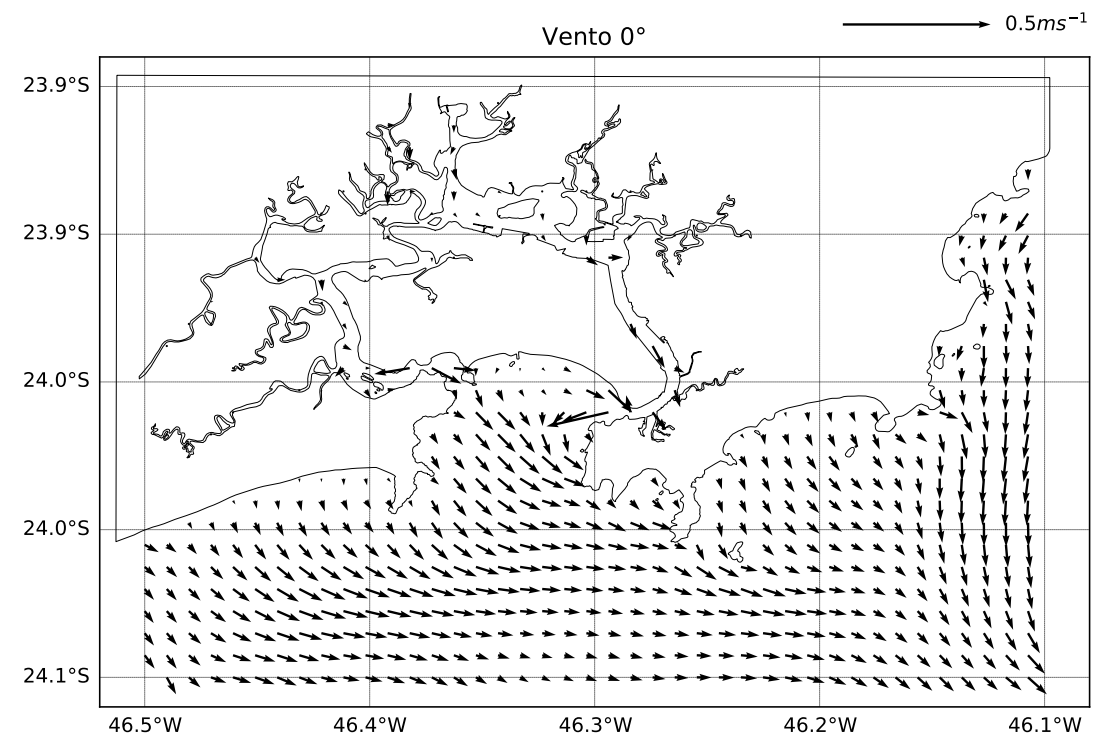

Figura 72: Campo de corrente média $(\mathrm{m} / \mathrm{s})$ referente à camada superficial para o mês de Fevereiro sobre influência de ventos de norte.

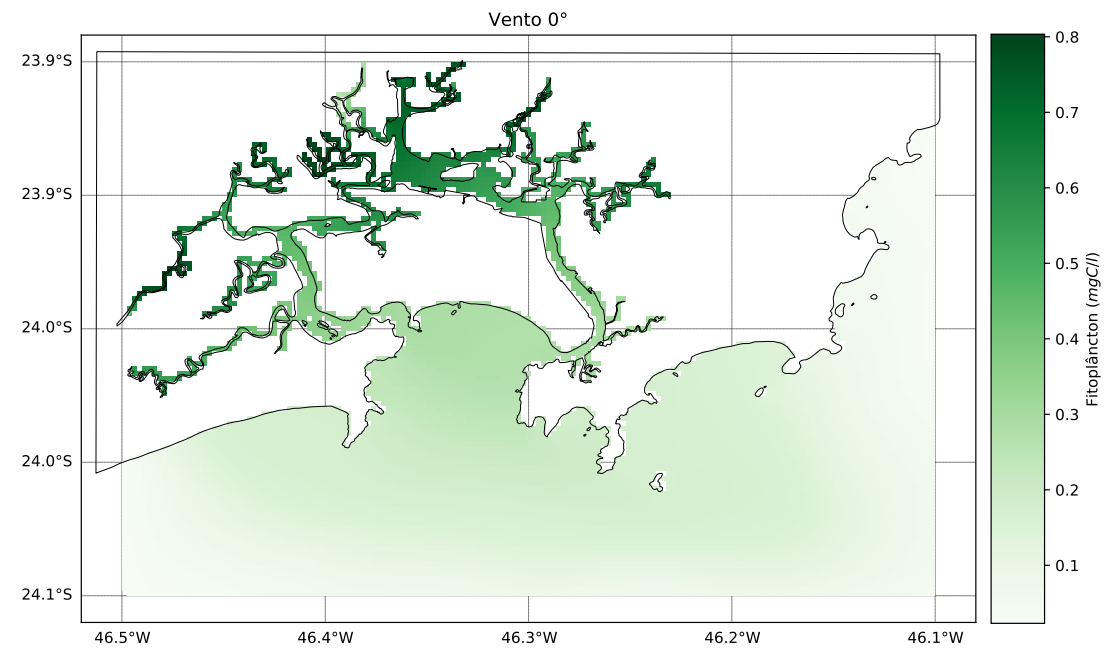

Figura 73: Concentração média de fitoplâncton $(m g C / l)$ referente à camada superficial para o mês de Fevereiro sobre influência de ventos de norte. 


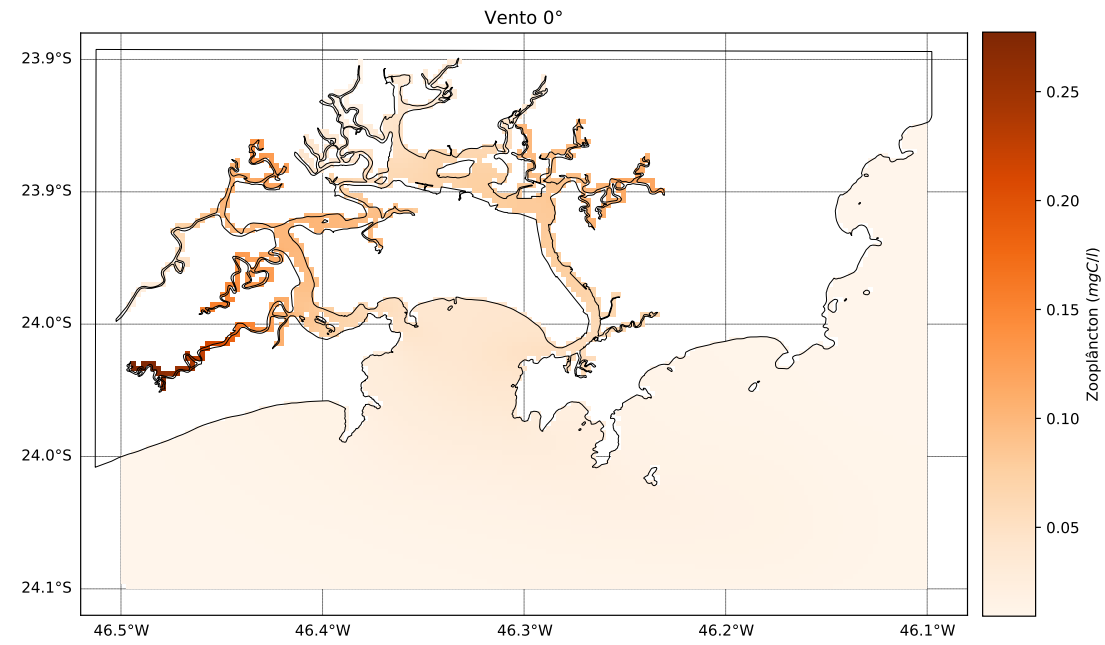

Figura 74: Concentração média de zooplâncton $(m g C / l)$ referente à camada superficial para o mês de Fevereiro sobre influência de ventos de norte.

Como pode ser observado na figura 72 , ventos de norte produziram correntes para leste e para sudeste. Estas correntes provocaram uma maior distribuição de fitoplâncton para a região de Praia Grande, Baía de Santos e Guarujá (Figura 73). O zooplâncton, por sua vez, teve maior concentração na região leste da Baía de Santos, próximo da região do Canal de Santos (Figura 74).

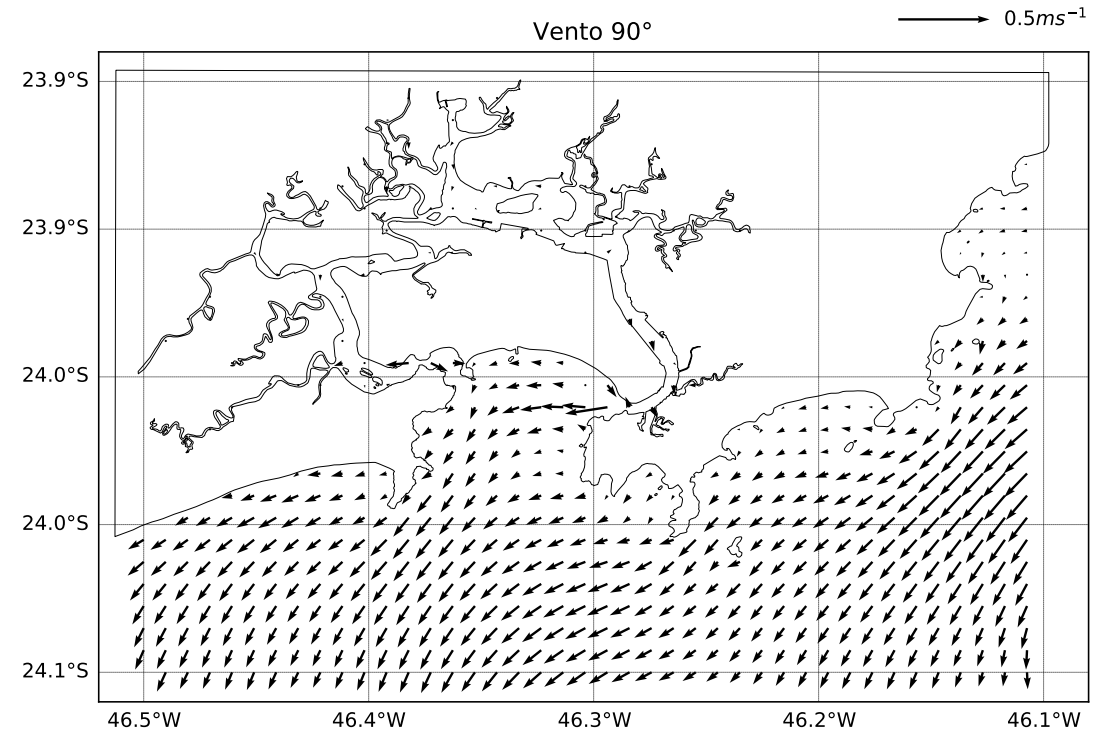

Figura 75: Campo de corrente média $(\mathrm{m} / \mathrm{s})$ referentes à camada superficial para o mês de Fevereiro sobre influencia de ventos de leste. 


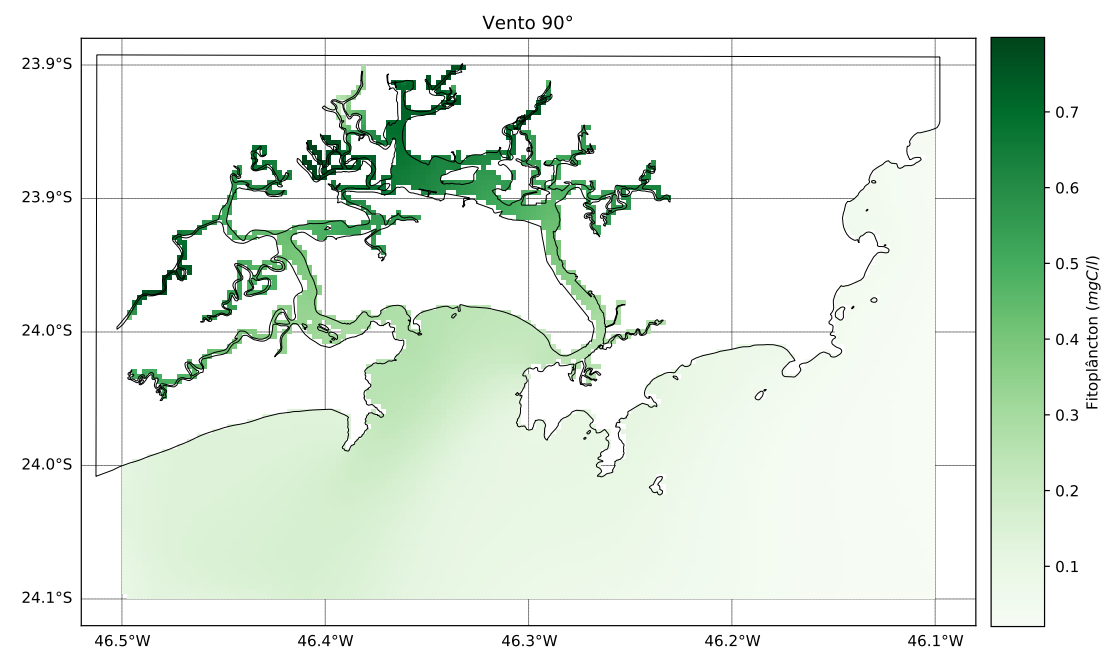

Figura 76: Concentração média de fitoplâncton $(m g C / l)$ referente à camada superficial para o mês de Fevereiro sobre influência de ventos de leste.

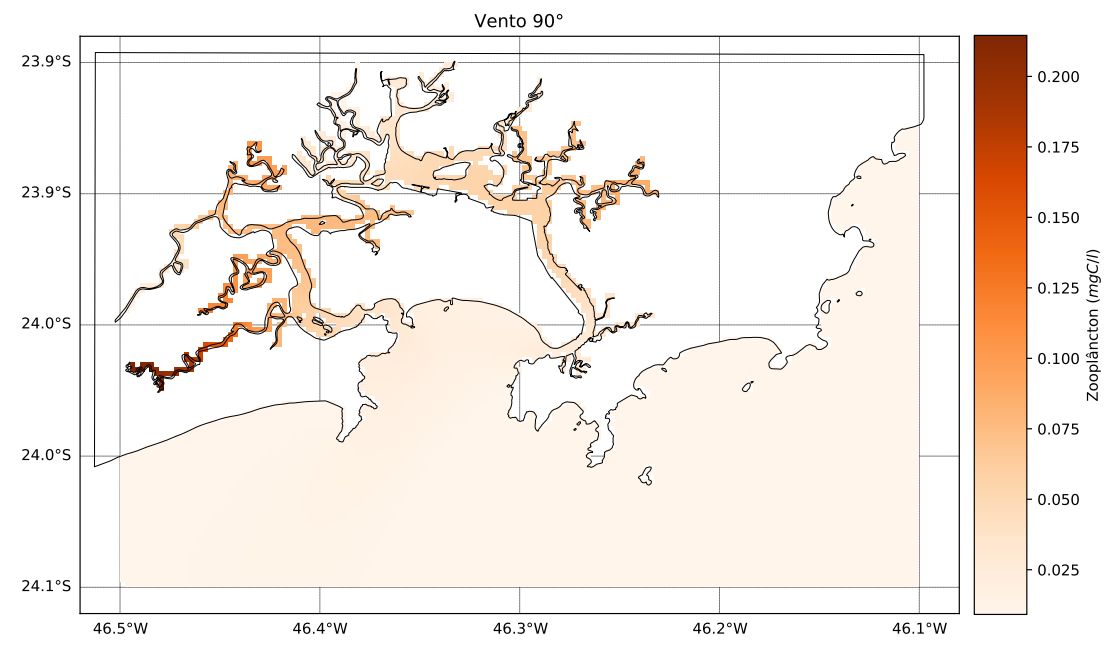

Figura 77: Concentração média de zooplâncton $(m g C / l)$ referente à camada superficial para o mês de Fevereiro sobre influência de ventos de norte.

A figura 75 mostra que ventos de leste produzem correntes predominantemente para sudoeste. Estas correntes provocaram uma maior concentração de fitoplâncton na região oeste da Baía de Santos e na região oeste do domínio (Figura 76). Para a distribuição espacial de zooplâncton, não houve concentração elevada em nenhuma região em específico (Figura 77). 


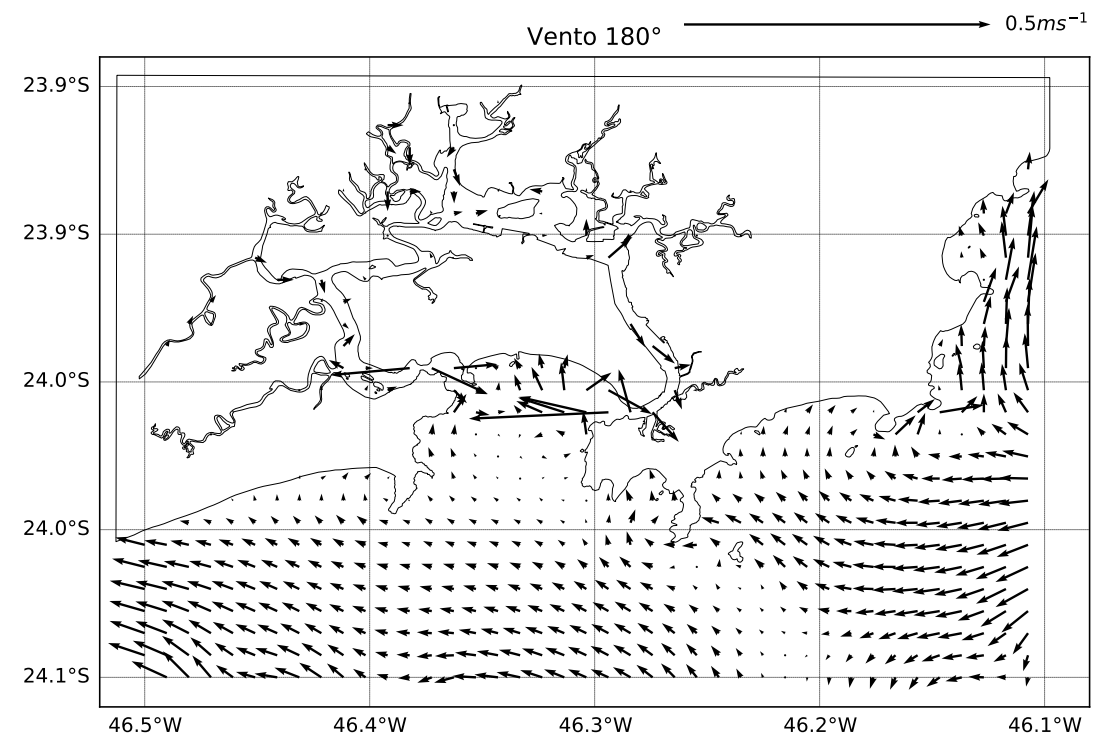

Figura 78: Campo de corrente média $(\mathrm{m} / \mathrm{s})$ referentes à camada superficial para o mês de Fevereiro sobre influência de ventos de sul.

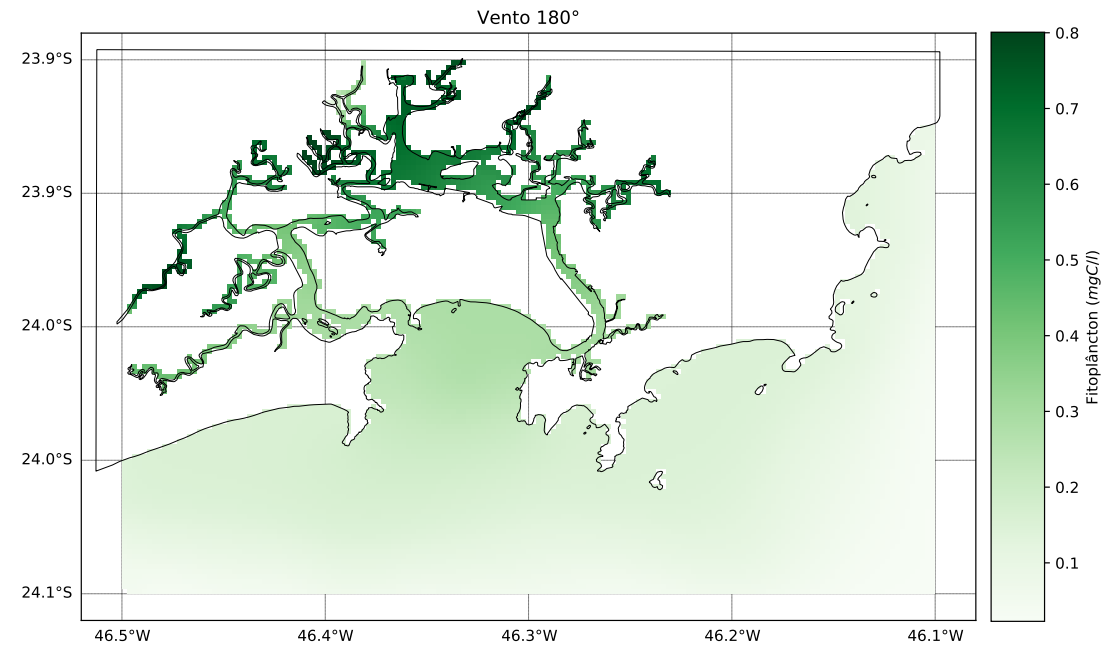

Figura 79: Concentração média de fitoplâncton $(m g C / l)$ referente à camada superficial para o mês de Fevereiro sobre influência de ventos de sul. 


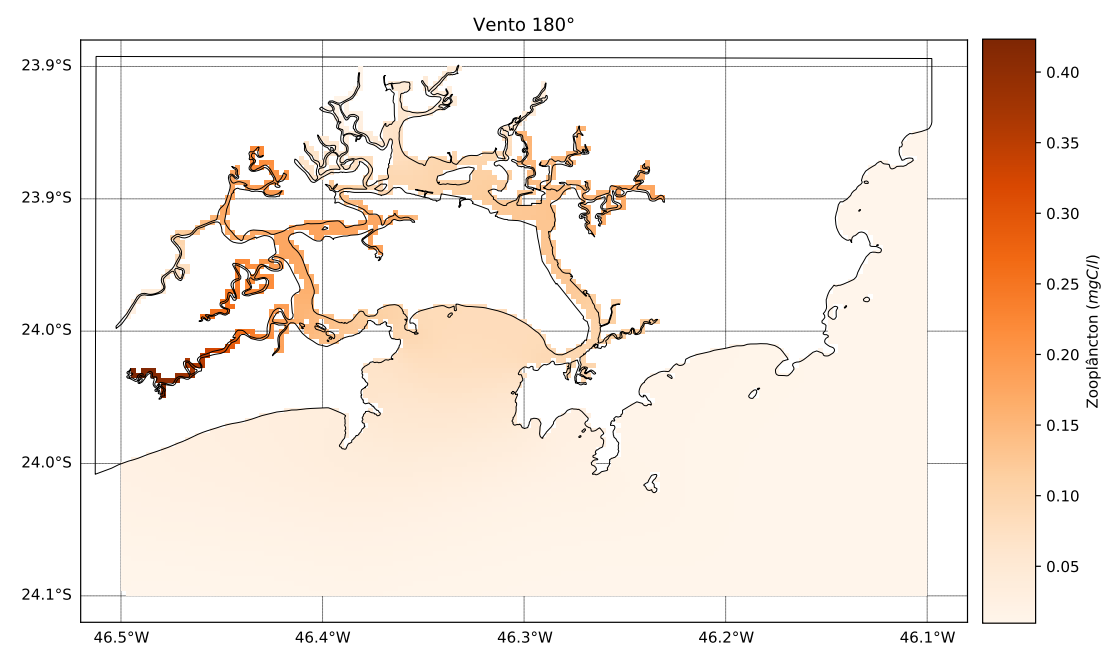

Figura 80: Concentração média de zooplâncton $(m g C / l)$ referente à camada superficial para o mês de Fevereiro sobre influência de ventos de norte.

Para ventos de sul, temos que as correntes tendem a seguir para oeste do domínio e para norte na região próxima de Bertioga (Figura 78). As correntes geradas nestas condições provocaram uma distribuição homogênea para o fitoplâncton em todo o domínio. Nestas condições o zooplâncton apresentou maiores concentrações próximo da Praia Grande, na Baía de São Vicente, Baía de Santos e no Canal de Santos.

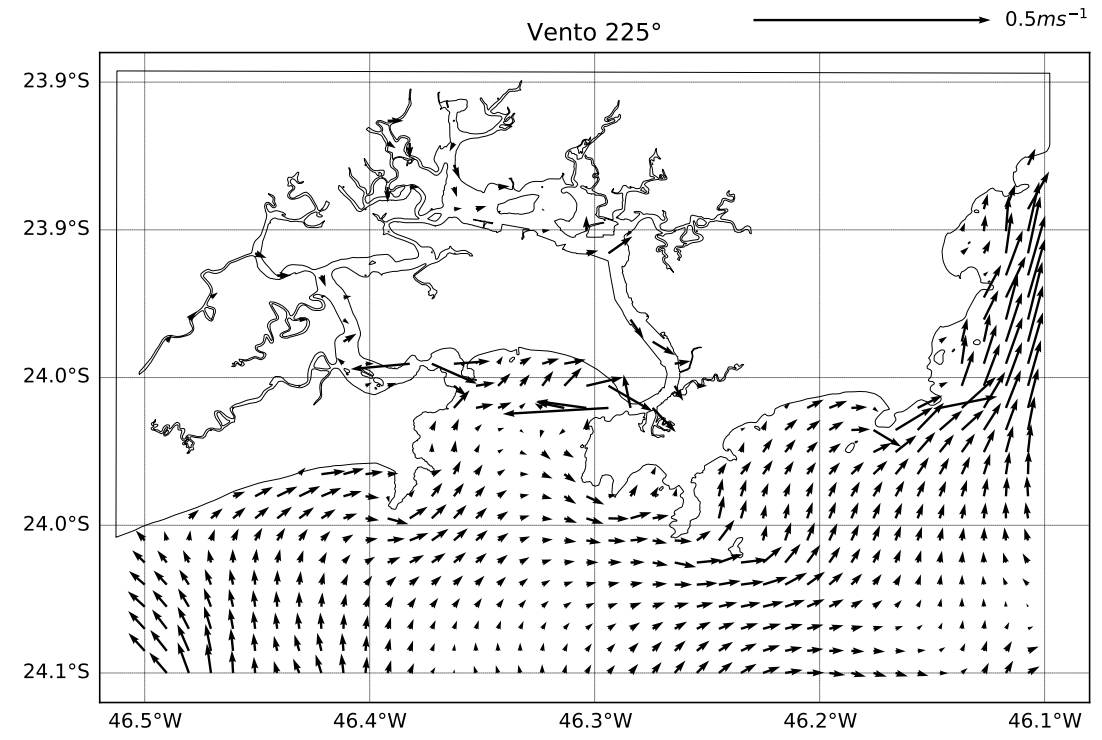

Figura 81: Campo de corrente média $(\mathrm{m} / \mathrm{s})$ referente à camada superficial para o mês de Fevereiro sobre influência de ventos de sudoeste. 


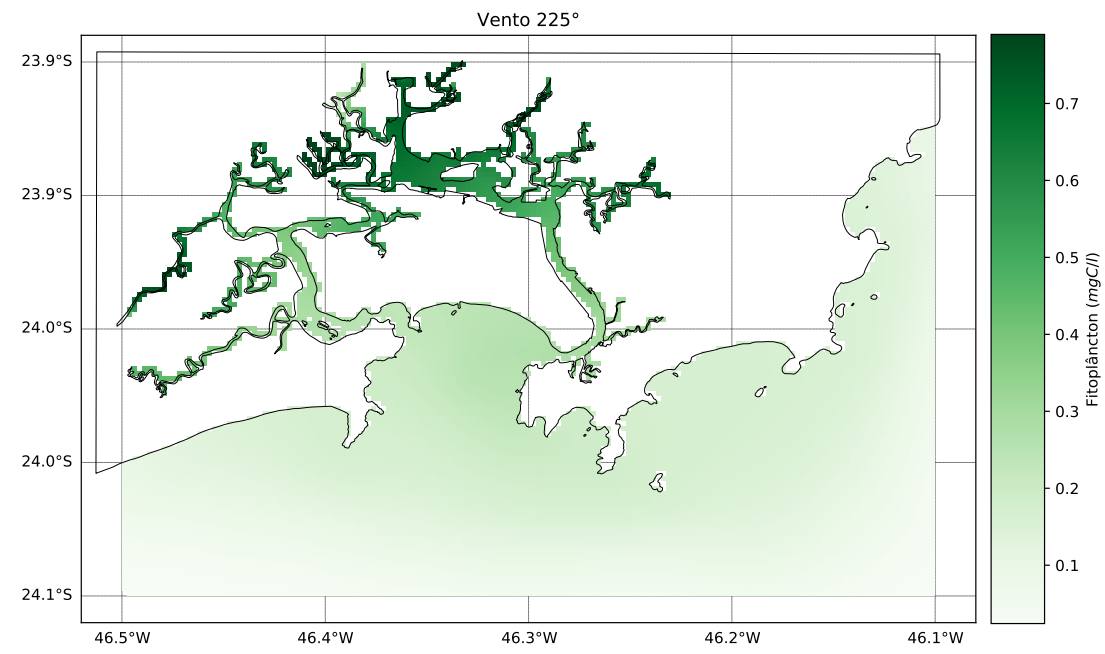

Figura 82: Concentração média de fitoplâncton $(m g C / l)$ referente à camada superficial para o mês de Fevereiro sobre influência de ventos de sudoeste.

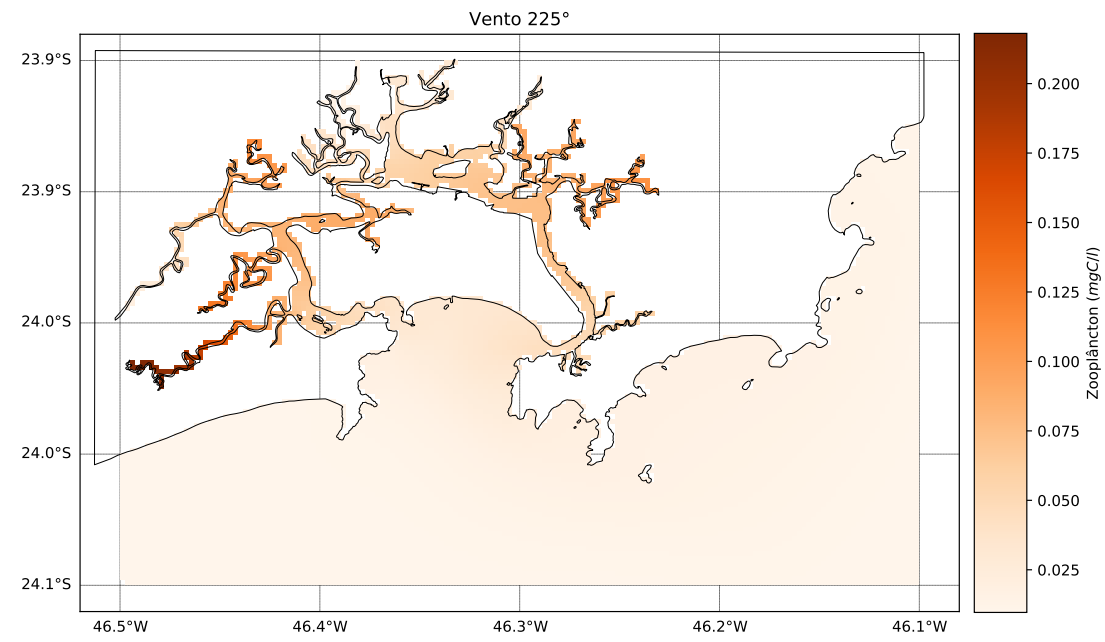

Figura 83: Concentração média de zooplâncton $(m g C / l)$ referente à camada superficial para o mês de Fevereiro sobre influência de ventos de norte.

Ventos de sudoeste provocaram correntes para nordeste que seguem o contorno da costa (Figura 81). As correntes deste cenário fizeram com que a concentração de fitoplâncton ficasse bem distribuída, atingindo até a região próxima de Bertioga, apenas a região à oeste de Praia Grande apresentou baixas concentrações (Figura 82). Já o zooplâncton apresentou baixas concentrações na Baía de São vicente e altas concentrações à leste da Baía de Santos e no Canal de Santos (Figura 83). 
Tabela 11: Resultados da simulação para o mês de Fevereiro sob forçante de ventos de norte. "all" são resultados para todo o domínio, "int" refere à região interna e "C1"à Baía de Santos

\begin{tabular}{|c|c|c|c|c|c|c|}
\hline Propriedade & Unidade & Região & $\min$ & $\max$ & mean & std \\
\hline \multirow[t]{3}{*}{ Temperatura } & \multirow[t]{3}{*}{${ }^{\circ} \mathrm{C}$} & all & 22.1916 & 27.4114 & 24.4285 & 1.4756 \\
\hline & & int & 26.1791 & 27.4114 & 27.1586 & 0.1987 \\
\hline & & $\mathrm{C} 1$ & 24.8463 & 26.8951 & 26.3477 & 0.4373 \\
\hline \multirow[t]{3}{*}{$\overline{\text { Salinidade }}$} & \multirow[t]{3}{*}{ psu } & all & 18.0515 & 36.0000 & 34.3873 & 3.8775 \\
\hline & & int & 18.0515 & 33.8251 & 25.0835 & 4.3223 \\
\hline & & $\mathrm{C} 1$ & 32.5102 & 35.6166 & 34.2634 & 0.6177 \\
\hline \multirow[t]{3}{*}{ Oxigênio } & \multirow[t]{3}{*}{$\mathrm{mg} / \mathrm{l}$} & all & 5.6903 & 9.4930 & 8.5289 & 0.9203 \\
\hline & & int & 5.6903 & 7.4999 & 6.5206 & 0.3875 \\
\hline & & $\mathrm{C} 1$ & 7.0070 & 8.5677 & 7.5695 & 0.3219 \\
\hline \multirow[t]{3}{*}{ Amônia } & \multirow[t]{3}{*}{$\mathrm{mg} / \mathrm{l}$} & all & 0.0021 & 0.0835 & 0.0035 & 0.0038 \\
\hline & & int & 0.0042 & 0.0835 & 0.0085 & 0.0090 \\
\hline & & $\mathrm{C} 1$ & 0.0032 & 0.0072 & 0.0048 & 0.0009 \\
\hline \multirow[t]{3}{*}{$\overline{\text { Nitrato }}$} & \multirow[t]{3}{*}{$\mathrm{mg} / \mathrm{l}$} & all & 0.0001 & 0.0947 & 0.0131 & 0.0132 \\
\hline & & int & 0.0001 & 0.0947 & 0.0034 & 0.0127 \\
\hline & & $\mathrm{C} 1$ & 0.0004 & 0.0014 & 0.0008 & 0.0002 \\
\hline \multirow[t]{3}{*}{ Nitrito } & \multirow[t]{3}{*}{$\mathrm{mg} / \mathrm{l}$} & all & 0.0004 & 0.0049 & 0.0009 & 0.0005 \\
\hline & & int & 0.0006 & 0.0049 & 0.0012 & 0.0008 \\
\hline & & $\mathrm{C} 1$ & 0.0008 & 0.0030 & 0.0021 & 0.0004 \\
\hline \multirow[t]{3}{*}{ Fósforo inorgânico } & \multirow[t]{3}{*}{$\mathrm{mg} / \mathrm{l}$} & all & 0.0301 & 0.1128 & 0.0400 & 0.0154 \\
\hline & & int & 0.0462 & 0.1128 & 0.0703 & 0.0123 \\
\hline & & $\mathrm{C} 1$ & 0.0395 & 0.0729 & 0.0637 & 0.0065 \\
\hline \multirow[t]{3}{*}{$\overline{\text { Fitoplâncton }}$} & \multirow[t]{3}{*}{$\mathrm{mgC} / \mathrm{l}$} & all & 0.0231 & 0.8035 & 0.1825 & 0.1550 \\
\hline & & int & 0.0796 & 0.8035 & 0.5329 & 0.1448 \\
\hline & & $\mathrm{C} 1$ & 0.1873 & 0.2979 & 0.2634 & 0.0220 \\
\hline \multirow[t]{3}{*}{ Zooplâncton } & \multirow[t]{3}{*}{$\mathrm{mgC} / \mathrm{l}$} & all & 0.0092 & 0.2773 & 0.0239 & 0.0278 \\
\hline & & int & 0.0111 & 0.2773 & 0.0819 & 0.0425 \\
\hline & & $\mathrm{C} 1$ & 0.0194 & 0.0519 & 0.0382 & 0.0067 \\
\hline
\end{tabular}


Tabela 12: Resultados da simulação para o mês de Fevereiro sob forçante de ventos de leste. "all" são resultados para todo o domínio, "int" refere à região interna e "C1"à Baía de Santos

\begin{tabular}{|c|c|c|c|c|c|c|}
\hline Propriedade & Unidade & Região & $\min$ & $\max$ & mean & std \\
\hline \multirow[t]{3}{*}{ Temperatura } & ${ }^{\circ} \mathrm{C}$ & all & 22.0367 & 27.3516 & 23.6718 & 1.3745 \\
\hline & & int & 24.7007 & 27.3516 & 26.8760 & 0.5635 \\
\hline & & $\mathrm{C} 1$ & 23.0458 & 25.5157 & 24.4320 & 0.5216 \\
\hline \multirow[t]{3}{*}{ Salinidade } & psu & all & 18.0521 & 36.0000 & 34.5570 & 3.8461 \\
\hline & & int & 18.0521 & 34.3706 & 25.4110 & 4.6228 \\
\hline & & $\mathrm{C} 1$ & 33.9687 & 35.8956 & 35.0828 & 0.3540 \\
\hline \multirow[t]{3}{*}{ Oxigênio } & $\mathrm{mg} / \mathrm{l}$ & all & 5.7658 & 9.5456 & 8.9040 & 0.8663 \\
\hline & & int & 5.7658 & 8.4961 & 6.7389 & 0.5423 \\
\hline & & $\mathrm{C} 1$ & 8.0477 & 9.3880 & 8.7601 & 0.2690 \\
\hline \multirow[t]{3}{*}{ Amônia } & $\mathrm{mg} / \mathrm{l}$ & all & 0.0020 & 0.0831 & 0.0034 & 0.0037 \\
\hline & & int & 0.0035 & 0.0831 & 0.0078 & 0.0090 \\
\hline & & $\mathrm{C} 1$ & 0.0035 & 0.0092 & 0.0049 & 0.0008 \\
\hline \multirow[t]{3}{*}{ Nitrato } & $\mathrm{mg} / \mathrm{l}$ & all & 0.0001 & 0.0945 & 0.0214 & 0.0133 \\
\hline & & int & 0.0001 & 0.0945 & 0.0036 & 0.0126 \\
\hline & & $\mathrm{C} 1$ & 0.0014 & 0.0198 & 0.0068 & 0.0043 \\
\hline \multirow[t]{3}{*}{ Nitrito } & $\mathrm{mg} / \mathrm{l}$ & all & 0.0005 & 0.0049 & 0.0009 & 0.0005 \\
\hline & & int & 0.0005 & 0.0049 & 0.0011 & 0.0008 \\
\hline & & $\mathrm{C} 1$ & 0.0010 & 0.0036 & 0.0020 & 0.0003 \\
\hline \multirow[t]{3}{*}{ Fósforo inorgânico } & $\mathrm{mg} / \mathrm{l}$ & all & 0.0300 & 0.1074 & 0.0365 & 0.0116 \\
\hline & & int & 0.0457 & 0.1074 & 0.0628 & 0.0109 \\
\hline & & $\mathrm{C} 1$ & 0.0340 & 0.0531 & 0.0460 & 0.0039 \\
\hline \multirow[t]{3}{*}{ Fitoplâncton } & $\mathrm{mgC} / \mathrm{l}$ & all & 0.0204 & 0.7983 & 0.1495 & 0.1579 \\
\hline & & int & 0.0819 & 0.7983 & 0.5107 & 0.1507 \\
\hline & & $\mathrm{C} 1$ & 0.1179 & 0.2716 & 0.2182 & 0.0335 \\
\hline \multirow[t]{3}{*}{ Zooplâncton } & $\mathrm{mgC} / \mathrm{l}$ & all & 0.0091 & 0.2146 & 0.0169 & 0.0203 \\
\hline & & int & 0.0108 & 0.2146 & 0.0603 & 0.0331 \\
\hline & & $\mathrm{C} 1$ & 0.0102 & 0.0307 & 0.0174 & 0.0035 \\
\hline
\end{tabular}


Tabela 13: Resultados da simulação para o mês de Fevereiro sob forçante de ventos de sul. "all" são resultados para todo o domínio, "int"refere à região interna e "C1"à Baía de Santos

\begin{tabular}{|c|c|c|c|c|c|c|}
\hline Propriedade & Unidade & Região & $\min$ & $\max$ & mean & std \\
\hline \multirow[t]{3}{*}{ Temperatura } & \multirow[t]{3}{*}{${ }^{\circ} \mathrm{C}$} & all & 22.0960 & 27.6451 & 24.6767 & 1.6922 \\
\hline & & int & 26.1817 & 27.4823 & 27.2877 & 0.1811 \\
\hline & & $\mathrm{C} 1$ & 26.4010 & 27.6451 & 27.2135 & 0.2954 \\
\hline \multirow[t]{3}{*}{ Salinidade } & \multirow[t]{3}{*}{ psu } & all & 18.0486 & 36.0000 & 34.2603 & 3.9534 \\
\hline & & int & 18.0486 & 32.9886 & 24.8533 & 4.3605 \\
\hline & & $\mathrm{C} 1$ & 31.5250 & 34.9634 & 33.4191 & 0.7489 \\
\hline \multirow[t]{3}{*}{ Oxigênio } & \multirow[t]{3}{*}{$\mathrm{mg} / \mathrm{l}$} & all & 5.6161 & 9.5289 & 8.3566 & 1.0497 \\
\hline & & int & 5.6161 & 7.4841 & 6.3883 & 0.3728 \\
\hline & & $\mathrm{C} 1$ & 6.5596 & 7.4832 & 6.8928 & 0.2467 \\
\hline \multirow[t]{3}{*}{ Amônia } & \multirow[t]{3}{*}{$\mathrm{mg} / \mathrm{l}$} & all & 0.0020 & 0.0833 & 0.0042 & 0.0041 \\
\hline & & int & 0.0052 & 0.0833 & 0.0101 & 0.0088 \\
\hline & & $\mathrm{C} 1$ & 0.0039 & 0.0204 & 0.0072 & 0.0017 \\
\hline \multirow[t]{3}{*}{ Nitrato } & \multirow[t]{3}{*}{$\mathrm{mg} / \mathrm{l}$} & all & 0.0001 & 0.0945 & 0.0122 & 0.0126 \\
\hline & & int & 0.0001 & 0.0945 & 0.0034 & 0.0127 \\
\hline & & $\mathrm{C} 1$ & 0.0004 & 0.0088 & 0.0011 & 0.0009 \\
\hline \multirow[t]{3}{*}{ Nitrito } & \multirow[t]{3}{*}{$\mathrm{mg} / \mathrm{l}$} & all & 0.0003 & 0.0078 & 0.0009 & 0.0006 \\
\hline & & int & 0.0007 & 0.0049 & 0.0013 & 0.0007 \\
\hline & & $\mathrm{C} 1$ & 0.0009 & 0.0078 & 0.0022 & 0.0008 \\
\hline \multirow[t]{3}{*}{ Fósforo inorgânico } & \multirow[t]{3}{*}{$\mathrm{mg} / \mathrm{l}$} & all & 0.0295 & 0.1131 & 0.0420 & 0.0180 \\
\hline & & int & 0.0464 & 0.1131 & 0.0737 & 0.0132 \\
\hline & & $\mathrm{C} 1$ & 0.0534 & 0.1046 & 0.0759 & 0.0068 \\
\hline \multirow[t]{3}{*}{ Fitoplâncton } & \multirow[t]{3}{*}{$\mathrm{mgC} / \mathrm{l}$} & all & 0.0228 & 0.8007 & 0.1776 & 0.1515 \\
\hline & & int & 0.0815 & 0.8007 & 0.5182 & 0.1559 \\
\hline & & $\mathrm{C} 1$ & 0.1948 & 0.2897 & 0.2630 & 0.0217 \\
\hline \multirow[t]{3}{*}{ Zooplâncton } & \multirow[t]{3}{*}{$\mathrm{mgC} / \mathrm{l}$} & all & 0.0097 & 0.4233 & 0.0358 & 0.0476 \\
\hline & & int & 0.0117 & 0.4233 & 0.1335 & 0.0688 \\
\hline & & $\mathrm{C} 1$ & 0.0446 & 0.0996 & 0.0740 & 0.0118 \\
\hline
\end{tabular}


Tabela 14: Resultados da simulação para o mês de Fevereiro sob forçante de ventos de sudoeste. "all"são resultados para todo o domínio, "int"refere à região interna e "C1"à Baía de Santos

\begin{tabular}{|c|c|c|c|c|c|c|}
\hline Propriedade & Unidade & Região & $\min$ & $\max$ & mean & std \\
\hline \multirow[t]{3}{*}{ Temperatura } & \multirow[t]{3}{*}{${ }^{\circ} \mathrm{C}$} & all & 22.1051 & 27.4099 & 24.4070 & 1.5457 \\
\hline & & int & 26.1806 & 27.4099 & 27.1743 & 0.1919 \\
\hline & & $\mathrm{C} 1$ & 24.7387 & 27.0913 & 26.3136 & 0.5857 \\
\hline \multirow[t]{3}{*}{ Salinidade } & \multirow[t]{3}{*}{$\mathrm{psu}$} & all & 18.0523 & 36.0000 & 34.4775 & 3.8412 \\
\hline & & int & 18.0523 & 34.5624 & 25.4566 & 4.7528 \\
\hline & & $\mathrm{C} 1$ & 32.3053 & 35.9543 & 34.6426 & 0.8158 \\
\hline \multirow[t]{3}{*}{ Oxigênio } & \multirow[t]{3}{*}{$\mathrm{mg} / \mathrm{l}$} & all & 5.7465 & 9.5243 & 8.5411 & 0.9500 \\
\hline & & int & 5.7465 & 7.4665 & 6.5050 & 0.3733 \\
\hline & & $\mathrm{C} 1$ & 6.8628 & 8.6516 & 7.5893 & 0.4358 \\
\hline \multirow[t]{3}{*}{ Amônia } & \multirow{3}{*}{$\mathrm{mg} / \mathrm{l}$} & all & 0.0020 & 0.0834 & 0.0036 & 0.0037 \\
\hline & & int & 0.0033 & 0.0834 & 0.0082 & 0.0090 \\
\hline & & $\mathrm{C} 1$ & 0.0025 & 0.0177 & 0.0046 & 0.0017 \\
\hline \multirow[t]{3}{*}{ Nitrato } & \multirow[t]{3}{*}{$\mathrm{mg} / \mathrm{l}$} & all & 0.0001 & 0.0947 & 0.0129 & 0.0126 \\
\hline & & int & 0.0001 & 0.0947 & 0.0034 & 0.0127 \\
\hline & & $\mathrm{C} 1$ & 0.0004 & 0.0087 & 0.0012 & 0.0009 \\
\hline \multirow[t]{3}{*}{ Nitrito } & \multirow[t]{3}{*}{$\mathrm{mg} / \mathrm{l}$} & all & 0.0004 & 0.0075 & 0.0008 & 0.0005 \\
\hline & & int & 0.0005 & 0.0049 & 0.0011 & 0.0008 \\
\hline & & $\mathrm{C} 1$ & 0.0005 & 0.0075 & 0.0018 & 0.0008 \\
\hline \multirow[t]{3}{*}{ Fósforo inorgânico } & \multirow[t]{3}{*}{$\mathrm{mg} / \mathrm{l}$} & all & 0.0293 & 0.1059 & 0.0379 & 0.0127 \\
\hline & & int & 0.0459 & 0.1059 & 0.0649 & 0.0097 \\
\hline & & $\mathrm{C} 1$ & 0.0304 & 0.0817 & 0.0526 & 0.0092 \\
\hline \multirow[t]{3}{*}{ Fitoplâncton } & \multirow[t]{3}{*}{$\mathrm{mgC} / \mathrm{l}$} & all & 0.0242 & 0.7897 & 0.1756 & 0.1475 \\
\hline & & int & 0.0804 & 0.7897 & 0.5062 & 0.1607 \\
\hline & & $\mathrm{C} 1$ & 0.1709 & 0.2760 & 0.2307 & 0.0260 \\
\hline \multirow[t]{3}{*}{ Zooplâncton } & \multirow[t]{3}{*}{$\mathrm{mgC} / \mathrm{l}$} & all & 0.0097 & 0.2181 & 0.0208 & 0.0230 \\
\hline & & int & 0.0110 & 0.2181 & 0.0711 & 0.0333 \\
\hline & & $\mathrm{C} 1$ & 0.0114 & 0.0442 & 0.0269 & 0.0078 \\
\hline
\end{tabular}

As tabelas 11, 12, 13 e 14 apresentam resultados de valor mínimo, valor máximo, média e desvio padrão para as propriedades da água forçadas por diferentes regimes de vento. Analisando estes resultados é possível observar que diferentes regimes de vento também influenciaram a concentração de fito e zooplâncton neste ambiente. As simulações com ventos de norte e sul apresentaram maiores concentrações de fitoplâncton e a simulação com ventos de sul apresentou maiores valores de concentração de zooplâncton. 
Tabela 15: Resultados de velocidade de corrente $\left(m s^{-1}\right)$ para a simulação do mês de Fevereiro sob diferentes regimes de ventos. "all"são resultados para todo o domínio, "int" refere à região interna e "C1" à Baía de Santos. O sentido do vento segue a convenção meteorológica.

\begin{tabular}{llllll}
\hline Vento & Região & min & max & mean & std \\
\hline $0^{\circ}$ & all & 0.0010 & 1.1206 & 0.1144 & 0.0628 \\
& int & 0.0010 & 0.9744 & 0.1129 & 0.1089 \\
& C1 & 0.0021 & 0.7841 & 0.0875 & 0.0655 \\
\hline $90^{\circ}$ & all & 0.0012 & 1.1252 & 0.1315 & 0.0619 \\
& int & 0.0012 & 0.9770 & 0.1120 & 0.1080 \\
& C1 & 0.0054 & 0.7858 & 0.0985 & 0.0608 \\
\hline $180^{\circ}$ & all & 0.0009 & 1.1132 & 0.0958 & 0.0663 \\
& int & 0.0009 & 0.9714 & 0.1091 & 0.1072 \\
& C1 & 0.0014 & 0.7785 & 0.0650 & 0.0658 \\
\hline $225^{\circ}$ & all & 0.0026 & 1.1136 & 0.1035 & 0.0682 \\
& int & 0.0030 & 0.9705 & 0.1104 & 0.1074 \\
& C1 & 0.0030 & 0.7807 & 0.0692 & 0.0652 \\
\hline
\end{tabular}




\section{Discussão}

Os resultados do modelo hidrodinâmico demonstram que foram consideradas condições de contorno apropriadas e que modelo consegue representar satisfatoriamente as variações do nível do mar (Figuras 24 e 25) e o sistema de correntes (Figuras 26, 28).

O modelo apresentou valores altos de temperatura $\left(>26.5^{\circ} \mathrm{C}\right)$ para a região interna do estuário mesmo com o sombreamento utilizado para reproduzir o efeito da vegetação. Entretanto, o modelo conseguiu representar a variação de temperatura entre superfície e fundo, gradiente de temperatura perpendicular à costa e também a diferença de temperatura entre verão e inverno.

Os resultados do modelo apontam elevado grau de eutrofização do sistema. Este estado é evidenciado pelo deficit de oxigênio na região interna do complexo estuarino de Santos-São Vicente.

A distribuição espacial de fitoplâncton foi coerente com resultados de trabalhos anteriores, foi observado maior concentrações na região interna do modelo e próximo de descarga de esgoto (Braga et al., 2000). Apesar disto, a concentração de fitoplâncton foi baixa. Esta diferença pode ser resultado de baixo aporte de nutrientes de rios, esgotos ou emissário e também pelo fato do modelo não assimilar matéria orgânica proveniente da floresta nativa e manguezais (Ribeiro, 2012).

Foram estudadas a influência da radiação solar e temperatura da água no crescimento do fitoplâncton. Para realizar a fotossíntese, o fitoplâncton utiliza energia solar para sintetizar matéria orgânica. A temperatura da água afeta velocidade de reações químicas e o metabolismo de organismos. Assim, tanto a temperatura da água quanto a radiação solar aceleram o crescimento do fitoplâncton. Neste trabalho maiores concentrações de fitoplâncton foram observados em cenários de maior temperatura e radiação solar.

Tanto a luminosidade quanto a temperatura afetam o crescimento do zooplâncton de forma positiva, apesar disto, maiores concentrações de zooplâncton ocorreram em cenários de menor temperatura e radiação solar. Isto pode ser explicado pois radiação solar alta pode estressar ou matar o zooplâncton impedindo o crescimento de sua população, além disto a radiação solar aquece a água. Altas temperaturas aceleram o metabolismo do fitoplâncton, porém acima da temperatura ótima de crescimento desta propriedade da água pode prejudicar o crescimento do zooplâncton.

Os ventos geram correntes marinhas que transportam propriedades da água do mar. A interação de correntes marinhas, como convergência e divergência podem provocar fenômenos como ressurgência e subsidência de massas de água. Ressurgência de águas profundas ou de subsuperfície trazem águas ricas em nutrientes para superfície. Para a região estudada, foi observada a influência de diferentes regimes de vento na distribuição espacial e concentração de fito e zooplâncton.

Para que modelos numéricos sejam úteis na gestão de recursos, eles devem reproduzir as principais características do sistema, capturando os processos mais importantes e as interações entre os compartimentos do sistema (Mateus et al., 2008). A falta de dados detalhados de entrada para forçar o modelo e dados para a calibração e validação limitam a aplicação do modelo em um ecossistema complexo, como o sistema estuarino de SantosSão Vicente. Mesmo com as limitações e incertezas da modelagem numérica, ela é uma ferramenta importante para gestão do recurso, pois possui abordagem integrada 
e sistemática, auxiliando não só na compreensão do estado do ecossistema, mas também a prevenção baseados diferentes cenários (Ribeiro, 2012).

\section{Conclusão}

Os resultados do modelo mostraram que a temperatura da água foi superestimada. Como os dados atmosféricos estão adequados, acredita-se que alguma informação no módulo SurfaceFluxes ou WaterProperties deve estar equivocada.

Houve uma inversão na sazonalidade da concentração de zooplâncton, esta inversão pode ser explicada pela temperatura da água e pela variável de temperatura de crescimento ótimo, que inibiram seu crescimento.

Apesar de concentrações menores que outros trabalhos, o modelo conseguiu produzir resultados coerentes da concentração de fitoplâncton. Estes resultados podem ser justificados pela concentração de nutrientes introduzidas no sistema através de descarga de rios e esgoto, que por sua vez devem estar subestimadas.

As simulações com diferentes valores para temperatura e radiação solar, mostraram os efeitos tanto na concentração quanto distribuição espacial do fitoplâncton. Além disto os resultados mostraram que a temperatura do ar teve maior influência na concentração de fitoplâncton.

Diferentes regimes de vento influenciaram tanto a concentração quanto a distribuição espacial de fito e zooplâncton. Os resultados do modelo permitiram identificar as regiões onde a concentração foi alterada.

Sob a perspectiva da gestão integrada dos recursos, a utilização da modelagem numérica se mostrou uma ferramenta útil, levando em conta que reproduziu as principais características do sistema.

Em geral, o modelo apresentou resultados satisfatórios. Como sugestão para trabalhos futuros, aporte de nutrientes provenientes de floresta e manguezais podem ser implementados; outros organismos como macroalgas, diferentes formas de fito e zooplâncton, bivalves, artrópodes, peixes também podem ser modelados e estudados; caixas de integração podem ser expandidas para o estudo das regiões vizinhas ao complexo Estuarino de Santos-São Vicente. 


\section{Referências}

Afonso, C. M. (2006). A paisagem da Baixada Santista: urbanização, transformação e conservação. EdUSP.

Bernardes, B. D. L. (2007). Hydrodynamical and Ecological Modelling of the North Sea. Master's thesis, Universidade Técnica de Lisboa.

Braga, E. S., Bonetti, C. V., Burone, L., and Bonetti Filho, J. (2000). Eutrophication and bacterial pollution caused by industrial and domestic wastes at the baixada santista estuarine system-brazil. Marine Pollution Bulletin, 40(2):165-173.

Brandimarte, L., Popescu, I., and Neamah, N. K. (2015). Analysis of fresh-saline water interface at the shatt al-arab estuary. International Journal of River Basin Management, 13:17-25.

CETESB (2006). Relatório de qualidade das águas interiores do estado de São Paulo. Technical report, CETESB.

Chapra, S. (1997). Surface Water-quality Modeling. McGraw-Hill series in water resources and environmental engineering. McGraw-Hill.

CODESP (2008). EIA-RIMA da Dragagem de aprofundamento do canal e bacias de evolução do Porto Organizado de Santos.

Day, J. (1989). Estuarine Ecology. A Wiley-Interscience publication. Wiley.

Gary, E. and Erofeeva, L. (Acesso: 2017). OSU Tidal Data Inversion. http://volkov. oce.orst.edu/tides/.

Gianesella, S. M. F. and Saldanha-Corrêa, F. M. P. (2007). Hydrology, nutrients, phytoplankton biomass, primary productivity and heterotrophic vs. autotrophic balance in Santos Estuarine System. Relatório do projeto ECOMANAGE.

Gianesella, S. M. F. and Saldanha-Corrêa, F. M. P.; Ancona, C. M. (2008). Projeto "A Influência do Complexo Estuarino da Baixada Santista Sobre o Ecossistema de Plataforma Continental Adjacente" (Junho de 2008) Capítulo 5-Sub-projeto Influência dos estuários sobre o fluxo de energia e ciclagem de materiais nos primeiros níveis da cadeia trófica da plataforma de Santos. 5.1.1- Estuário e Baía de Santos 5.1.2- Canal de Bertioga. Relatório à FAPESP.

Harari, J., de Camargo, R., and Cacciari, P. L. (1999). Implantação de um sistema de previsão de marés e de correntes de maré na Baixada Santista através de modelo numérico tridimensional. Universidade de São Paulo, Instituto oceanográfico.

Kramer, K. J., Brockmann, U. H., and Warwick, R. M. (1992). Manual of sampling and analytical procedures for tidal estuaries. TNO Institute of Environmental Sciences, Laboratory of Applied Research.

Lamparelli, C. C., Moura, D. O. d., and Lopes, C. F. (1999). Mapeamento dos ecossistemas costeiros do estado de Sao Paulo. Governo do Estado de São Paulo, Secretaria de Estado do Meio Ambiente. 
Legates, D. R. and McCabe, G. J. (1999). Evaluating the use of "goodness-of-fit" measures in hydrologic and hydroclimatic model validation. Water resources research, 35(1):233241.

Malhadas, M. S., Mateus, M. D., Brito, D., and Neves, R. (2014). Trophic state evaluation after urban loads diversion in a eutrophic coastal lagoon (Óbidos Lagoon, Portugal): a modeling approach. Hydrobiologia, 740:231-251.

Marinha (Acesso: 2017). http://www.mar.mil.br/dhn/chm/box-cartas-nauticas/ cartas.html.

Martins, F., Leitão, P., Silva, A., and Neves, R. (2001). 3D modelling in the Sado estuary using a new generic vertical discretization approach. Oceanologica Acta, 24:51-62.

Mateus, M., Sampaio, A., and Mateus, S. (2008). An ecological model application to the santos estuary, brazil: testing and validation. Perspectives on Integrated Coastal Zone Management in South America. IST Press, Lisboa, pages 401-424.

Miller, R. (2007). Numerical modeling of ocean circulation. Cambridge University Press, Cambridge.

MOHID (2009). Mohid Description. http://www.mohid.com.

Monteiro, C. A. d. F. (1973). A dinâmica climática e as chuvas no estado de São Paulo. Instituto de Geografia.

MOSER, G. (2002). Aspectos da eutrofização na Baixada Santista: distribuição espaço temporal de biomassa fitoplanctônica e produtividade primária; transporte de nutrientes, material em suspensão e biomassa fitoplanctônica. PhD thesis, Tese de Doutorado em Oceanografia Biológica. Instituto Oceanográfico.

Neves, R. (1985). Étude experimentale et modélisation des circulations trasitoire et résiduelle dans l'estuaire du sado. $\mathrm{PhD}$ thesis, $\mathrm{Ph}$. D. Thesis, Univ. Liège.

Neves, R., Baretta, J., and Mateus, M. (2008). Perspectives on integrated coastal zone management in South America. IST Press.

Portela, L. (1996). Mathematical modelling of hydrodynamic processes and water quality in Tagus estuary. PhD thesis, Ph. D. thesis, Instituto Sup. Técnico, Tech. Univ. of Lisbon, 1996.(in Portuguese).

PRIMAD (2005). Programa Regional de Identificação e Monitoramento de Áreas de Habitação Desconforme. Agência Metropolitada da Baixada Santista. Relatório Final.

Ribeiro, R. B. (2012). Modelagem Numérica da Influência das Fontes de Nutrientes Sobre a Variabilidade da Biomassa Fotoplanctônica no Sistema Estuarino de StantosSão Vicente. Master's thesis, Universidade de São Paulo. PROCAM.

Saha, S., Moorthi, S., Pan, H.-L., Wu, X., Wang, J., Nadiga, S., Tripp, P., Kistler, R., Woollen, J., Behringer, D., et al. (2010). The ncep climate forecast system reanalysis. Bulletin of the American Meteorological Society, 91(8):1015-1058. 
Sampaio, A. (2010). Avaliação da correlação entre parâmetros de qualidade da água e socioeconômicos no complexo estuarino de Santos - São Vicente, através de modelagem numérica ambiental. Master's thesis, Universidade de São Paulo.

Sampaio, A., Mateus, M., and Berzin, G. (2008a). A modelling approach to the study of faecal pollution in the Santos Estuary. Perspectives on integrated coastal zone management in South America. IST Press, Lisboa, Portugal, pages 425-434.

Sampaio, A., Mateus, M., and Ribeiro, R. (2008b). Assessing the impact of several development scenarios on the water quality in Santos Estuary. Perspectives on integrated coastal zone management in South America. IST Press, Lisboa, Portugal, pages $435-444$.

Sampaio, A. F. P., Ribeiro, R. B., Schmiegelow, J. M. M., and Santos, J. A. P. (2009). Levantamento da área de cobertura do manguezal do sistema estuarino de Santos-São Vicente - São Vicente. PROCAM/USP. In: Ribeiro, R. B., Modelagem Numérica da Influência das Fontes de Nutrientes Sobre a Variabilidade da Biomassa Fotoplanctônica no Sistema Estuarino de Stantos-São Vicente. Universidade de São Paulo. 2012.

Smith, V. H., Tilman, G. D., and Nekola, J. C. (1999). Eutrophication: impacts of excess nutrient inputs on freshwater, marine, and terrestrial ecosystems. Environmental pollution, 100(1-3):179-196.

Thornton, K. W. and Lessem, A. S. (1978). A temperature algorithm for modifying biological rates. Transactions of the American Fisheries Society, 107(2):284-287.

Trancoso, A., Saraiva, S., Fernandes, L., Pina, P., Leitao, P., and Neves, R. (2005). Modelling macroalgae using a 3d hydrodynamic-ecological model in a shallow, temperate estuary. Ecological Modelling, 187(2):232-246.

UNESCO, I. and SCOR, I. (1981). Tenth report of the joint panel on oceanographic tables and standards.

Valiela, I. (2013). Marine ecological processes. Springer Science \& Business Media.

WALTERS, C. (1988). Ecologia de sistemas: O método dos sistemas e os modelos matemáticos em ecologia. ODUM, EP Ecologia. Rio de Janeiro: Ed. Guanabara, pages 323-339. 